\title{
Análise Empírica de Algoritmos de Revisão sobre Bases de Crenças
}

\author{
Renato Urquiza Lundberg
}

\author{
DisSERTAÇÃO APRESENTADA \\ $\mathrm{AO}$ \\ Instituto DE MatemáticA E Estatística \\ DA \\ UNIVERSIDADE DE SÃo PAUlO \\ PARA \\ OBTENÇÃO DO TÍTULO \\ $\mathrm{DE}$ \\ Mestre em CiÊnCia da Computação
}

Programa: Programa de Pós-Graduação em Ciência da Computação Orientador: Prof. ${ }^{a}$. Dr. ${ }^{a}$ Renata Wassermann 


\section{Análise Empírica de Algoritmos de Revisão sobre Bases de Crenças}

Esta dissertação contém as correções e alterações sugeridas pela Comissão Julgadora durante a defesa realizada por Renato Urquiza Lundberg em 21/03/2013.

O original encontra-se disponível no Instituto de Matemática e Estatística da Universidade de São Paulo.

Comissão Julgadora:

- Profa. Dra. Renata Wasserman (orientadora) - IME-USP

- Prof. Dr. Fabio Gagliardi Cozman - EP-USP

- Prof. Dr. Adolfo Gustavo Serra Seca Neto - UTFPR 
These aren't the droids you're looking for.

- Obi-Wan Kenobi (Star Wars, 1977) 


\section{Agradecimentos}

À minha orientadora Renata Wasserman, pelos apontamentos sempre precisos, por ter me proporcionado oportunidades e pela compreensão.

Aos colegas do IME pela importante troca de informações e colaboração com o desenvolvimento deste trabalho.

Aos professores do IME, por terem proporcionado um intenso aprendizado durante a Graduação e Mestrado.

À equipe da MAPS, pela compreensão durante as ausências e por me permitir transformar o escritório em um local de ensino.

Aos meus pais e irmãs, pelo carinho, apoio e pela criação consistente, que se tornou a base de todo o meu desenvolvimento pessoal e profissional.

À minha querida Maíra, pelo companheirismo, incentivo e dedicação. Agradeço, também, pelas revisões de texto, sugestões e pelo material gráfico. 


\section{Resumo}

A área de revisão de crenças estuda a forma como agentes racionais operam sobre seus conhecimentos, permitindo que estes evoluam à vista de novas informações. Muitas das formas de manipulação do conhecimento hoje utilizadas foram desenvolvidas tendo como base o paradigma estabelecido por Alchourrón, Gärdenfors e Makinson em 1985, que evoluiu nas últimas décadas sob influência de diversas correntes de pensamento, dando origem a múltiplas abordagens para a estruturação de operadores sobre crenças. Esta dissertação limita-se à análise das duas principais construções de operadores sobre bases de crenças, bem como suas propriedades e relações. A partir desta análise, foi construído um framework computacional que permitiu a análise empírica do comportamento destas construções em diversos casos gerados, de modo a averiguar a eficiência real dos algoritmos envolvidos. Também são expostos detalhes do framework, construído de forma flexível para permitir sua reutilização em trabalhos futuros.

Palavras-chave: revisão de crenças, bases de crenças, contração por partial meet, contração kernel 


\section{Abstract}

Belief revision studies the ways rational agents change their beliefs, allowing them to evolve when exposed to new information. Many of the belief change forms currently used were developed based on the paradigm established by Alchourrón, Gärdenfors and Makinson in 1985, which evolved over the last decades under the influence of several distinct fields, originating multiple approaches to implement operators on beliefs. This dissertation is limited to the analysis of the two main constructions of operators on belief bases, including their properties and relations. Based on this analysis, a computational framework was created to allow the empirical analysis of the behavior of these constructions on generated scenarios, in order to measure the real efficiency of the algorithms concerned. It also describes the framework, built aiming for flexibility in order to allow it's usage in future works.

Keywords: belief revision, belief bases, partial meet contraction, kernel contraction 


\section{Sumário}

Lista de Figuras $\quad$ xi

1 Introdução $\quad 1$

1.1 Motivação e Contribuição . . . . . . . . . . . . . . . . . . . 2

1.2 Organização do Trabalho . . . . . . . . . . . . . . . . . . . . 2

1.3 Notação . . . . . . . . . . . . . . . . . . . . . . . . . . . 2

2 Fundamentação Teórica $\quad \mathbf{5}$

2.1 O Paradigma AGM . . . . . . . . . . . . . . . . . . . . . 5

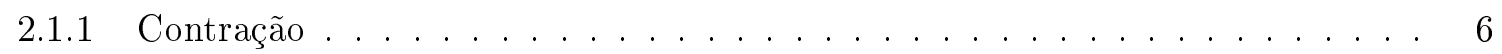

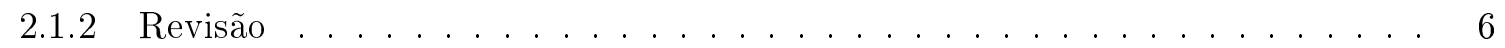

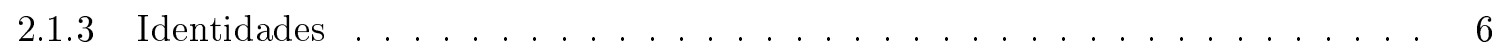

2.1 .4 Partial meet . . . . . . . . . . . . . . . . . . . 7

2.1 .5 Inconveniências . . . . . . . . . . . . . . . . . . 8

2.2 Bases de Crenças . . . . . . . . . . . . . . . . . . . 8

2.2.1 Partial meet sobre bases . . . . . . . . . . . . . . . . . 9

2.2 .2 Kernel . . . . . . . . . . . . . . . . . . . . . 11

2.3 Relações entre construções . . . . . . . . . . . . . . . . . . . . . . . . . . . . . . . . . . . . . . .

2.3 .1 Incisão e Seleção . . . . . . . . . . . . . . . . . . . . . . . 14

2.3 .2 Kernel e Resíduo . . . . . . . . . . . . . . . . . . . . . 15

2.4 Complexidade Computacional . . . . . . . . . . . . . . . . . 16

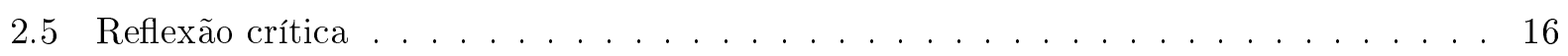

3 Implementação $\quad 19$

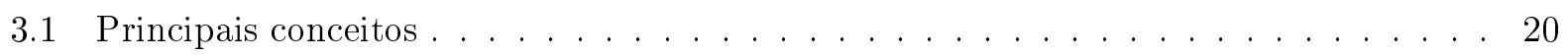

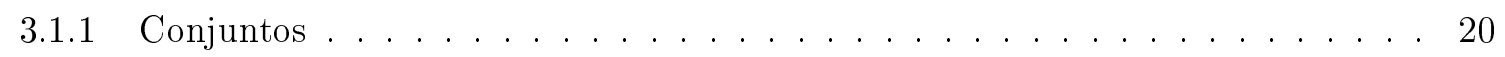

3.1 .2 Sentenças . . . . . . . . . . . . . . . . . . 20

3.1.3 Provadores de teoremas . . . . . . . . . . . . . . . . . 21

3.1 .4 Revisão e Contração . . . . . . . . . . . . . . . . . . . . . . . . . . 21

3.1 .5 Revisão e Contração Kernel . . . . . . . . . . . . . . . . . . . . . . . 21

$3.1 .6 \quad$ Operador Kernel . . . . . . . . . . . . . . . . . . . . . . . . . 22

3.1.7 Revisão e Contração Partial Meet . . . . . . . . . . . . . . . . . . . . 24

3.1 .8 Operador Resíduo . . . . . . . . . . . . . . . . . . . 25

3.2 Geração de Cenários . . . . . . . . . . . . . . . . . 26

3.2 .1 Fábrica de sentenças . . . . . . . . . . . . . . . . 26 
3.2.2 Fábrica de conjuntos de sentenças . . . . . . . . . . . . . . . 27

3.2 .3 Fábrica de cenários de contração . . . . . . . . . . . . . . . 28

3.2 .4 Pseudoaleatoriedade . . . . . . . . . . . . . . . . . . . 28

3.3 Perfil de execução . . . . . . . . . . . . . . . . . . . . . . . 28

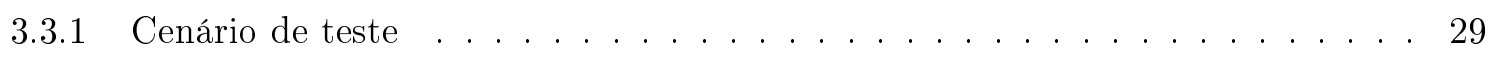

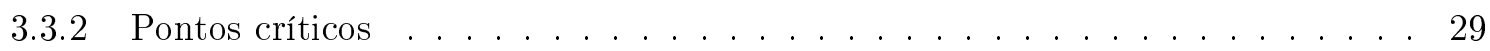

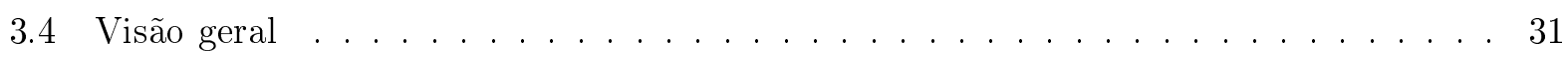

4 Testes $\quad 33$

4.1 Medições. . . . . . . . . . . . . . . . . . . . . . . . . 33

4.1 .1 Medição de Tempo . . . . . . . . . . . . . . . . . . . . 34

4.2 Cenários Executados . . . . . . . . . . . . . . . . . . 35

4.3 Resultados . . . . . . . . . . . . . . . . . 37

4.3 .1 Tempos médios . . . . . . . . . . . . . . . . 37

4.3 .2 Tempos mínimos . . . . . . . . . . . . . . . . . . . 39

4.3 .3 Chamadas a provadores . . . . . . . . . . . . . . . 41

4.3.4 Tamanho médio dos resultados intermediários . . . . . . . . . . . . . . . . 42

4.3.5 Iterações buscando conjuntos . . . . . . . . . . . . . . . . . . . . . 44

4.3.6 Tempo gasto com provadores de teoremas . . . . . . . . . . . . . . . . . 45

5 Considerações Finais $\quad 47$

5.1 Conclusão . . . . . . . . . . . . . . . . . . . . . . . . 47

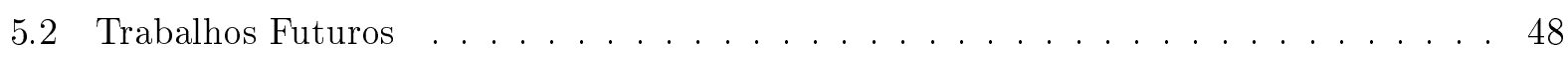

$\begin{array}{ll}\text { Referências Bibliográficas } & 49\end{array}$ 


\section{Lista de Figuras}

3.1 Diagrama de classes com diversas implementações de provadores. . . . . . . . . . . . 21

3.2 Diagrama de classes com diversas implementações de contração. . . . . . . . . . . . 31

4.1 Tempo médio de execução em nanosegundos dos algoritmos por número de cláusulas em cenários com 10 variáveis _ . . . . . . . . . . . . . . . 37

4.2 Tempo médio de execução em nanosegundos dos algoritmos por número de cláusulas em cenários com 15 variáveis . . . . . . . . . . . . . . . . 37

4.3 Tempo médio de execução em nanosegundos dos algoritmos por número de cláusulas

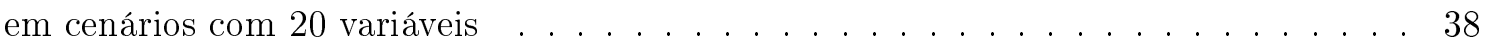

4.4 Tempo médio com mínimo dos algoritmos por número de cláusulas em cenários com 10 variáveis . . . . . . . . . . . . . . . . . . . . . . . 39

4.5 Tempo médio com mínimo dos algoritmos por número de cláusulas em cenários com 15 variáveis . . . . . . . . . . . . . . . . . . . . . . . . 39

4.6 Tempo médio com mínimo dos algoritmos por número de cláusulas em cenários com 20 variáveis . . . . . . . . . . . . . . . . . . . . . 40

4.7 Número médio de chamadas aos provadores de teoremas por número de cláusulas em cenários com 10 variáveis . . . . . . . . . . . . . . . . . . . . . 41

4.8 Número médio de chamadas aos provadores de teoremas por número de cláusulas em cenários com 15 variáveis . . . . . . . . . . . . . . . . . . . . . 41

4.9 Número médio de chamadas aos provadores de teoremas por número de cláusulas em cenários com 20 variáveis . . . . . . . . . . . . . . . . . . . . . . . . . 42

4.10 Tamanho médio do número de conjuntos do resultado intermediário por número de cláusulas em cenários com 10 variáveis . . . . . . . . . . . . . . . . . 42

4.11 Tamanho médio do número de conjuntos do resultado intermediário por número de cláusulas em cenários com 15 variáveis . . . . . . . . . . . . . . . . . 43

4.12 Tamanho médio do número de conjuntos do resultado intermediário por número de cláusulas em cenários com 20 variáveis . . . . . . . . . . . . . . . 43

4.13 Número médio de iterações buscando subconjuntos por número de cláusulas em cenários com 10 variáveis . . . . . . . . . . . . . . . . . . . . . . 44

4.14 Número médio de iterações buscando subconjuntos por número de cláusulas em cenários com 15 variáveis . . . . . . . . . . . . . . . . . . . . . . 44

4.15 Número médio de iterações buscando subconjuntos por número de cláusulas em cenários com 20 variáveis . . . . . . . . . . . . . . . . . . . 45 
4.16 Proporção de tempo gasto com chamadas a provadores de teoremas por número de cláusulas em cenários com 10 variáveis . . . . . . . . . . . . . . . . . . 45

4.17 Proporção de tempo gasto com chamadas a provadores de teoremas por número de cláusulas em cenários com 15 variáveis . . . . . . . . . . . . . . . . 46

4.18 Proporção de tempo gasto com chamadas a provadores de teoremas por número de cláusulas em cenários com 20 variáveis . . . . . . . . . . . . . . . . . 46 


\section{Capítulo 1}

\section{Introdução}

Como um agente racional com um certo conjunto de crenças deve reagir frente a novas informações? Esta é a pergunta central estudada pela área de revisão de crenças. Este é um campo de estudo multidisciplinar, sendo alvo de estudo por filósofos, cientistas da computação e interessados em geral em sistemas que operem sobre bases de conhecimento. Os estudos no campo foram fortemente marcados pelo artigo seminal escrito por Alchourrón, Gärdenfors e Makinson em 1985 [AGM85], onde o problema foi estabelecido formalmente, assim como a definição de postulados que definem critérios claros de racionalidade para operadores sobre conjuntos de crenças. A formalização do problema e dos critérios de racionalidade tiveram importância estrutural, servindo de base e orientação para os estudos que se seguiram nas décadas seguintes.

Entretanto, a formalização estabelecida foi proposta para agentes cujo conhecimento é representado por um conjunto de crenças fechado logicamente por algum operador lógico, o que gera alguns inconvenientes, tais como a impossibilidade de representar inconsistências e o custo computacional impeditivo, o que tornava implementar operadores impraticável. Alternativamente, Hansson propôs em [Han91] a representação do conhecimento de um agente através de um conjunto arbitrário de sentenças, denominado base de crenças, demonstrando ser possível a construção de operadores racionais sobre estes conjuntos sem a utilização do fecho lógico, seguindo critérios muito semelhantes aos propostos anteriormente. Esta nova forma de representação abriu portas para abordagens alternativas dos algoritmos e novos operadores, por ser atrativa tanto do ponto de vista funcional quanto computacional.

Existem duas construções principais utilizadas para a criação de operadores sobre bases de crenças, kernel e partial meet. Seja $A$ um agente racional com base de conhecimento $B$, um conjunto de sentenças lógicas, que queira adicionar ao seu conhecimento um fato $\alpha$ sem criar inconsistências. Um operador construído por kernel irá identificar todos os subconjuntos mínimos de $B$ que contradizem $\alpha$, removendo ao menos um elemento de cada conjunto para em seguida anexar o novo conhecimento. Alternativamente, a construção por partial meet busca subconjuntos máximos de $B$ que não contradizem $\alpha$, realizando a intersecção de alguns destes conjuntos e adicionando $\alpha$ com segurança. Enquanto um tenta identificar e eliminar as fontes de inconsistência com o mínimo de mudança possível, outra tenta identificar o máximo de conhecimento que pode ser retido.

A literatura acerca do comportamento de operadores sobre bases de crenças é extensa, inclusive no que diz respeito às diferenças entre os resultados obtidos pelos operadores construídos das duas formas descritas acima, mas consiste em grande parte de trabalhos teóricos. Dado que os operadores possuem aplicações reais, como na criação de agentes inteligentes e sistemas especialistas, surge naturalmente a questão de que abordagem seguir para a implementação. Esta questão é de grande importância, pois o problema é de alta complexidade computacional, tornando fundamental a escolha de um algoritmo eficiente. O objetivo deste trabalho é explorar as diferenças entre implementações de operadores sobre bases de crenças, utilizando diferentes algoritmos e abordagens, analisando empiricamente seus comportamentos e recursos computacionais necessários. Foi investigada a hipótese de que seria possível a criação de uma heurística capaz de identificar, dada uma instância do problema, que algoritmo consumirá menos recursos. 
Foi criado um framework para a implementação de diferentes operações sobre bases de crenças com um elevado grau de reaproveitamento, de forma a viabilizar a comparação das construções em um ambiente homogêneo. O framework provê os conceitos das construções, estruturas de dados para o armazenamento de fórmulas e operadores lógicos. Essa divisão irá permitir que os algoritmos se tornem independentes do contexto, tornando intercambiáveis lógicas e representações, além de promover a composição de algoritmos para a criação dos operadores. Neste framework foram implementados os mesmos operadores com diferentes algoritmos internos, com um compartilhamento significativo de código e interfaces similares, além do ferramental necessário para a geração automática de cenários para testes e estruturas para coletas de dados sobre a execução.

Com a estrutura construída foi criada uma massa de testes utilizando lógica proposicional, sobre a qual foram executados quatro implementações distintas do mesmo operador, realizando a coleta dos dados de execução. Com base na análise dos dados levantados foi possível tirar conclusões acerca dos recursos exigidos e sobre a possibilidade da criação de uma heurística.

\subsection{Motivação e Contribuição}

A motivação deste trabalho foi estabelecer uma base para comparação direta de diferentes algoritmos sobre bases de crenças, habilitando a aplicação em lógicas distintas e uma comparação honesta entre as diferentes abordagens sob um ponto de vista computacional. A criação deste framework foi necessária, pois apesar de já existirem diversas implementações de operadores de revisão de crenças na literatura, tais como Immortal ([CW91]), SATEN ([WS00]) e BReLS ([Lib99]), todas possuem foco em alguma construção e lógica específicas, não permitindo comparações diretas entre as abordagens.

A contribuição direta deste trabalho é uma análise detalhada do comportamento de diferentes implementações de algoritmos sobre bases de crenças para lógica proposicional. Também é contribuição o framework, em parte apresentado em [LRW12], estruturado para servir de base para trabalhos futuros, estando preparado para integrar novas lógicas, criação de heurísticas e novos operadores.

\subsection{Organização do Trabalho}

Esta dissertação começa com a base teórica utilizada como fundamentação dos trabalhos realizados, apresentada no Capítulo 2. Na Seção 2.1 é apresentado o paradigma que norteia a área de revisão de crenças. Em 2.2 são expostos trabalhos posteriores em bases de crenças, que são representações mais adequadas computacionalmente e possuem resultados interessantes do ponto de vista prático. São expostas duas abordagens principais para operações sobre bases de crenças, partial meet e kernel. Em sequência, a Seção 2.3 exibe relações entre as construções para operadores sobre bases de crenças, mostrando que abordagens aparentemente antagônicas são na verdade intimamente relacionadas.

O Capítulo 3 descreve o desenvolvimento do framework, passando pela sua elaboração, múltiplas implementações de algoritmos, estrutura de geração de cenários e análises de performance. A seguir o Capítulo 4 detalha os procedimentos de testes realizados e explora os resultados obtidos, realizando uma análise empírica dos comportamentos dos algoritmos e dos problemas.

Finalmente, o Capítulo 5 apresenta uma conclusão sobre os resultados obtidos e lista futuros trabalhos a serem desenvolvidos com base nos resultados obtidos.

\subsection{Notação}

Ao longo desta dissertação serão consideradas sentenças de uma linguagem proposicional $L$ com os conectivos lógicos usuais $\neg, \vee$ e $\wedge$. Serão utilizadas as letras $\alpha$ e $\beta$ para denotar fórmulas nesta linguagem $L$, e conjuntos de fórmulas em letras maiúsculas $(A, B \ldots)$. Também será utilizado o 
operador de consequência $C n$, que deve ser considerado o operador de consequência clássico a não ser que seja dito o contrário. 


\section{Capítulo 2}

\section{Fundamentação Teórica}

Neste capítulo serão exploradas as fundações teóricas da dinâmica de crenças, de forma a embasar este trabalho e permitir uma implementação sólida do framework que permitirá análises empíricas sobre o assunto.

Inicialmente será exposto o paradigma definido por Alchourrón, Gärdenfors e Makinson, que norteia todos os estudos da área e é base para o entendimento de todos os demais trabalhos. O paradigma define um framework teórico para a dinâmica de conhecimento, representado por conjuntos fechados logicamente, podendo ser utilizado para qualquer lógica que atenda a algumas suposições básicas, inclusive propondo uma construção para a criação de operações de dinâmica de conhecimento.

Em seguida é explorada uma abordagem de representação de conhecimento por bases de crenças, conjuntos não fechados logicamente, mais adequada computacionalmente. Os estudos realizados nas últimas décadas sobre bases de crenças foram realizados sobre duas abordagens antagônicas para a construção das operações, atingindo resultados análogos. A compreensão da construção dos operadores e a relação entre as abordagens serão o fundamento teórico para o desenvolvimento deste trabalho.

\subsection{O Paradigma AGM}

O paradigma que norteou os estudos na área nas últimas décadas foi estabelecido em [AGM85], onde foram definidas as operações básicas sobre conjuntos de crenças, assim como uma série de postulados que os operadores devem atender para serem considerados racionais. Além de definir um framework teórico para o estudo destes operadores, também é apresentada uma forma para construção da operação utilizando o conceito de partial meet.

O framework assume a existência de um operador de consequência $C n$, que leva um conjunto de proposições a outro, tal que para quaisquer conjuntos de proposições $A$ e $B$ onde $A \subseteq B$, vale que $A \subseteq C n(A), C n(A)=C n(C n(A))$ e $C n(A) \subseteq C n(B)$. É assumido que $C n$ contém as tautologias lógicas, é compacto (se $\beta \in C n(A), \beta \in C n(Y)$ para algum $Y$ subconjunto finito de $B$ ), e satisfaz a regra de introdução de disjunções nas premissas (se $\beta \in C n\left(A \cup\left\{\alpha_{1}\right\}\right)$ e $\beta \in C n\left(A \cup\left\{\alpha_{2}\right\}\right.$ ), segue que $\left.\beta \in C n\left(A \cup\left\{\alpha_{1} \vee \alpha_{2}\right\}\right)\right)$.

Uma teoria é um conjunto de proposições fechado sobre $C n$.

É dito que um conjunto de proposições $A$ é consistente se não existe proposição $\beta$ tal que $\beta \in C n(A)$ e $\neg \beta \in C n(A)$.

A operação mais básica a ser feita sobre uma teoria é denominada expansão, em que uma proposição é adicionada a um conjunto de proposições, que é em seguida fechado logicamente pelo operador $C n: A+\alpha=C n(A \cup\{\alpha\})$. Essa operação pode resultar em um conjunto inconsistente.

Com base nestas definições são estabelecidas as operações de contração e revisão. 


\subsubsection{Contração}

O operador de contração - opera sobre uma teoria $A$ e uma proposição $\alpha$. A intuição é que o resultado seja um uma teoria consistente que não contenha $\alpha$. Formalmente o operador deve atender aos seguintes postulados [AGM82] para ser considerado racional:

- $(\dot{-} 1) A \dot{-} \alpha$ é uma teoria quando $A$ é uma teoria $($ fecho $)$.

- $(\dot{-} 2)$ Se $\alpha \notin C n(\varnothing)$, então $\alpha \notin C n(A \dot{-} \alpha)$ (sucesso).

- $(\dot{-} 3) A \dot{-} \alpha \subseteq A($ inclusão $)$.

- $(\dot{-} 4)$ Se $\alpha \notin C n(A)$, então $A \dot{-} \alpha=A$ (vacuidade).

- $(\dot{-} 5) A \subseteq C n((A \dot{-} \alpha) \cup\{\alpha\})$ quando $A$ é uma teoria (recuperação).

- $(\dot{-} 6)$ Se $C n(\alpha)=C n(\beta)$, então $A \dot{-} \alpha=A \dot{-} \beta$ (extensionalidade).

O postulado de sucesso garante que caso $\alpha$ não seja uma tautologia o resultado da contração não implicará $\alpha$. A inclusão garante que as implicações da teoria resultante da contração estão contidas na teoria original, portanto não houve geração de outros conhecimentos, apenas remoção. A vacuidade garante que se não é necessário remover nenhuma sentença, pois a teoria já não implica em $\alpha$, nada é feito. A recuperação implica que uma contração seguida por uma expansão deverá conter a teoria original. A extensionalidade garante que as contrações por proposições logicamente equivalentes geram resultado idêntico.

\subsubsection{Revisão}

O operador de revisão $\dot{+}$ atua sobre uma teoria $A$ e uma proposição $\alpha$, resultando em uma teoria consistente que contém $\alpha$. Formalmente o operador deve atender aos seguintes postulados [Gär88]:

- $(\dot{+} 1) A \dot{+} \alpha$ é sempre uma teoria. (fecho)

- $(\dot{+} 2) \alpha \in A \dot{+} \alpha$. (sucesso)

- (+ 3$) A \dot{+} \alpha \subseteq C n(A \cup\{\alpha\})$. (inclusão)

- $(\dot{+} 4)$ Se $\neg \alpha \notin A$, então $C n(A \cup\{\alpha\}) \subseteq A \dot{+} \alpha$. (preservação $)$

- $(\dot{+} 5)$ Se $\neg \alpha \notin C n(\varnothing)$, então $A \dot{+} \alpha$ é consistente sob $C n$. (consistência)

- $(\dot{+} 6)$ Se $C n(\alpha)=C n(\beta)$, então $A \dot{+} \alpha=A \dot{+} \beta$. (equivalência)

Estas propriedades descrevem com rigor matemático o comportamento esperado dos operadores, sem definir como chegar ao resultado.

Os postulados de sucesso e fecho garantem que o resultado da revisão é uma teoria que contém $\alpha$. A inclusão garante que a teoria resultante implica em $\alpha$; o postulado de consistência afirma que desde que $\neg \alpha$ não seja uma tautologia o resultado será consistente. O postulado da preservação diz que informação não deve ser removida da teoria sem necessidade, pois caso a teoria não seja contrária a $\alpha$ a revisão e a expansão possuem o mesmo resultado. A equivalência garante que a revisão por proposições logicamente equivalentes geram resultado idêntico.

\subsubsection{Identidades}

Em [Gär88] é demonstrado que os operadores podem ser definidos em termos um do outro, através de duas equações de identidade:

Identidade de Levi: $A \dot{+} \alpha=(A \dot{-} \neg \alpha)+\alpha$.

Identidade de Harper: $A \dot{-} \alpha=(A \dot{+} \neg \alpha) \cap A$.

Um operador de contração que atenda aos postulados gera, através destas identidades, um operador de revisão que também atende às propriedades desejadas (e vice-versa). Este comportamento permite que este estudo possa se concentrar nas construções para contração. 


\subsubsection{Partial meet}

Os postulados, apesar de definirem as propriedades que um operador deve atender, não definem um resultado único: uma contração sobre uma mesma teoria e mesma sentença pode admitir como resultado diversas teorias diferentes, e ainda assim atender aos postulados. Os postulados também não afirmam nada sobre o algoritmo para realizar a contração, deixando indefinido o caminho para se chegar ao resultado. Diversas construções para a contração AGM podem ser encontradas na literatura ([AGM82, AM85, Gro88, GM88]), todas com equivalência provada aos postulados AGM para contração. A seguir será exposta a construção dos operadores de contração e revisão utilizando partial meet.

2.1.4.1 Definição. [AGM82] Seja A uma teoria e $\alpha$ uma fórmula. $O$ conjunto resíduo $A \perp \alpha$ de $A$ e $\alpha$ é tal que, para qualquer $B, B \in A \perp \alpha$ se e somente se:

- $B \subseteq A$

- $\alpha \notin C n(B)$

- Para todo $B^{\prime}$ tal que $B \subset B^{\prime} \subseteq A, \alpha \in C n\left(B^{\prime}\right)$

O conjunto resíduo é, portanto, o conjunto de todos os subconjuntos de $A$ que falham em implicar $\alpha$ e que são maximais, pois a adição de qualquer elemento em $A \backslash B$ gera em um conjunto que implica $\alpha$. Este operador tem resultado totalmente definido, apesar de não haver uma forma única de obtê-lo, e é um resultado intermediário fundamental para a construção dos operadores sobre teorias.

2.1.4.2 Definição. [AGM85] Uma função de seleção para uma teoria A é uma função $\gamma$ tal que:

- Se $A \perp \alpha \neq \varnothing$, então $\varnothing \neq \gamma(A \perp \alpha) \subseteq A \perp \alpha$

- Senão, $\gamma(A \perp \alpha)=\{A\}$

O papel da função de seleção é, portanto, selecionar os melhores conjuntos do conjunto resíduo, de acordo com algum critério, resultando em um subconjunto dos conjuntos maximais que não implicam em alguma sentença.

A partir da função de seleção e do conjunto resíduo, podemos construir uma função de contração sobre teorias:

2.1.4.3 Definição. [AGM85] Um operador de contração por partial meet é um operador $\dot{-}$, definido por uma função de seleção $\gamma$, tal que, dado um conjunto de sentenças $A$ e uma sentença $\alpha$ :

$A \dot{-} \alpha=\bigcap \gamma(A \perp \alpha)$

Intuitivamente, esta construção toma os maiores subconjuntos de informação que não implicam o que se quer remover e faz uma intersecção dos conjuntos mais importantes. A ideia é reter o máximo de informação no ato da contração, lidando sempre com conjuntos maximais. É importante notar que o resultado da contração é totalmente dependente do critério escolhido pela função de seleção. Os operadores construídos a seguir utilizando uma função de seleção, independente de seu critério, atenderão aos postulados que os caracterizam como racionais, mesmo que os resultados não sejam intuitivos do ponto de vista humano.

2.1.4.4 Teorema. [AGM85] Seja - uma função que, dada uma sentença $\alpha$ e um conjunto de sentenças $A$, resulta em um conjunto de sentenças $A \dot{-} \alpha$. Para toda teoria $A, \dot{-} e ́$ um operador de contração por partial meet se e somente se $\dot{-}$ satisfaz os postulados de $(\dot{-} 1)$ a $(\dot{-} 6)$

Segue pelo teorema que a construção por partial meet caracteriza totalmente os postulados. Qualquer operador construído possui o resultado de um operador por partial meet.

A partir da construção da contração por partial meet, também podemos construir a revisão por partial meet, utilizando a Identidade de Levi. 
2.1.4.5 Definição. Um operador de revisão por partial meet é um operador $\dot{+}$ sobre uma teoria $A$ e uma sentença $\alpha$, definido por uma função de seleção $\gamma$, tal que:

$$
A \dot{+} \alpha=C n(\bigcap \gamma(A \perp \neg \alpha) \cup\{\alpha\})
$$

Como pode ser visto acima, a revisão consiste em primeiro tomar a intersecção dos melhores subconjuntos maximais da teoria inicial que não implicam em $\neg \alpha$, para em seguida adicionar $\alpha$ com segurança. Assim como a operação de contração, o resultado da revisão é totalmente dependente do critério de escolha da função de seleção. Segue pelo teorema abaixo que a operação de revisão descrita segue os postulados para revisão, devido às propriedades da operação de contração original.

2.1.4.6 Teorema. [Gär88] Se $\dot{-}$ é um operador de contração que satisfaz os postulados de $(\dot{-} 1)$ $a(\dot{-} 4)$ e $(\dot{-} 6)$, então a função de revisão associada pela Identidade de Levi satisfaz os postulados de $(\dot{+} 1) a(\dot{+} 6)$.

\subsubsection{Inconveniências}

O paradigma mostrado brevemente acima, apesar de ser elegante do ponto de vista teórico, implica em sérios problemas quanto a sua computabilidade.

Em primeiro lugar, o framework opera sempre em conjuntos logicamente fechados, que são tipicamente infinitos e por consequência de difícil manipulação e implementação. O próprio fecho lógico, utilizado extensamente, é por si só uma operação extremamente cara do ponto de vista computacional.

Outro ponto negativo desta abordagem resulta da homogeneidade das sentenças em um conjunto. Não há como identificar sentenças mais fundamentais e que deveriam ter preferência sobre outras em uma eventual contração. Além disso, o fecho lógico de uma teoria inconsistente é sempre o mesmo conjunto de sentenças, composto por toda a linguagem, enquanto na prática é de muita valia a análise de diferentes tipos de inconsistência.

A seguir será apresentada uma abordagem alternativa do problema de dinâmica de crenças, que evita algumas destas complicações ao não utilizar conjuntos fechados logicamente, permitindo inclusive novos operadores e construções de uso mais prático.

\subsection{Bases de Crenças}

Uma alternativa proposta como solução para os pontos negativos do paradigma AGM é a utilização de bases de crenças.

Uma base de crenças é um conjunto finito de sentenças que, juntamente com algum operador de consequência lógica, cria o conjunto de crenças de um agente. Note que não é necessário computar o conjunto de crenças, potencialmente infinito, basta representá-lo como um conjunto de sentenças. Note também que é comum que exista mais de uma base possível para a mesma teoria.

Uma base de crenças pode ser vista estritamente como uma representação de uma teoria, permitindo a armazenagem eficiente de um conjunto potencialmente infinito utilizando uma base finita. Entretanto uma base de crenças é capaz de guardar mais informações do que um conjunto de crenças fechado logicamente, pois armazenando sentenças explícitas pode-se tratá-las de maneira distinta de sentenças meramente derivadas, fornecendo dados para a elaboração de operadores lógicos com resultados mais intuitivos.

Todos os resultado abaixo, salvo dito o contrário, supõem apenas um operador de consequência que seja compacto e monotônico. Este é um ponto essencial para a validade das propriedades apresentadas, mas também amplia o horizonte de possibilidades das operações descritas, pois permite que estes resultados sejam explorados em múltiplas lógicas, tais como lógicas de descrição.

As implementações tratadas neste trabalho irão utilizar o modelo teórico construído sobre bases de crenças em [Han91] e [Han93], tendo como fundamento o paradigma estabelecido para conjuntos de crenças em [AGM85]. 


\subsubsection{Partial meet sobre bases}

As mesmas ideias propostas para a construção de operações sobre conjunto de crenças utilizando o conceito de partial meet podem ser aplicadas para construir operações sobre bases de crenças, com algumas adaptações e propriedades distintas.

2.2.1.1 Definição. [Han91] O operador de contração de bases por partial meet com função de seleção $\gamma$, designado $\dot{-}_{\gamma}$, que atua sobre uma base $B$ e uma sentença $\alpha$ e resulta em uma outra base, é tal que:

$$
B \dot{-}_{\gamma} \alpha=\bigcap \gamma(B \perp \alpha)
$$

O operador de contração por partial meet é construído de maneira análoga à forma definida em [AGM85]. Note, entretanto, que não é utilizado o fecho lógico e os conjuntos tratados são finitos.

2.2.1.2 Teorema. [Han93] O operador $\dot{-}_{\gamma}$ é uma contração por partial meet sobre uma base de crenças $B$ utilizando alguma função de seleção se e somente se:

- Se $\alpha \notin C n(\varnothing)$, então $\alpha \notin C n\left(B \dot{-}_{\gamma} \alpha\right)$ (sucesso)

- $B \dot{-}_{\gamma} \alpha \subseteq B$ (inclusão)

- Se $\beta \in B \backslash\left(B \dot{-}_{\gamma} \alpha\right)$, então existe $B^{\prime}$ tal que $B \dot{-}_{\gamma} \alpha \subseteq B^{\prime} \subseteq B, \alpha \notin C n\left(B^{\prime}\right)$ e $\alpha \in C n\left(B^{\prime} \cup\{\beta\}\right)$ (relevância)

- Se para todos os subconjuntos $B^{\prime}$ de $B, \alpha \in C n\left(B^{\prime}\right)$ se e somente se $\beta \in C n\left(B^{\prime}\right)$, então $B \dot{-}_{\gamma} \alpha=B \dot{-}_{\gamma} \beta$ (uniformidade)

Em [AGM85] o operador de revisão é construído a partir da contração utilizando a Identidade de Levi. Hansson definiu a aplicação direta desta identidade em bases de crenças como sendo uma revisão interna de base por partial meet.

2.2.1.3 Definição. [AGM85, Han93] O operador de revisão interna de bases de crenças por partial meet com função de seleção $\gamma$, designado $\mp_{\gamma}$, é tal que:

$B \mp_{\gamma} \alpha=\bigcap \gamma(B \perp \neg \alpha) \cup\{\alpha\}$

A operação descrita acima primeiro contrai, removendo da base elementos para evitar inconsistências com $\alpha$, e em seguida efetua a expansão.

2.2.1.4 Teorema. [Han93] O operador $\mp_{\gamma}$ é um operador de revisão interna de bases de crenças por partial meet se e somente se:

- $S e \neg \alpha \notin C n(\varnothing)$, então $\neg \alpha \notin C n(B \mp \gamma \alpha)$ (não-contradição)

- $B \mp_{\gamma} \alpha \subseteq B \cup\{\alpha\}$ (inclusão)

- Se $\beta \in B \backslash B \mp_{\gamma} \alpha$, então existe $B^{\prime}$ tal que $B \mp_{\gamma} \alpha \subseteq B^{\prime} \subseteq B \cup\{\alpha\}, \neg \alpha \notin C n\left(B^{\prime}\right)$, mas $\neg \alpha \in C n(B \cup\{\beta\})$ (relevância)

- $\alpha \in B \mp_{\gamma} \alpha$ (sucesso)

- Se para todo $B^{\prime} \subseteq B, \neg \alpha \in C n\left(B^{\prime}\right)$ se e somente se $\neg \beta \in C n\left(B^{\prime}\right)$, então $B \cap\left(B \mp_{\gamma} \alpha\right)=$ $B \cap\left(B \mp_{\gamma} \beta\right)$ (uniformidade)

Diferente do que ocorre quando trata-se de conjuntos de sentenças, uma base pode se tornar inconsistente sem que haja perda de informação, o que permite que a operação de revisão possa ser escrita de outra forma, denominada revisão externa de base por partial meet. Na revisão externa a expansão é realizada antes da contração, revertendo a Identidade de Levi [Han93], podendo ter como resultado intermediário uma base de crenças inconsistente. 
2.2.1.5 Definição. [Han93] O operador de revisão externa de bases de crenças por partial meet com função de seleção $\gamma$, designado $\pm_{\gamma}$, é tal que:

$$
B \pm_{\gamma} \alpha=\bigcap \gamma((B \cup\{\alpha\}) \perp \neg \alpha)
$$

2.2.1.6 Teorema. [Han93] Um operador $\pm_{\gamma}$ é um operador de revisão externa de bases de crenças por partial meet se e somente se:

- $S e \neg \alpha \notin C n(\varnothing)$, então $\neg \alpha \notin C n\left(B \pm_{\gamma} \alpha\right)$ (não-contradição)

- $B \pm_{\gamma} \alpha \subseteq B \cup\{\alpha\}$ (inclusão)

- Se $\beta \in B \backslash B \pm_{\gamma} \alpha$, então existe $B^{\prime}$ tal que $B \pm_{\gamma} \alpha \subseteq B^{\prime} \subseteq B \cup\{\alpha\}$ tal que $\neg \alpha \notin C n\left(B^{\prime}\right)$ e $\neg \alpha \in C n\left(B^{\prime} \cup\{\beta\}\right)$ (relevância)

- $\alpha \in B \pm_{\gamma} \alpha$ (sucesso)

- Se $\alpha$ e $\beta$ são elementos de $B$ e é verdade que para todo $B^{\prime} \subseteq B$ tal que $\neg \alpha \in C n\left(B^{\prime}\right)$ se e somente se $\neg \beta \in C n\left(B^{\prime}\right)$, então $B \cap\left(B \pm_{\gamma} \alpha\right)=B \cap\left(B \pm_{\gamma} \beta\right)$ (uniformidade fraca)

- $B+\alpha \pm_{\gamma} \alpha=B \pm_{\gamma} \alpha$ (pré-expansão)

As propriedades da revisão externa e interna são um pouco diferentes, e mesmo o resultado das operações pode mudar dependendo do caso. Na prática, existem casos em que uma é preferível à outra, mas este assunto não será abordado aqui.

A operação de consolidação por partial meet, sugerida em [Han91], opera apenas sobre uma base de crenças, potencialmente inconsistente, tendo como resultado um subconjunto consistente da base original. Esta operação pode ser modelada pela contração por falsum $(\perp)$. A ideia da consolidação por partial meet é encontrar na base inconsistente todos os subconjuntos maximais consistentes e proceder com a intersecção dos subconjuntos selecionados.

2.2.1.7 Definição. [Han91] O operador de consolidação de bases de crenças por partial meet com função de seleção $\gamma$, designado $!_{\gamma}$, é tal que:

$$
B !_{\gamma}=\bigcap \gamma(B \perp \perp)
$$

2.2.1.8 Teorema. [Was00] Um operador $!_{\gamma}$ é um operador de consolidaçâo de bases de crenças por partial meet se e somente se, dado um operador de inferência Cn monotônico, compacto e tal que $\perp \notin C n(\varnothing)$ :

- $\perp \notin C n\left(B !_{\gamma}\right)$ (consistência)

- $B !_{\gamma} \subseteq B$ (inclusão)

- Se $\alpha \in B \backslash\left(B !_{\gamma}\right)$, então existe $X$ tal que $B !_{\gamma} \subseteq X \subseteq B, \perp \notin C n(X)$ e $\perp \in C n(X \cup\{\alpha\})$ (relevância)

A semi-revisão por partial meet, $?_{\gamma}$, é uma operação proposta em [Han97], composta por uma expansão seguida de uma consolidação por partial meet. Esta operação contrasta com a revisão, pois não há garantia que durante a etapa de consolidação a crença adicionada seja descartada. Há uma chance que o agente rejeite o novo conhecimento, de acordo com a função de seleção utilizada.

2.2.1.9 Definição. [Han97] O operador de semi-revisão de bases de crenças por partial meet com função de seleção $\gamma$, designado ${ }_{\gamma}$, é tal que:

$$
B ?_{\gamma} \alpha=\bigcap \gamma((B \cup\{\alpha\}) \perp \perp)
$$

2.2.1.10 Teorema. [Was00] Um operador $?_{\gamma}$ é um operador de semi-revisão de bases de crenças por partial meet com função de seleção $\gamma$ se e somente se, dado um operador de consequência Cn monotônico, compacto, tal que $\perp \notin C n(\varnothing)$, para todos os conjuntos de sentenças $B$ e sentenças $\alpha$ : 
- $\perp \notin C n\left(B ?_{\gamma} \alpha\right)$ (consistência)

- $B ?_{\gamma} \alpha \subseteq B \cup\{\alpha\}$ (inclusão)

- Se $\beta \in B \backslash\left(B ?_{\gamma} \alpha\right)$, então existe $X$ tal que $B$ ? $_{\gamma} \alpha \subseteq X \subseteq B \cup\{\alpha\}, \perp \notin C n(X) e \perp \in$ $C n(X \cup\{\beta\})$ (relevância)

- $(B+\alpha) ?_{\gamma} \alpha=B ?_{\gamma} \alpha$ (pré-expansão)

- Se $\alpha, \beta \in B$, então $B ?_{\gamma} \alpha=B ?_{\gamma} \beta$ (troca interna)

Note que todas as operações construídas utilizam apenas, além de operações básicas de conjuntos, a noção de conjunto resíduo e função de seleção. Como o conjunto resíduo é totalmente definido, o resultado das operações é dependente do critério de escolha da função de seleção. Não importa a escolha deste critério, as operações continuarão respeitando as propriedades, e serão portanto racionais, mas poderão não ser intuitivas.

Por exemplo, suponha que Alice viu que a previsão do tempo indicava sol, mas ao sair de casa estava chovendo, e por consequência ela acaba realizando uma operação de semi-revisão. Ela poderia concluir que a previsão do tempo errou, ou que não está chovendo, desacreditando nos próprios olhos. Ambas as conclusões são racionais, este critério de escolha fica à cargo da função de seleção.

\subsubsection{Kernel}

Hansson propôs em [Han94] uma construção diferente para o operador de contração, baseado na idéia de contração segura explorada em Alchourrón e Makinson em [AM85]. A ideia é que se são tomados todos os conjuntos mínimos de uma base $B$ que implicam em uma sentença $\alpha$ e remove-se ao menos uma sentença de cada, obtém-se uma base que não implica $\alpha$. Por se tratar de conjuntos mínimos, é intuitivo esperar que computacionalmente esta abordagem seja mais eficiente.

O operador kernel identifica todos os subconjuntos mínimos de uma base de crenças que implicam em alguma sentença. Este é um resultado intermediário de todas as construções de operadores baseados em kernel, sendo utilizado para identificar, por exemplo, todos os conjuntos mínimos que implicam em uma crença que se queira contrair.

2.2.2.1 Definição. [Han94] O operador kernel, designado $\Perp$, é um operador tal que para todo conjunto $B$ de fórmulas e toda fórmula $\alpha, X \in B \Perp \alpha$ se e somente se:

- $X \subseteq B$

- $\alpha \in C n(X)$

- Se $Y \subset X$ segue que $\alpha \notin C n(Y)$

Note que o operador kernel possui um único resultado correto para uma entrada, mas não há um algoritmo definido para obtê-lo. Denomina-se cada subconjunto elemento do kernel um $\alpha$-kernel.

A função de incisão obtém um conjunto de sentenças que possui ao menos um elemento de cada $\alpha$-kernel. Esta função admite muitos resultados possíveis, e irá definir o comportamento dos operadores que serão apresentados abaixo.

2.2.2.2 Definição. [Han94] A função de incisão $\sigma$ é uma função tal que, para alguma base de crenças $B$ e sentença $\alpha$ :

- $\sigma(B \Perp \alpha) \subseteq \bigcup(B \Perp \alpha)$.

- Se $X \neq \varnothing$ e $X \in B \Perp \alpha$, então $X \cap \sigma(B \Perp \alpha) \neq \varnothing$. 
O operador de contração pode ser construído utilizando apenas o operador kernel e a função de incisão. O operador kernel identifica todos os subconjuntos mínimos que implicam em alguma crença que se queira excluir, dos quais ao menos uma sentença é escolhida pela função de incisão. A subtração dos elementos escolhidos pela função de incisão resulta em uma base que não implica a sentença, pois ao menos um elemento foi removido de cada conjunto mínimo que a implicava.

2.2.2.3 Definição. [Han94] $A$ contração kernel sobre uma base de crenças $B$, determinada por uma função de incisão $\sigma$, é uma operação $\dot{-}_{\sigma}$ tal que para todo $\alpha: B \dot{-}_{\sigma} \alpha=B \backslash \sigma(B \Perp \alpha)$

O resultado da contração kernel não é determinado, pois depende do critério da função de incisão, mas respeita algumas propriedades:

2.2.2.4 Teorema. [Han94] Um operador $\dot{-}_{\sigma}$ é um operador de contração sobre bases de crenças por kernel com função de incisão $\sigma$ se e somente se:

- Se $\alpha \in C n(\varnothing)$, então $\alpha \notin C n\left(B \dot{-}_{\sigma} \alpha\right)$ (sucesso)

- $B \dot{-}{ }_{\sigma} \alpha \subseteq B$ (inclusão)

- Se $\beta \in B \backslash B \dot{-}_{\sigma} \alpha$, então existe $B^{\prime} \subseteq B$ tal que $\alpha \notin C n\left(B^{\prime}\right)$ e $\alpha \in C n\left(B^{\prime} \cup\{\beta\}\right)$ (coreretainment)

- Se para todos os subconjuntos $B^{\prime}$ de $B, \alpha \in C n\left(B^{\prime}\right)$ se e somente se $\beta \in C n\left(B^{\prime}\right)$, então $B \dot{-}{ }_{\sigma} \alpha=B \dot{-}{ }_{\sigma} \beta$ (uniformidade)

Deve ser notado também que os postulados que caracterizam a contração kernel são idênticos aos postulados para contração por partial meet, exceto pelo postulado de core-retainment, que na contração por partial meet é reduzido pelo postulado da relevância, ligeiramente mais forte [Han92]. Como foi observado em [Was00], esta caracterização da operação de contração kernel torna-a um caso mais geral da contração por partial meet, portanto todo operador de contração kernel é um operador de contração por partial meet, mas nem toda contração por partial meet é uma contração kernel.

Utilizando a construção do operador de contração, é definido o operador de revisão interna através da Identidade de Levi:

2.2.2.5 Definição. [Was00] A revisão interna sobre bases de crenças B por kernel com função de incisão $\sigma$ é um operador $\mp_{\sigma}$ tal que para todo $\alpha$ :

$B \mp_{\sigma} \alpha=(B \backslash \sigma(B \Perp \neg \alpha)) \cup\{\alpha\}$

Assim como a contração, a revisão interna possui resultados dependentes da função de incisão utilizada, mas sempre atende a algumas propriedades:

2.2.2.6 Teorema. [Was00] Assumindo um operador de consequência Cn monotônico e compacto, um operador $\mp_{\sigma}$ é um operador de revisão interna por kernel com função de incisão $\sigma$ se e somente se:

- $S e \neg \alpha \notin C n(\varnothing)$, então $\neg \alpha \notin C n\left(B \mp_{\sigma} \alpha\right)$ (não-contradição)

- $B \mp_{\sigma} \alpha \subseteq B \cup\{\alpha\}$ (inclusão)

- Se $\beta \in B \backslash B \mp \sigma \alpha$, então existe $B^{\prime} \subseteq B$ tal que $\neg \alpha \notin C n\left(B^{\prime}\right)$ e $\neg \alpha \in C n\left(B^{\prime} \cup\{\beta\}\right)$ (core-retainment)

- $\alpha \in B \mp \sigma \alpha$ (sucesso)

- Se para todos os subconjuntos $B^{\prime}$ de $B, \neg \alpha \in C n\left(B^{\prime}\right)$ se e somente se $\neg \beta \in C n\left(B^{\prime}\right)$, então $B \cap\left(B \mp_{\sigma} \alpha\right)=B \cap\left(B \mp_{\sigma} \beta\right)$ (uniformidade) 
Assim como acontece com a revisão por partial meet, também é possível construir a revisão externa utilizando a forma reversa da Identidade de Levi:

2.2.2.7 Definição. [Was00] A revisão externa sobre bases de crenças B por kernel com função de incisão $\sigma$ é um operador $\pm_{\sigma}$ tal que para todo $\alpha$ :

$$
B \pm_{\sigma} \alpha=(B \cup\{\alpha\}) \backslash \sigma((B \cup\{\alpha\}) \Perp \neg \alpha)
$$

2.2.2.8 Teorema. [Was00] Assumindo um um operador de consequência Cn monotônico e compacto, um operador $\pm_{\sigma}$ é um operador de revisão externa por kernel com função de incisão $\sigma$ se e somente se:

- $S e \neg \alpha \notin C n(\varnothing)$, então $\neg \alpha \notin C n\left(B \pm_{\sigma} \alpha\right)$ (não-contradição)

- $B \pm_{\sigma} \alpha \subseteq B \cup\{\alpha\}$ (inclusão)

- Se $\beta \in B \backslash B \pm_{\sigma} \alpha$, então existe $B^{\prime} \subseteq B \cup\{\alpha\}$ tal que $\neg \alpha \notin C n\left(B^{\prime}\right) e \neg \alpha \in C n\left(B^{\prime} \cup\{\beta\}\right)$ (core-retainment)

- $\alpha \in B \pm_{\sigma} \alpha$ (sucesso)

- Se $\alpha$ e $\beta$ são elementos de $B$ e para todo $B^{\prime} \subseteq B$ tal que que $\neg \alpha \in C n\left(B^{\prime}\right)$ se e somente se $\neg \beta \in C n\left(B^{\prime}\right)$, então $B \cap\left(B \pm_{\sigma} \alpha\right)=B \cap\left(B \pm_{\sigma} \beta\right)$ (uniformidade fraca)

- $B+\alpha \pm_{\sigma} \alpha=B \pm_{\sigma} \alpha$ (pré-expansão)

O operador de consolidação também pode ser construído através de uma contração kernel, como descrito em [Han97], partindo do mesmo princípio de contração por falsum. A ideia, no caso, é encontrar em uma base possivelmente inconsistente todos os subconjuntos inconsistentes, selecionando ao menos um elemento de cada um e subtraindo da base original, tornando-a consistente.

2.2.2.9 Definição. [Han97] A consolidação de bases de crenças B por kernel com função de incisão $\sigma$, denotada $!_{\sigma}$, é tal que:

$B !_{\sigma}=B \backslash \sigma(B \Perp \perp)$

2.2.2.10 Teorema. [Was00] Dado um operador de inferência Cn monotônico, compacto e tal que $\perp \notin C n(\varnothing)$, um operador $!_{\sigma}$ é um operador de consolidação por kernel se e somente se:

- $\perp \notin C n\left(B !_{\sigma}\right)$ (consistência)

- $B !_{\sigma} \subseteq B$ (inclusão)

- Se $\alpha \in B \backslash\left(B !_{\sigma}\right)$, então existe $X$ tal que $X \subseteq B, \perp \notin C n(X)$ e $\perp \in C n(X \cup\{\alpha\})$ (coreretainment)

Em [Han97] também é proposto o operador de semi-revisão por kernel, composto por uma expansão seguida de uma consolidação por kernel. Da mesma forma que a semi-revisão por partial meet, não há garantia que a sentença sendo semi-revisada conste no conjunto final.

2.2.2.11 Definição. [Han97]] A semi-revisão de bases de crenças por kernel com função de incisão $\sigma$ é um operador $?_{\sigma}$ tal que:

$$
B ?_{\sigma} \alpha=(B \cup\{\alpha\}) \backslash \sigma((B \cup\{\alpha\}) \Perp \perp)
$$

2.2.2.12 Teorema. [Was00] Dado um operador de consequência Cn monotônico, compacto, tal que $\perp \notin C n(\varnothing)$, um operador $?_{\sigma}$ é um operador de semi-revisão por kernel se e somente se:

- $\perp \notin C n\left(B ?_{\sigma} \alpha\right)$ (consistência)

- $B ?_{\sigma} \alpha \subseteq B \cup\{\alpha\}$ (inclusão) 
- Se $\beta \in B \backslash\left(B ?_{\sigma} \alpha\right)$, então existe $X$ tal que $X \subseteq B \cup\{\alpha\}$ tal que $\perp \notin C n(X) e \perp \in C n(X \cup\{\beta\})$ (core-retainment)

- $(B+\alpha){ }_{\sigma} \alpha=B ?_{\sigma} \alpha$ (pré-expansão)

- Se $\alpha, \beta \in B$, então $B ?_{\sigma} \alpha=B ?_{\sigma} \beta$ (troca interna)

Note que, assim como ocorreu nas construções por partial meet, todas as operações por kernel utilizam apenas o conceito de kernel e a função de incisão. $\mathrm{O}$ operador kernel é totalmente definido, ficando o resultado sujeito ao critério da função de incisão, responsável por gerar um resultado adequado ao uso.

\subsection{Relações entre construções}

A representação do conhecimento por bases de crenças permite, além da técnica de partial meet possível em conjuntos fechados, uma segunda abordagem pelo kernel. Ambas abordagens permitem a construção de diversos operadores sobre bases de crenças (contração, revisão interna, revisão externa, consolidação e semi-revisão), cada um com propriedades bem definidas, mas semelhantes, para cada construção. A seguir serão exploradas as relações entre estas duas abordagens, que possuem resultados tão semelhantes apesar de em si serem tão distintas.

\subsubsection{Incisão e Seleção}

As funções de incisão e seleção são responsáveis por moldar o resultado dos operadores, por possuírem múltiplas implementações possíveis. Restringindo o comportamento destas funções é possível chegar propriedades mais específicas para os operadores, como é o exemplo das funções de incisão suaves:

2.3.1.1 Definição. [Han94] Uma função de incisão $\sigma$ é suave (smooth) se e somente se para todo $B^{\prime} \subseteq B$, se $\beta \in C n\left(B^{\prime}\right)$ e $\beta \in \sigma(B \Perp \alpha)$ então $B^{\prime} \cap \sigma(B \Perp \alpha) \neq \varnothing$.

Foi demonstrado em [Han94] que contrações kernel que utilizam funções de incisão suaves atendem a todas as propriedades que caracterizam as contrações por partial meet. Este resultado garante que toda contração suave por kernel possui uma contração correspondente por partial meet que obtém o mesmo resultado. Este resultado, entretanto, é válido apenas para teorias, não ocorrendo em contrações sobre bases de crenças.

Em [FFI06], entretanto, é demonstrado que em certas condições é possível tornar muito próximas as operações de contração kernel e partial meet, e explora uma construção da função de incisão a partir de uma função de seleção.

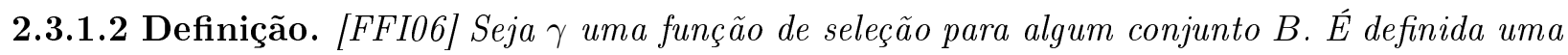
função de incisão associada $\sigma_{\gamma}$ tal que:

$\sigma_{\gamma}(B \Perp \alpha)=B \backslash \bigcap \gamma(B \perp \alpha)$

A função de incisão associada é definida completamente pela função de seleção. A construção inversa também é possível.

2.3.1.3 Definição. [FFI06] Seja $\sigma$ uma função de incisão para algum conjunto B. É definida uma função de seleção associada $\gamma_{\sigma}$ tal que:

$\gamma_{\sigma}(B \perp \alpha)=\left\{\begin{array}{l}\{H \in B \perp \alpha:(B \backslash \sigma(B \Perp \alpha)) \subseteq H\}, \text { se } B \perp \alpha \neq \varnothing \\ \{B\}, \text { caso contrário }\end{array}\right.$

É demonstrado em [FFI06] que as funções de seleção e de incisão podem ser transformadas de uma para a outra, isto é, uma pode ser definida em função da outra. Também é demonstrado que a volta da transformação resulta em uma função idêntica à original, desde que as seguintes propriedades sejam respeitadas: 
2.3.1.4 Definição. [AGM85] Uma função de seleção $\gamma$ é dita completa se e somente se quando $\bigcap \gamma(B \perp \alpha) \subseteq H$ e $H \in B \perp \alpha$, então $H \in \gamma(B \perp \alpha)$.

2.3.1.5 Definição. [Han99] Uma função de incisão é dita relevante se e somente se para todo $\beta \in \sigma(B \Perp \alpha)$ existe um $X$ tal que $(B \backslash \sigma(B \Perp \alpha)) \subseteq X \subseteq B, \alpha \notin C n(X)$ e $\alpha \in C n(X \cup\{\beta\})$.

Apesar de seguirem abordagens totalmente opostas ao problema, a possibilidade de transformação dos resultados nas duas direções, e até mesmo de construir as operações utilizando uma a outra, sob certas condições, são evidencias de que as duas abordagens são na verdade muito próximas.

\subsubsection{Kernel e Resíduo}

Ambas as abordagens contam com operadores para obtenção de resultados intermediários importantes para as construções, os conjuntos kernel e resíduo.

É provado em [FFI06] que a partir de uma função de incisão mínima é possível construir elementos do conjunto resíduo. Primeiramente é necessário definir um tipo específico de função de incisão:

2.3.2.1 Definição. [FFI06] Uma função de incisão $\sigma$ é dita mínima se não existe subconjunto próprio de $\sigma(B \Perp \alpha)$ que possa ser resultado de uma função de incisão.

Como o conjunto de sentenças escolhido pela função de incisão é mínimo, segue que o complemento deste conjunto com relação à base é um subconjunto da mesma que não implica na sentença e é maximal, logo um elemento do resíduo. Segue que é possível gerar todo o conjunto resíduo utilizando o kernel e uma função de incisão mínima. Mais formalmente, para todo $H \subseteq B, H \in B \perp \alpha$ se e somente se existe função de incisão mínima $\sigma$ tal que $H=B \backslash \sigma(B \Perp \alpha)$.

Portanto é possível obter o conjunto resíduo, importante resultado intermediário das operações por partial meet, a partir dos $\alpha$-kernels, sem que seja necessário utilizar o operador de consequência.

Outro ponto importante é o tamanho potencialmente exponencial dos conjuntos kernel e resíduo. Casos com resultados intermediários muito grandes podem ser um grande inconveniente durante a execução em um sistema real. Existem situações em que a diferença de tamanho entre o conjunto resíduo e o conjunto kernel é significativa, podendo favorecer uma abordagem do problema ou outra.

Tomando uma base de crenças proposicionais com $n$ crenças construída da seguinte forma:

$$
B=\bigcup_{0 \leq k<n}\left\{\neg b_{k}, a \vee b_{k}\right\}
$$

Por exemplo, para $n=2$ :

$$
\begin{array}{rlrl}
B=\{ & \neg b_{0}, a \vee b_{0}, & & (k=0) \\
& \left.\neg b_{1}, a \vee b_{1}\right\} & (k=1)
\end{array}
$$

Considerando a base de crenças descrita acima, tem-se que $B \Perp a$ possui $n$ elementos, onde cada elemento é um dos pares $\neg b_{k} ; a \vee b_{k}$, portanto possui tamanho linear com relação ao tamanho do problema. Já $B \perp a$ possui $2^{n}$ elementos, pois este é o número de incisões mínimas possíveis nos $n$ elementos do kernel, de 2 elementos cada. A tendência, portanto, é que operadores construídos tendo como base o conceito de kernel sejam mais eficientes para problemas como este, dado que o kernel cresce linearmente enquanto o resíduo cresce exponencialmente.

Também pode-se construir um caso oposto, considere uma base de crenças construída da seguinte forma:

$$
B=\bigcup_{0 \leq i<2}\left\{\left\{b_{i, 0}, b_{i, n} \rightarrow a\right\} \cup \bigcup_{0 \leq k<n}\left\{b_{i, k} \rightarrow c_{k}, c_{k} \rightarrow b_{i, k+1}\right\}\right\}
$$

Por exemplo, para $n=2$ : 


$$
\begin{array}{rlrl}
B=\left\{b_{0,0}, b_{0,2} \rightarrow a,\right. & & (i=0) \\
& b_{0,0} \rightarrow c_{0}, c_{0} \rightarrow b_{0,1}, & & (i=0, k=0) \\
b_{0,1} \rightarrow c_{1}, c_{1} \rightarrow b_{0,2}, & & (i=0, k=1) \\
b_{1,0}, b_{1,2} \rightarrow a, & & (i=1) \\
b_{1,0} \rightarrow c_{0}, c_{0} \rightarrow b_{1,1}, & & (i=1, k=0) \\
& \left.b_{1,1} \rightarrow c_{1}, c_{1} \rightarrow b_{1,2}\right\} & & (i=1, k=1)
\end{array}
$$

Dada a base de crenças descrita acima, pode ser observado que o tamanho do resíduo cresce linearmente, tendo, mais precisamente, $4 n+4$ elementos, enquanto o kernel tem tamanho $2^{n+1}$. Na solução de problemas desta família operadores baseados em resíduo terão vantagem no tamanho do resultado intermediário, por ter crescimento linear, em oposição ao crescimento linear do kernel.

É possível construir, portanto, exemplos em que cada uma das abordagens se mostra mais efetiva que a outra. Um operador hipotético poderia ser construído utilizando algum procedimento de escolha entre abordagem kernel e resíduo, baseado na estrutura das sentenças. Estes casos claramente introduzem uma dúvida à ideia intuitiva de que a abordagem kernel, por conjuntos minimais, é mais eficiente.

\subsection{Complexidade Computacional}

Tratando-se de uma implementação destes operadores, não pode deixar de ser mencionada a complexidade computacional destes. [Neb96] explora a classe de complexidade de diversos operadores sobre bases de crenças, inclusive o operador de revisão proposto por [Han94].

Primeiramente é necessário definir algumas classes de complexidade. Seja $\mathbf{P}$ a classe dos problemas de decisão computáveis em uma Máquina de Turing determinística em tempo polinomial, e NP a classe dos problemas de decisão computáveis em tempo polinomial por Máquinas de Turing não determinísticas. Seja $\mathbf{X}$ uma classe de problemas de decisão, define-se $\mathbf{P}^{\mathbf{X}}$ como a classe de problemas decidíveis em tempo polinomial por uma Máquina de Turing determinística com acesso a um oráculo capaz de decidir algum problema $\mathbf{Q} \in \mathbf{X}$ em tempo constante. De maneira similar, $\mathbf{N P}^{\mathbf{X}}$ é a classe de problemas decidíveis em tempo polinomial por uma Máquina de Turing não determinística com acesso a um oráculo para algum problema $\mathbf{Q} \in \mathbf{X}$. Com base nas noções acima, são definidos os conjunto $\Sigma_{k}^{p}$ e $\Pi_{k}^{p}$ tais que:

$$
\begin{gathered}
\Sigma_{0}^{p}=\Pi_{0}^{p}=\mathbf{P} \\
\Sigma_{k+1}^{p}=\mathbf{N P}^{\Sigma_{k}^{p}} \\
\Pi_{k+1}^{p}=\operatorname{co} \Sigma_{k+1}^{p}
\end{gathered}
$$

De acordo com [Neb96], a complexidade computacional da revisão de bases de crenças para lógicas proposicionais é $\Pi_{2}^{p}$ - completo. Mesmo para casos simples como lógicas de Horn e limitando o tamanho das fórmulas por uma constante o problema ainda é coNP-completo. Tratam-se, portanto, de problemas que demandam uma enorme quantidade de recursos computacionais, qualquer implementação deve ser muito cuidadosa com o consumo de recursos e performance, e a escolha da lógica utilizada pode causar uma mudança dramática na complexidade do problema.

\subsection{Reflexão crítica}

Neste capítulo foram apresentados os conceitos que estruturam operadores sobre bases de crenças, divididos em duas grandes abordagens, kernel e partial meet. Apesar de serem abordagens antagônicas, por conjuntos maximais e minimais, os operadores construídos são muito semelhantes 
em suas propriedades, existindo inclusive relações entre as construções que evidenciam que talvez elas sejam mais próximas do que parece inicialmente.

Foram vistos 5 operadores, contração, revisão interna, revisão externa, consolidação e semirevisão. Todos puderam ser construídos usando ambas as abordagens, chegando em resultados com propriedades muito semelhantes. Diversas das propriedades se mantinham entre os dois casos, com a única exceção da propriedade de relevância, encontrada nas operações por partial meet, cuja propriedade correspondente nas operações por kernel, core-retainment, é mais fraca [Han99]. Isso se dá pois a abordagem por kernel é um caso mais genérico da operação por partial meet [Han94], fazendo com que toda operação por partial meet seja uma operação por kernel, mas o inverso não seja sempre possível.

Outra evidência da proximidade dos conceitos são as relações exploradas. As funções de incisão e seleção são críticas na construção dos operadores. A existência de funções associadas indica uma correlação muito forte, assim como a possibilidade de construir o conjunto resíduo a partir do kernel.

A existência das duas abordagens leva claramente a um questionamento sobre qual delas utilizar, para obter melhores resultados e menor necessidade de recursos computacionais, preocupações comuns para uma utilização prática. Intuitivamente a abordagem kernel é mais eficiente, por utilizar conjuntos minimais, portanto menores e exigindo menos tempo para cálculo e espaço para armazenagem. Existem, entretanto, construções onde a abordagem por kernel gera um número exponencial de conjuntos intermediários, enquanto o conjunto de resíduos mantém um crescimento linear, gerando dúvida sobre algo inicialmente intuitivo.

O desenvolvimento deste trabalho, descrito no próximo capítulo, irá descrever a implementação de um framework que irá possibilitar uma comparação empírica destas duas construções, culminando na medição de seus comportamentos e da taxa de crescimento dos recursos computacionais necessários. 


\section{Capítulo 3}

\section{Implementação}

A teoria de revisão de crenças é baseada em um framework matemático muito bem definido. Este fato permite que múltiplos operadores sejam comparados teoricamente, e a base conceitual comum facilita a comunicação entre membros da comunidade científica. Um dos objetivos deste trabalho é criar um framework computacional alinhado com as fundações matemáticas, viabilizando que o mesmo também ocorra no campo das implementações, permitindo que diferentes algoritmos possam ser comparados empiricamente. Conceitos e operadores matemáticos são traduzidos diretamente ao framework computacional, portanto quando um mesmo conceito é utilizado em diversas ocasiões este também pode ser reutilizado na prática.

Apesar de muitos dos trabalhos sobre revisão de crenças na literatura terem sido propostos tendo como base a lógica proposicional clássica, a grande maioria dos resultados independe da lógica utilizada. Diferentes lógicas e operadores de consequência podem ser utilizados, dado que estes atendam a determinados requisitos, como serem compactos [HW02, FPA04].

O framework proposto segue os mesmos princípios: todo operador de consequência deve ser utilizável através de uma API comum, e os usuários do operador devem depender apenas desta, portanto o operador pode ser trocado livremente. Um operador de revisão de crenças que dependa de um operador de consequência abstrato pode ser utilizado com qualquer lógica, qualquer representação de sentença ou implementação do operador de consequência. A possibilidade de troca do operador de consequência é central no framework proposto, trazendo os benefícios das abstrações utilizadas nos trabalhos teóricos.

O framework matemático utiliza frequentemente composição para construir conceitos cada vez mais complexos. Esta forma de construção está diretamente relacionada à práticas comuns em programação orientada a objetos, tais como composição e injeção de dependências: se um conceito depende de outro, deve recebê-lo no ato da construção.

Este esforço em manter a arquitetura do framework alinhada com a fundamentação matemática vai além do operador de consequência. Todos os conceitos possuem uma API bem definida: conjuntos, sentenças, operadores de revisão, contração, resíduo, kernel e funções de incisão e seleção.

Os benefícios desta coerência são notáveis. As implementações são independentes da lógica utilizada, tornando possível o intercâmbio de operadores. Escrever novos operadores é uma tarefa muito simples, pois todos os conceitos básicos já estão definidos: a tradução de fórmulas e pseudocódigo para código real e funcional é direta. O framework traz consigo uma boa estrutura para a elaboração de testes unitários, tornando simples a criação de casos de testes que garantam o bom comportamento do algoritmo implementado.

O framework também inclui uma série de ferramentas parametrizáveis para a criação de cenários pseudoaleatórios. Como todos os operadores compartilham uma API, é possível medir os recursos computacionais exigidos por diversas implementações para os mesmos cenários. Já que todos os operadores compartilham conceitos básicos, e a implementação consiste apenas do algoritmo específico, comparações são justas. 


\subsection{Principais conceitos}

O framework é escrito em Java, uma linguagem que mostrou ter recursos adequados à proposta, tendo um bom desempenho, suporte a programação orientada a objetos e grande popularidade, o que diminui a curva de aprendizado a colaboradores.

Como foi descrito acima, os elementos chave do framework são suas abstrações, que serão apresentadas à seguir. Os trechos de código tiveram comentários e linhas em branco omitidos, assim como métodos auxiliares triviais.

\subsubsection{Conjuntos}

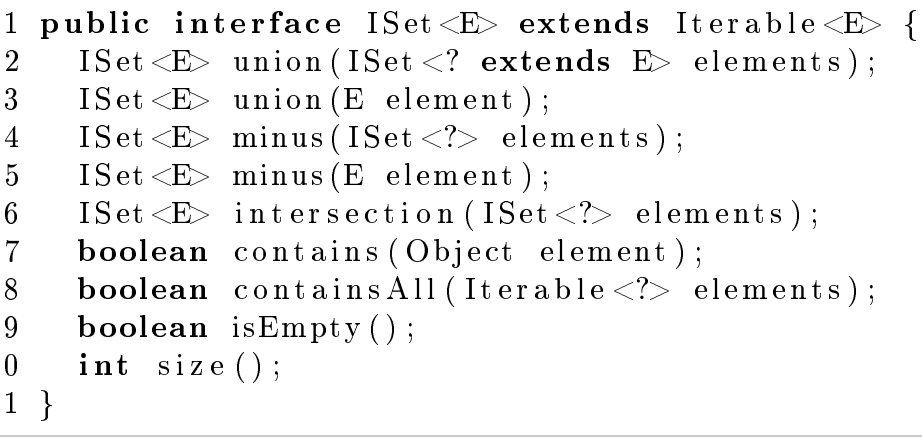

O conceito de conjuntos é amplamente utilizado em quase todos os ramos da matemática, e a área de revisão de crenças não é exceção. Conjuntos possuem operações bem estabelecidas $(\cup, \cap, \subset$, $\checkmark$ ), e normalmente são imutáveis, pois uma vez definidos nunca são alterados os elementos que o constituem. Ter uma implementação imutável de conjuntos com estas operações usuais é útil durante a escrita de algoritmos, permitindo código altamente expressivo.

Por exemplo, a fórmula $A=B \cap(C \backslash D)$ pode ser implementada pelo código a seguir, fazendo uso da API descrita acima:

$A=B$. intersection (C.minus (D))

Tornar fácil a manipulação de conjuntos facilita a tradução de algoritmos para código real, diminuindo a chance de erros na tradução e diminuindo a curva de aprendizado.

A implementação de conjuntos imutáveis é vital para todos os algoritmos implementados neste trabalho, sendo necessário que seja eficiente e que exija pouca memória, pois é comum que um enorme número de conjuntos seja manipulado durante a resolução de determinadas instâncias de problemas.

\subsubsection{Sentenças}

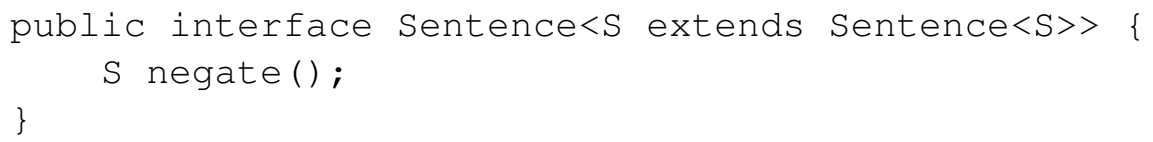

Uma sentença é qualquer objeto imutável que possa retornar sua negação. Ainda assim é possível utilizar sentenças que não suportem negação, mas deve ser levado em consideração se o operador em questão necessita deste recurso. Fora a negação e a imutabilidade não há qualquer restrição à representação interna de uma sentença ou lógica utilizada.

Atualmente o framework conta com implementações funcionais de sentenças proposicionais e axiomas de lógicas de descrição (OWL2 ${ }^{1}$ ).

\footnotetext{
${ }^{1}$ http://www.w3.org/TR/owl2-overview/
} 


\subsubsection{Provadores de teoremas}

Outro recurso utilizado nas construções é o operador de consequência lógica. A teoria faz pouquíssimas suposições acerca da lógica utilizada, e este operador é o único ponto de contato das implementações com a lógica sendo utilizada. O isolamento do provador de teoremas é, portanto, equivalente a isolar a própria lógica tratada pelos algoritmos que serão descritos.

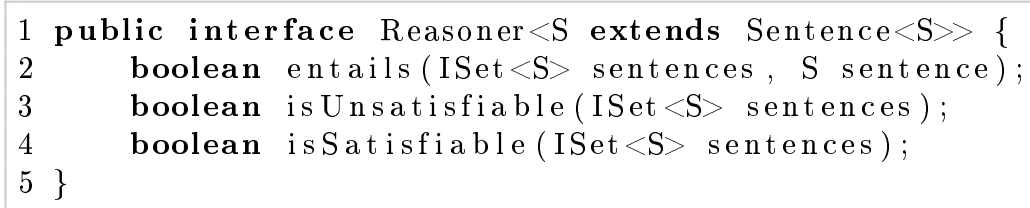

A interface acima encapsula a implementação dos operadores lógicos, permitindo que todos os algoritmos sobre bases de crenças possam operar sem conhecer a lógica sendo utilizada. O provador é qualquer objeto que saiba responder perguntas básicas sobre conjuntos de sentenças.

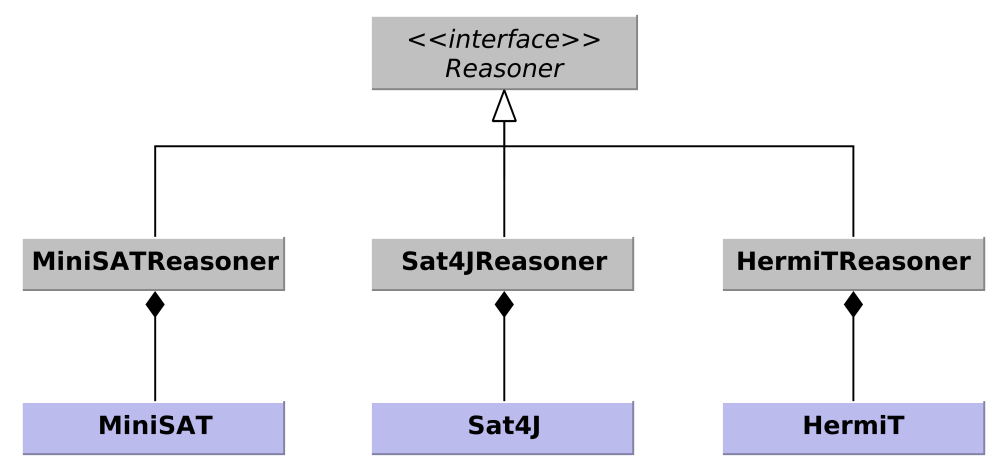

Figura 3.1: Diagrama de classes com diversas implementações de provadores.

Atualmente exitem três implementações de Reasoner, evidência de que o operador de consequência é realmente intercambiável. É possível utilizar como sentenças cláusulas proposicionais utilizando o provador de teoremas SAT4J ${ }^{2}$ ou MiniSAT ${ }^{3}$, e axiomas OWL através do provador HermiT ${ }^{4}$.

\subsubsection{Revisão e Contração}

Também são definidas interfaces unificadas para as operações de contração e revisão:

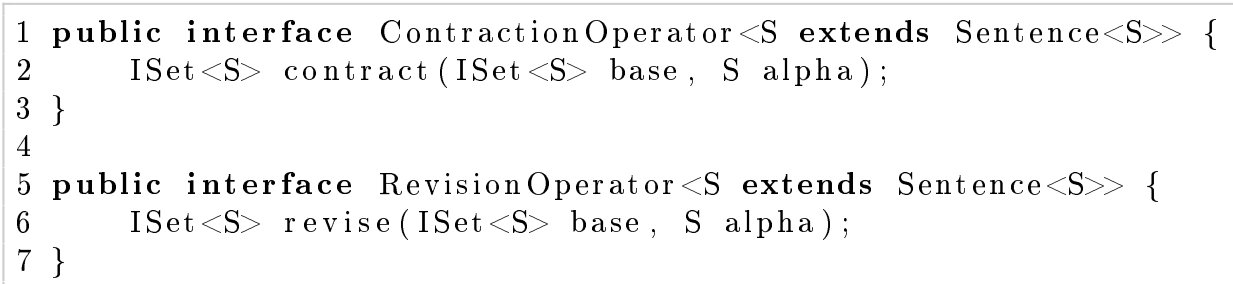

Estas definições permitem que múltiplas implementações possam coexistir, permitindo fácil intercâmbio. Em casos que seja utilizada injeção de dependências, um usuário do operador precisa apenas conhecer a interface, desconhecendo totalmente a implementação sendo utilizada. Essa liberdade permite a substituição do operador por algum que seja mais apropriado para a situação atual.

\subsubsection{Revisão e Contração Kernel}

Com as interfaces de contração e revisão definidas, pode-se construir suas implementações utilizando uma abordagem por Kernel.

\footnotetext{
${ }^{2}$ http://www.sat4j.org/

${ }^{3}$ http://minisat.se/

${ }^{4} \mathrm{http}: / /$ www.hermit-reasoner.com/
} 
A construção via kernel faz uso de dois outros operadores, que também não possuem implementação definida e também precisam de interfaces adequadas, o operador kernel $(\Perp)$ e a função de incisão $(\sigma)$.

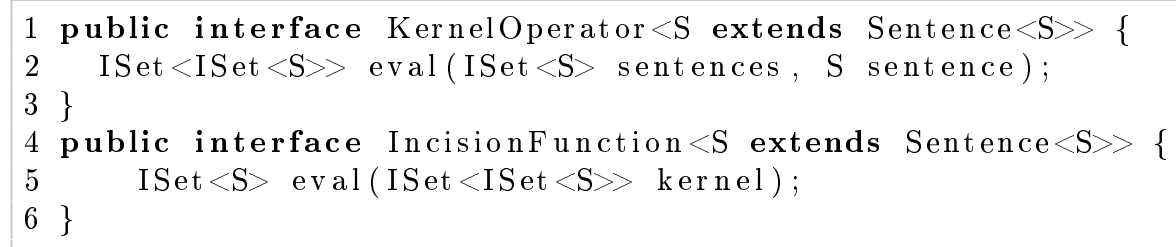

Com os operadores básicos definidos, pode-se construir as operações de revisão e contração por kernel. Para construir a contração kernel, descrita na teoria por $B \dot{-}_{\sigma} \alpha=B \backslash \sigma(B \Perp \alpha)$, deve-se traduzir diretamente a fórmula para a linguagem:

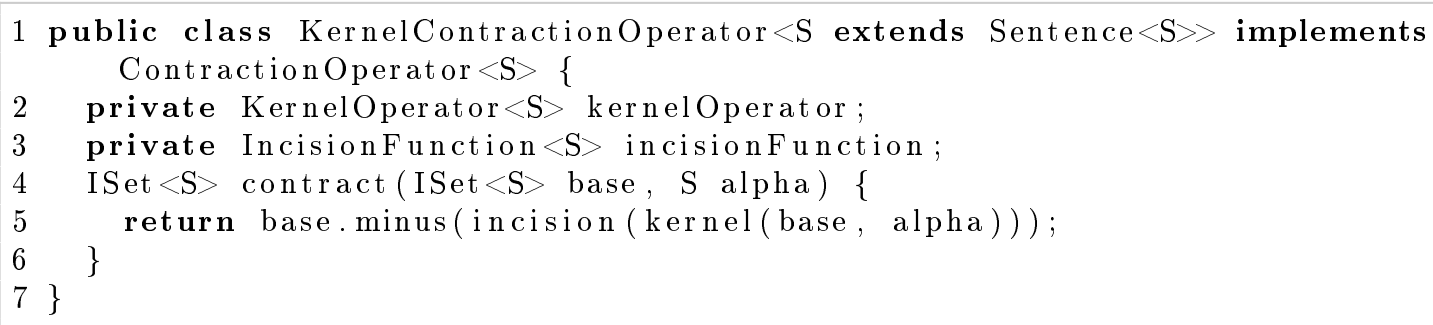

Também pode-se construir a revisão kernel interna, descrita pela fórmula $B \mp \sigma \alpha=(B \backslash \sigma(B \Perp$ $\neg \alpha)) \cup\{\alpha\}$, resultando na seguinte implementação:

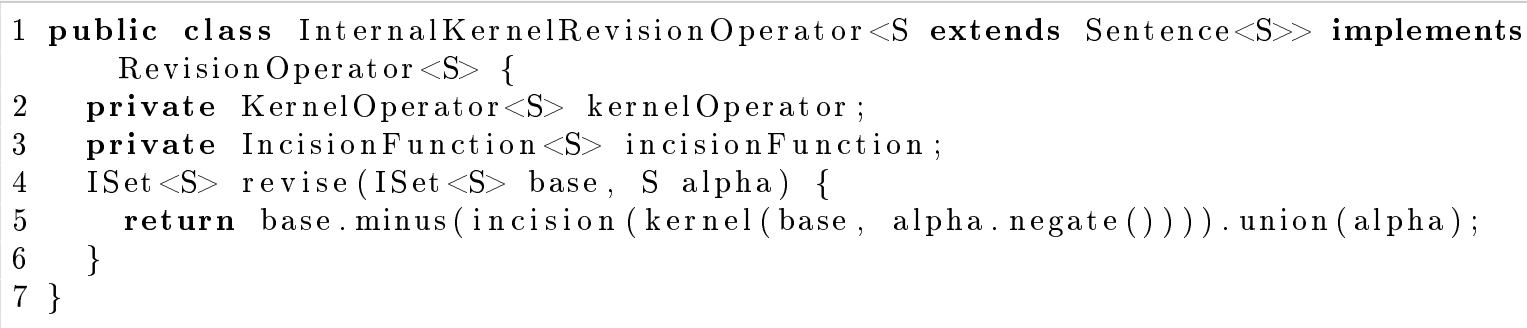

Para construir a revisão kernel externa utilizam-se os mesmos conceitos, descrita na teoria como $B \pm_{\sigma} \alpha=(B \cup\{\alpha\}) \backslash \sigma((B \cup\{\alpha\}) \Perp \neg \alpha)$, chegando ao seguinte resultado:

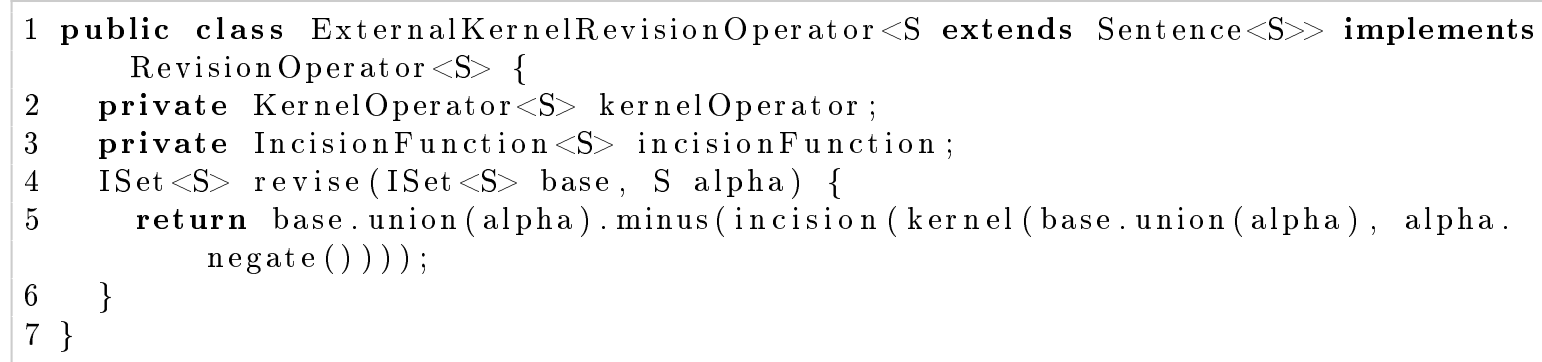

Como é possível ver pelos trechos acima, a implementação baseada nos conceitos já separados pelo framework teórico permitiu uma descrição fluente de operadores complexos. Ainda é necessário, entretanto, explorar a implementação do operador kernel e da função de incisão. A função de incisão permite implementações triviais corretas do ponto de vista teórico, mas de resultado insatisfatório por não ser intuitivo, e não é objetivo desta dissertação explorar este assunto. O resultado do operador kernel é totalmente definido, mas não o algoritmo utilizado para alcançá-lo, que será explorado em seguida.

\subsubsection{Operador Kernel}

O operador kernel $(\Perp)$, descrito em [Han94], deve encontrar o conjunto de todos os subconjuntos de uma base de conhecimento que implicam em alguma sentença. $\mathrm{O}$ algoritmo trivial para o caso seria iterar por todos os subconjuntos da base buscando tais conjuntos, eliminando aqueles que não 
forem minimais. Esta abordagem, entretanto, é extremamente custosa, devido ao enorme número de subconjuntos possíveis, mesmo para problemas de tamanho modesto.

São descritos em [Rib10], com base em [Kal06], algoritmos para o cálculo do kernel. A proposta é utilizar o algoritmo de Reiter para computação de cortes mínimos em uma classe de conjuntos, descrito em [Rei87] e corrigido em [GSW89], para guiar a busca, permitindo que todos os elementos sejam encontrados sem que seja necessário avaliar cada subconjunto. Dentro do algoritmo de Reiter, basta ser capaz de encontrar um único subconjunto dentro de um espaço dado para que a busca seja feita.

Para identificar um dos elementos do kernel é utilizado um procedimento denominado expandeencolhe. A ideia deste procedimento é selecionar elementos de uma base até que se obtenha um subconjunto inconsistente, em seguida este conjunto é contraído mantendo a inconsistência até que não seja possível continuar. Ao final deste procedimento o conjunto resultante é um dos elementos do kernel.

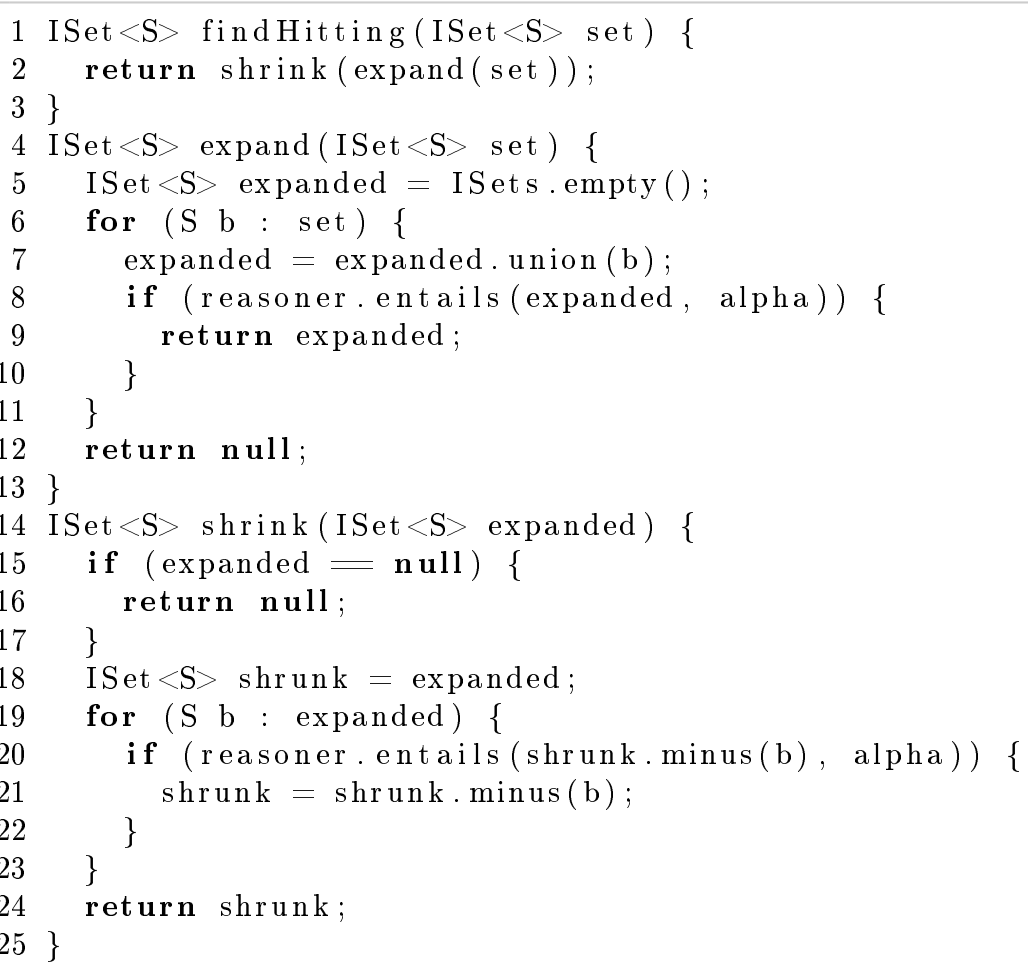

Uma das grandes vantagens do expande-encolhe é sua abrangência, basta que o provador de teoremas tenha a funcionalidade de verificar satisfatibilidade para que esta abordagem possa ser utilizada. Como esta funcionalidade é muito básica, presente em praticamente todo provador, este algoritmo é adequado a um grande número de lógicas. Por requerer apenas um provador padrão, e nenhum conhecimento específico acerca da lógica utilizada, esta abordagem é chamada de BlackBox.

Em [Rib10] e [Kal06] também é descrito um método chamado Glass-Box, que utilizaria uma versão pesadamente modificada do provador de teoremas para conseguir extrair mais informações sobre a consulta, como as sentenças utilizadas para chegar a uma inconsistência. Com essas informações seria possível implementar métodos muito mais eficientes para encontrar os elementos do Kernel.

No caso proposicional, o procedimento descrito se aproxima muito do problema do núcleo insatisfazível, cuja implementação é muito comum em provadores de teoremas modernos devido às vastas aplicações, como verificação automática de hardware e software, design de hardware e para desenvolvimento de sistemas que forneçam explicações sobre determinados problemas [LS08].

O uso da operação do provador de teoremas para resolução do núcleo insatisfazível permite a implementação do operador kernel utilizando um número muito menor de chamadas, efetuando boa parte da busca dentro do próprio provador. O custo de cada chamada é, entretanto, conhecidamente 
mais exigente em recursos computacionais. Como pode ser visto no trecho abaixo, para encontrar um elemento do kernel é necessário apenas uma chamada ao resolvedor de núcleo insatisfazível.

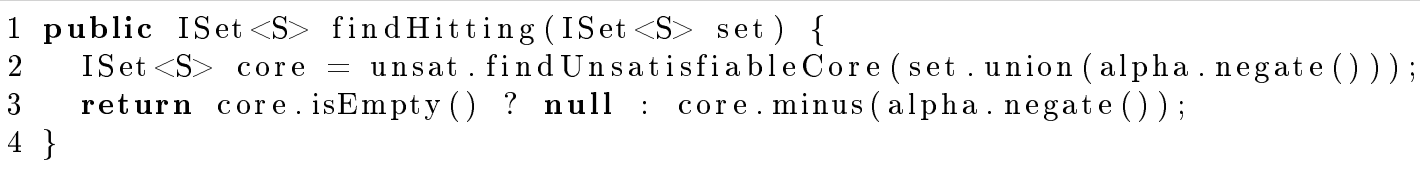

A abordagem Glass-Box continua sendo independente de lógica, entretanto nem toda lógica possui um provador com esta funcionalidade. Há necessidade de suporte especial do provador a esse tipo de chamada.

\subsubsection{Revisão e Contração Partial Meet}

As operações por partial meet também fazem uso de operações mais básicas para serem construídas, no caso o operador de conjunto resíduo $\perp$ e a função de seleção $\gamma$.

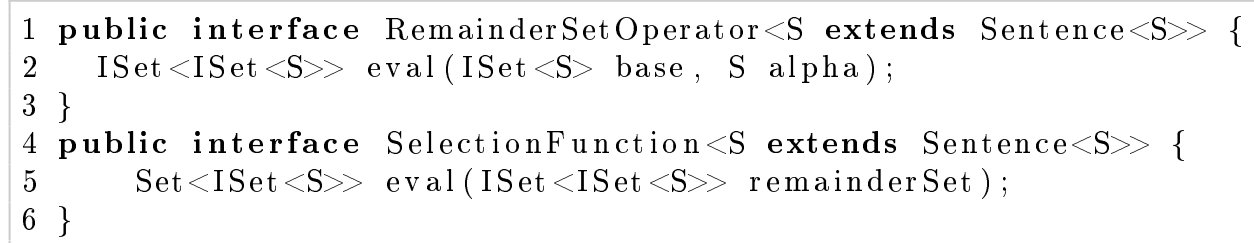

Fazendo uso dos operadores descritos acima, pode-se construir o operador de contração por partial meet, definido originalmente como $B \dot{-}_{\gamma} \alpha=\bigcap \gamma(B \perp \alpha)$ :

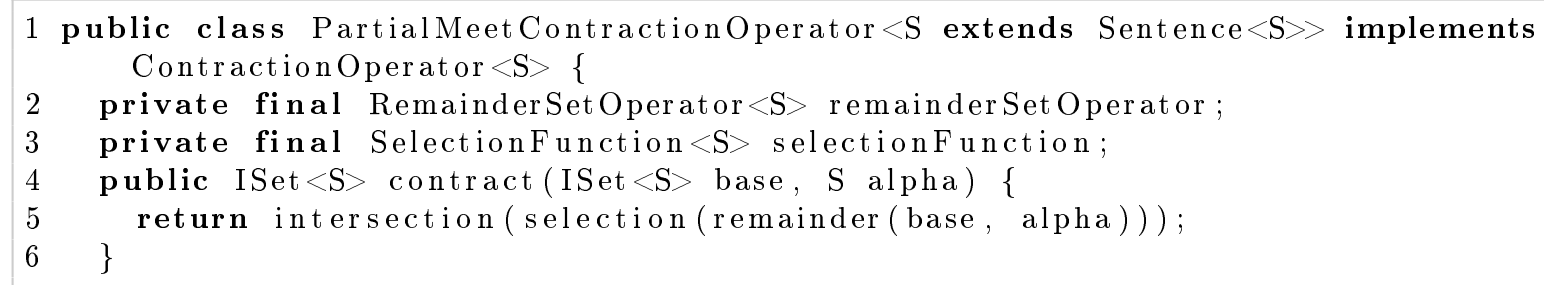

Da mesma forma, pode-se construir a revisão interna por partial meet, definida por $B \mp_{\gamma} \alpha=$ $\bigcap \gamma(B \perp \neg \alpha) \cup\{\alpha\}:$

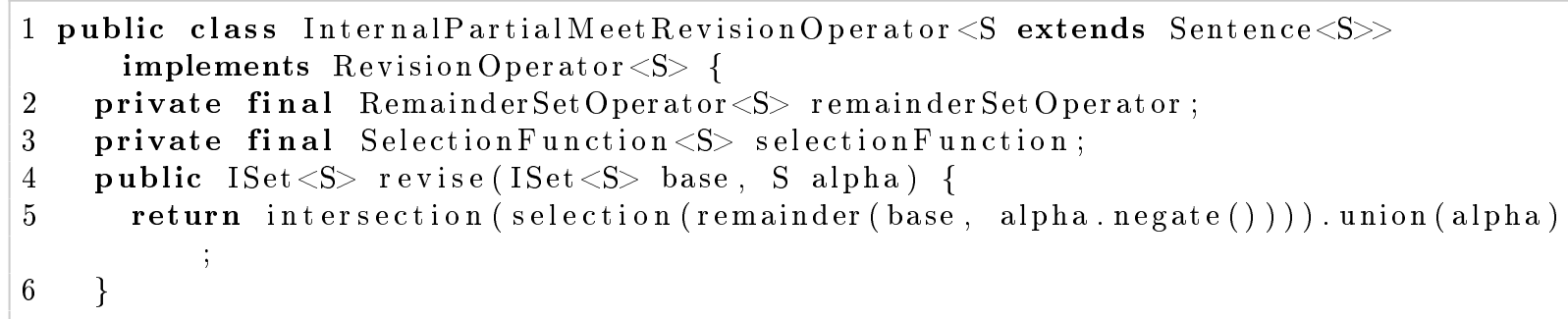

Finalmente, tem-se a construção da revisão externa por partial meet, dada por $B \pm_{\gamma} \alpha=$ $\bigcap \gamma((B \cup\{\alpha\}) \perp \neg \alpha)$ :

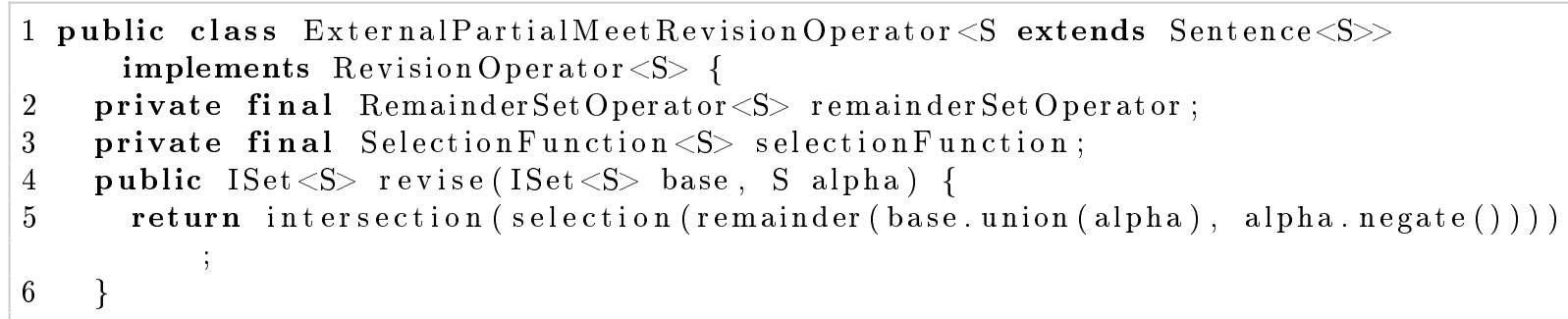

Assim como ocorreu na construção por kernel, a abordagem por partial meet também faz uso de operações mais primitivas para construir diversos operadores mais poderosos. A separação na implementação do operador resíduo $\perp$ e da função de seleção $\gamma$ permitiu que o operador de contração e os dois operadores de revisão fossem construídos facilmente. A construção de boas funções de 
seleção não será abordada aqui, pois foge ao objetivo desta dissertação. O operador resíduo tem seu resultado completamente definido na teoria, mas não o algoritmo para implementá-lo, o que será abordado em seguida.

\subsubsection{Operador Resíduo}

O operador resíduo deve encontrar todos os conjuntos maximais de uma base que falham em implicar uma dada sentença. Esta operação poderia ser feita iterando por todos os subconjuntos possíveis e eliminando os não maximais, mas o grande número de subconjuntos torna esta abordagem inviável do ponto de vista computacional.

A busca do conjunto resíduo foi construída de forma análoga à implementação sugerida por [Rib10] para o kernel. Apesar do algoritmo ser intuitivamente mais adequado para encontrar subconjuntos mínimos, também é possível utilizar o algoritmo de Reiter e o expande-encolhe para encontrar os conjuntos resíduo, que são maximais, bastando buscar todos os complementos dos conjuntos maximais. Abaixo está um trecho do código que utiliza o expande-encolhe para encontrar o complemento de um dos conjuntos resíduo.

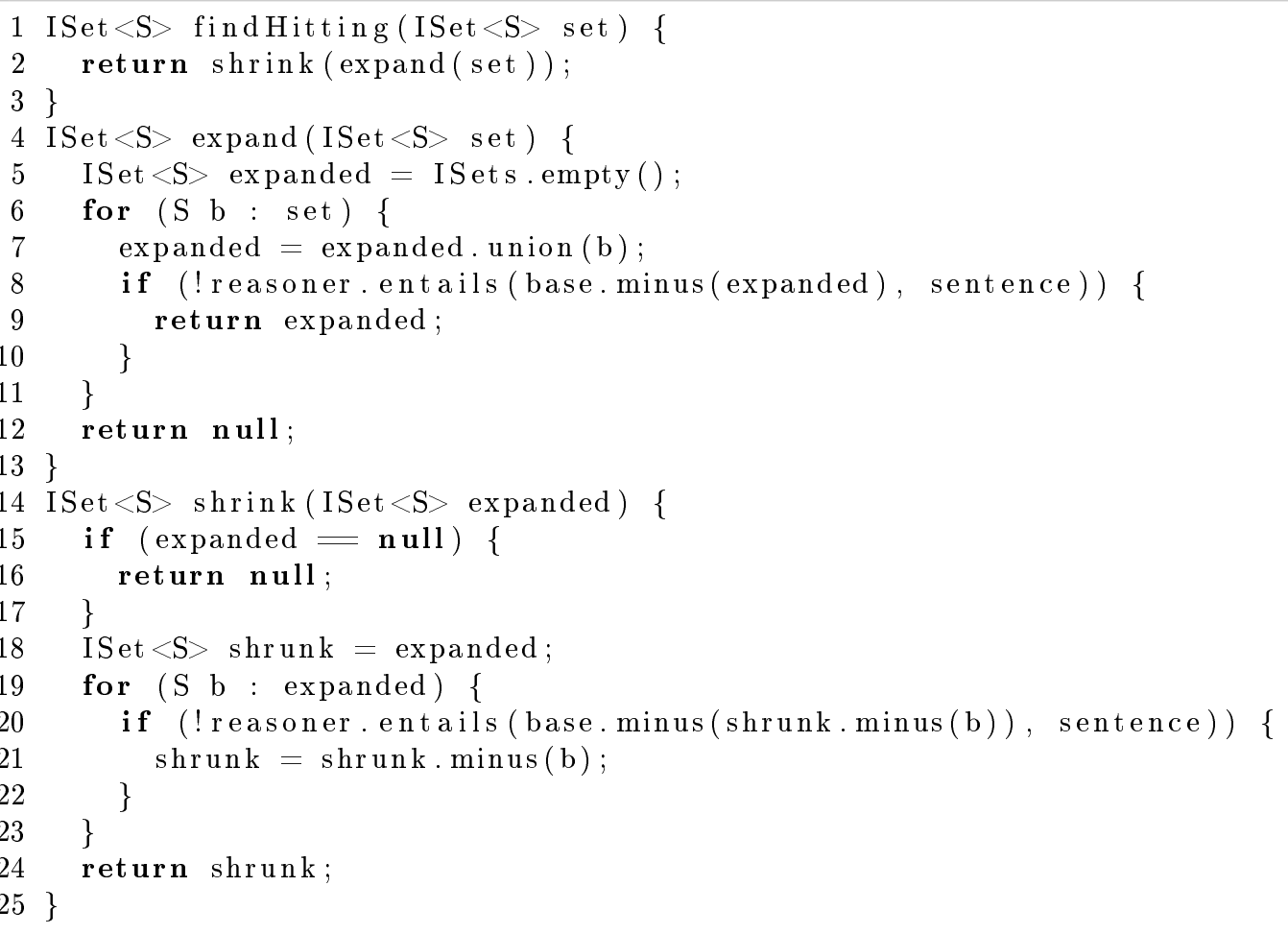

Este algoritmo para encontrar um dos elementos do resíduo requer apenar um provador de teoremas básicos, é uma estratégia Black-Box, tornando-o apropriado para quase qualquer lógica.

Também é possível construir uma abordagem Glass-Box do operador resíduo. No caso foi utilizada a funcionalidade que muitos provadores para lógica proposicional modernos possuem de encontrar o conjunto satisfazível máximo. Desta forma é possível encontrar um elemento do resíduo utilizando uma única chamada ao provador.

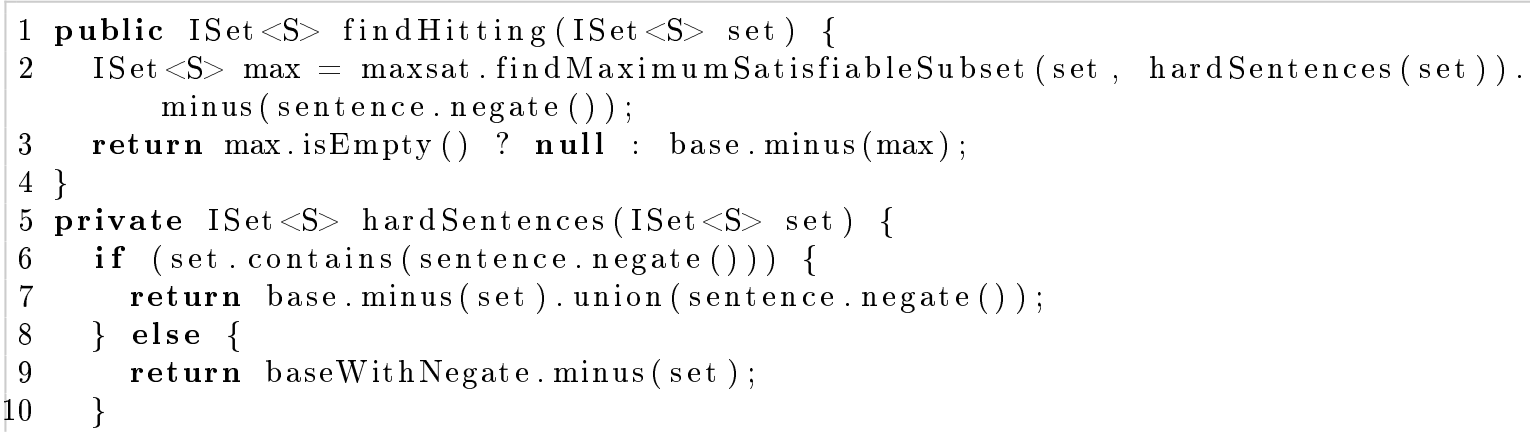


$11\}$

A chamada ao conjunto satisfazível máximo tipicamente pede um conjunto de sentenças que não poderá ser desconsiderado, o que permite guiar a busca dentro do algoritmo de Reiter e evitar encontrar subconjuntos duplicados.

\subsection{Geração de Cenários}

A proposta do framework é permitir a avaliação empírica de algoritmos em um grande número de cenários, portanto é necessário fornecer também o aparato para a geração destes.

O objetivo foi a geração de cenários em lógica proposicional, escolhidos de forma uniforme dentro das possibilidades existentes, de forma reprodutível e parametrizável. A geração deve ser uniforme para garantir que o resultado não seja tendencioso para algum caso específico. Também deve ser reprodutível para permitir que o experimento possa ser realizado novamente, e deve ser parametrizável para a geração de cenários dentro de um determinado espaço amostral que se queira estudar.

\subsubsection{Fábrica de sentenças}

O framework conta com uma interface unificada para fábricas de sentenças (SentenceFactory).

Atualmente conta com duas implementações, uma que cria cláusulas proposicionais arbitrárias e outra que gera cláusulas de Horn. Ambas permitem que seja definido o número de variáveis do problema em questão e tamanhos mínimo e máximo das cláusulas geradas. Para cada sentença criada é possível forçar que determinados átomos estejam presentes, recurso utilizado quando o resultado não seria aceitável de outra forma, como será mostrado mais adiante. O trecho abaixo gera cláusulas arbitrárias aleatórias.

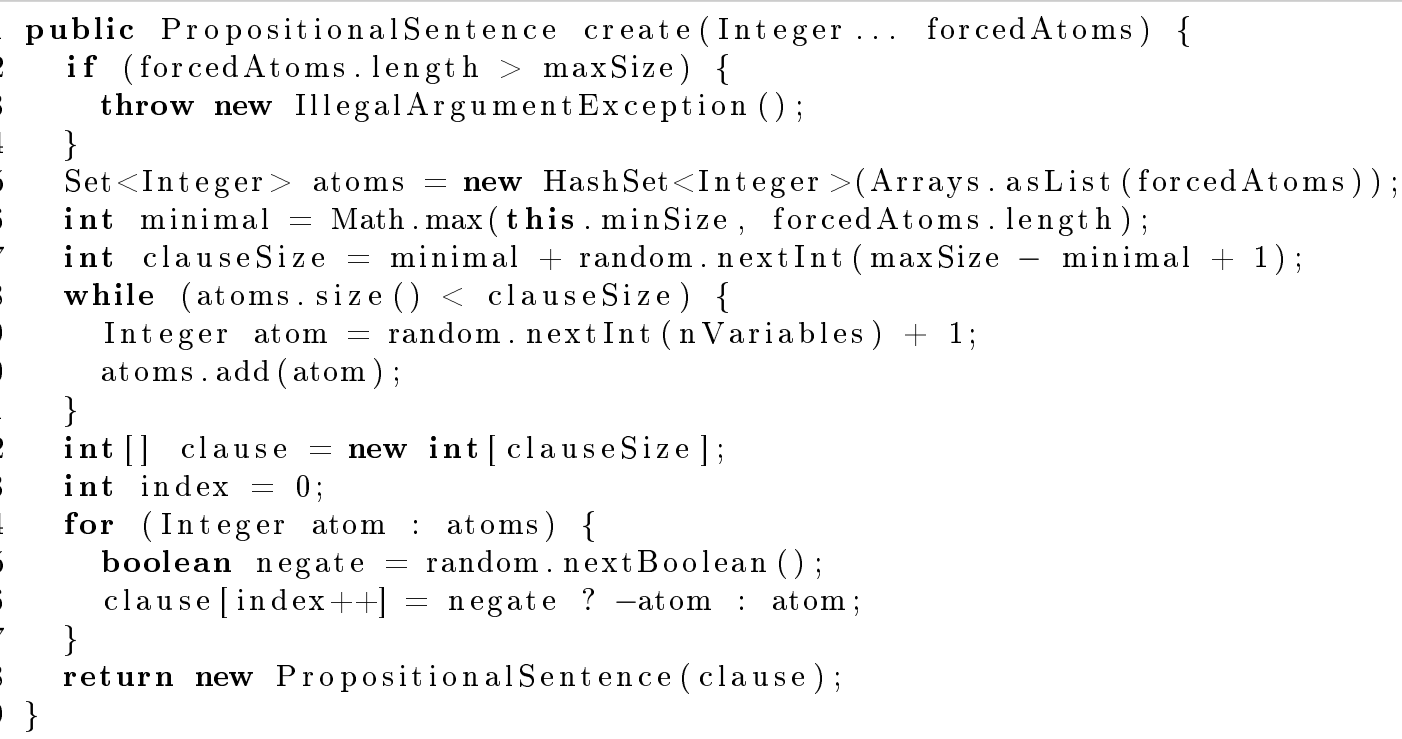

Inicialmente é criado um conjunto de átomos que farão parte da cláusula, o tamanho da cláusula é sorteado, e inteiros aleatório são sorteados até que o conjunto possua o número de elementos. Em seguida a cláusula é criada, atribuindo a cada índice um literal, dado por um dos átomos e um sinal também sorteado. Este procedimento produz cláusulas escolhidas uniformemente dentro do universo de escolhas possíveis.

A geração de cláusulas de Horn é idêntica até a escolha dos átomos, a escolha dos literais é feita de forma a gerar apenas cláusulas de Horn:

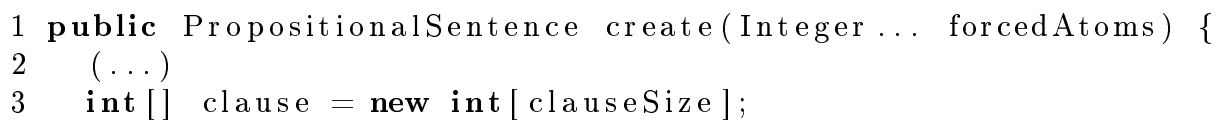




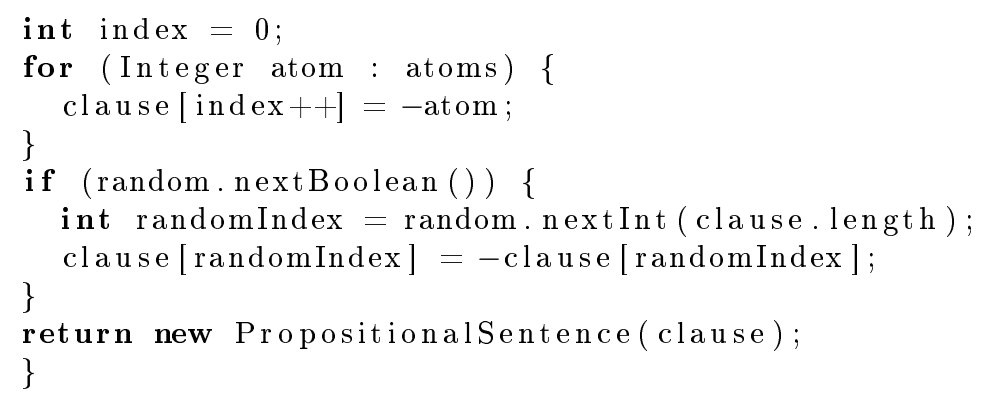

Como pode ser visto acima, todos os átomos são registrados inicialmente como literais negativos. Em seguida, é sorteado se esta cláusula terá ou não um elemento positivo, caso sim algum literal sorteado na cláusula será tornado positivo. Este procedimento irá gerar cláusulas de Horn escolhidas uniformemente dentro do universo de possibilidades.

\subsubsection{Fábrica de conjuntos de sentenças}

O framework também conta com uma interface para a criação de conjuntos de sentenças. O criador de conjuntos de sentenças tipicamente utiliza ao menos um criador de sentenças e compõe o resultado da maneira esperada. Existem hoje duas implementações, uma simplesmente gera conjuntos quaisquer de sentenças, outra cria conjuntos satisfazíveis de sentenças. O código abaixo realiza a construção de um conjunto de sentenças com um número determinado de variáveis e cláusulas:

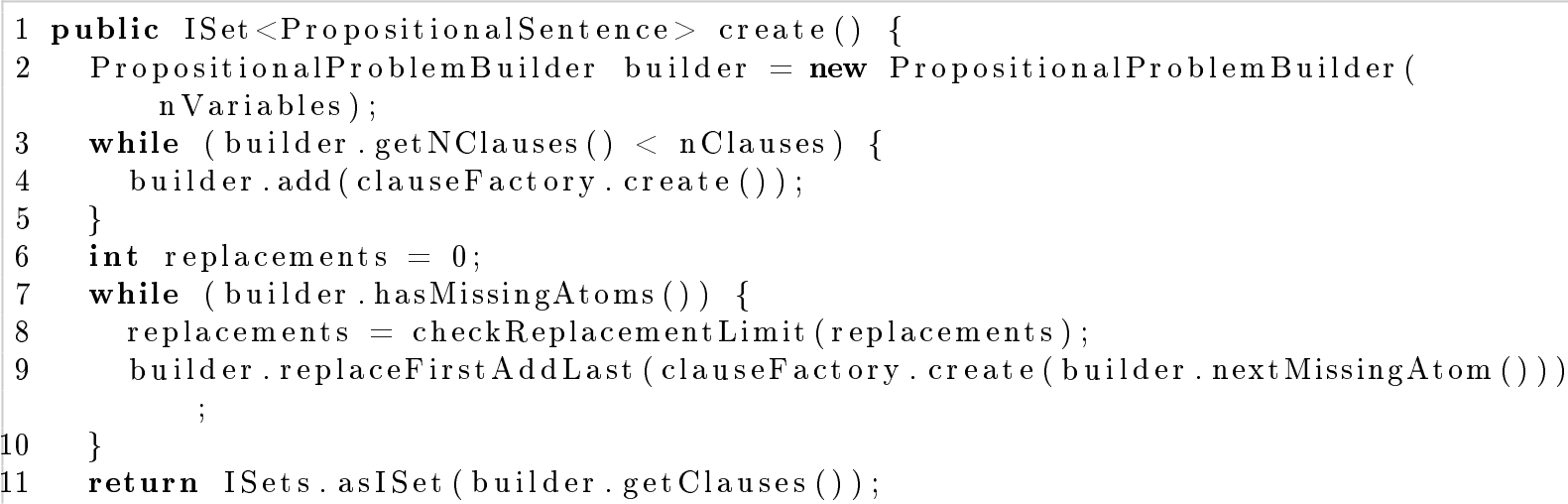

É utilizada uma classe auxiliar que mantém atualizada a contagem da ocorrência de átomos, desta forma o algoritmo simplesmente adiciona sentenças até que o número de cláusulas seja atendido, e em seguida substitui a primeira cláusula por outra que contém algum átomo que não tenha ocorrido em nenhuma cláusula. O processo acaba, portanto, com conjunto de cláusulas com o número desejado e com o número de átomos correto.

O trecho abaixo é responsável pela criação de conjuntos satisfazíveis. O tratamento é muito similar ao anterior, adicionando-se a preocupação em manter sempre um conjunto satisfazível a cada passo.

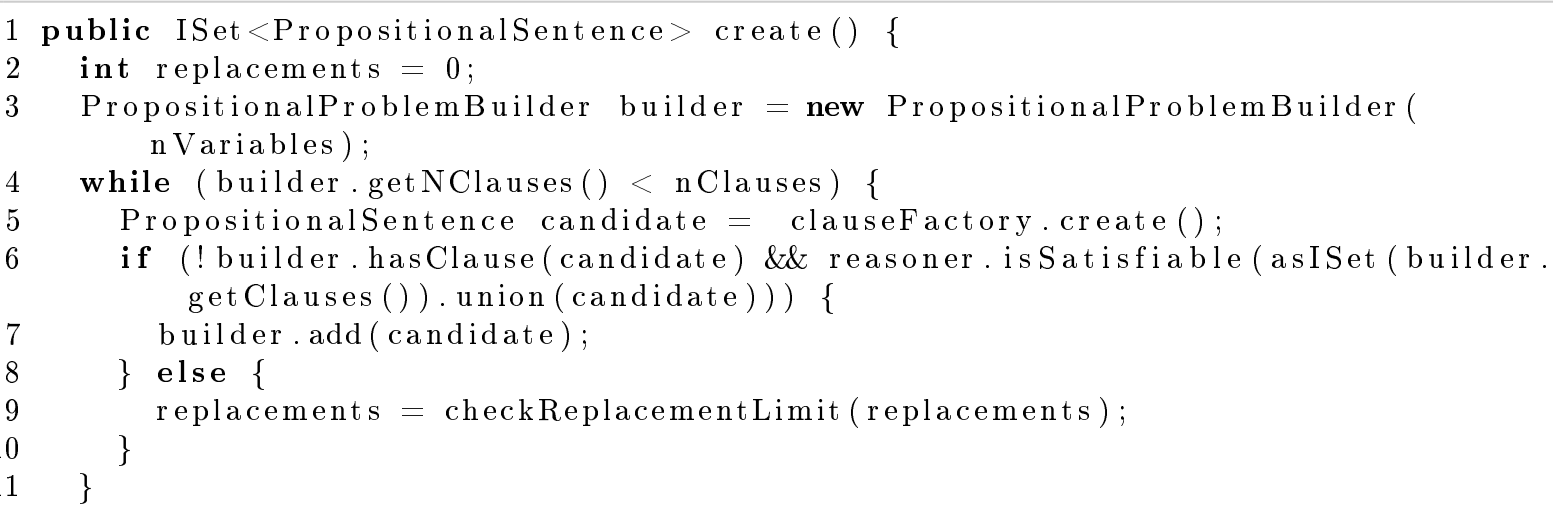


12

13

14

15

16

16

18

19 $20\}$

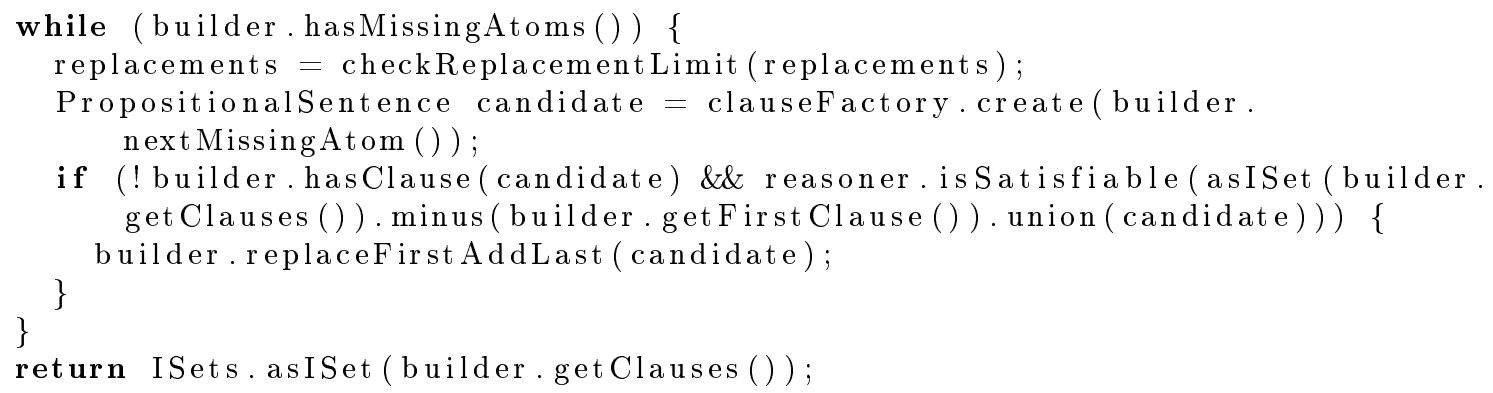

Note que há uma preocupação em manter a contagem de substituições. Para algumas configurações encontrar um conjunto pode ser muito difícil, ou mesmo impossível. Um conjunto com poucas variáveis e muitas cláusulas dificilmente é satisfazível, por exemplo.

\subsubsection{Fábrica de cenários de contração}

Dadas fábricas de sentenças e de conjuntos de sentenças, a criação de fábricas de cenários de contração é razoavelmente simples. Um cenário de contração consiste em uma base de conhecimento satisfazível e uma sentença implicada pela base. O código abaixo é suficiente para a criação de um cenário:

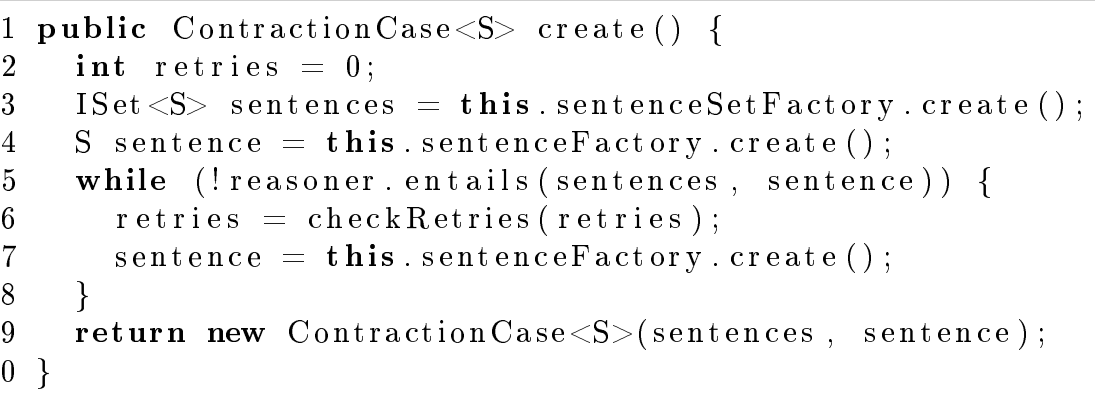

\subsubsection{Pseudoaleatoriedade}

Como pode ser visto pelos trechos de código descritos acima, a utilização de fontes de números aleatórios se restringe à fábrica de sentenças, as demais fábricas utilizam apenas uma fonte de sentenças aleatórias. Como fonte para números aleatórios pode ser utilizada qualquer implementação de java.util.Random.

A utilização da implementação padrão, que gera uma sequência de números pseudoaleatórios baseada em uma semente, pode ser utilizada para conseguir gerar cenários de uma maneira reprodutível, dispensando a armazenagem de instâncias completas de problemas. Essa abordagem permite que, de maneira muito simples, duas versões distintas de um algoritmo sejam executadas em momentos diferentes em um grande número de cenários idênticos, permitindo comparações de melhorias feitas nos algoritmos ao longo do tempo. Como a geração de cenários é algo muito rápido, armazenar suas sementes e gerá-los quando necessário é mais prático que armazenar instâncias.

\subsection{Perfil de execução}

Uma vez que o framework está estabelecido, funcionando corretamente e com a habilidade de gerar cenários, é possível fazer uma análise do perfil de execução (profiling) para verificar as etapas do processo que demandam mais recursos, com uma consequente tentativa de reduzir as necessidades.

Primeiramente é necessário elaborar um cenário de teste. Este cenário deve levar alguns minutos para ser executado e deve corresponder a um ou mais cenários reais, podendo ser executado diversas vezes. A execução deve ser feita com ferramentas adequadas à medição, que indicarão os trechos 
em que a execução leva mais tempo, o que pode evidenciar gastos desnecessários de processamento e a necessidade de melhorias. A implementação da melhoria deve ser seguida de uma nova execução para verificar se a modificação foi efetiva. Caso tenha sido um novo ponto de melhoria tipicamente é evidenciado e inicia-se um ciclo iterativo de aprimoramento.

\subsubsection{Cenário de teste}

Ao longo do desenvolvimento foram feitos testes utilizando uma grande variedade de cenários. Alguns dos resultados serão evidenciados abaixo utilizando um cenário específico. O cenário escolhido para análise de perfil de execução consta na solução de 10 problemas de contração, cada um executado 10 vezes, em 5 algoritmos distintos. Foram utilizadas nas medições problemas utilizando lógica proposicional, com cláusulas de tamanho 3, envolvendo 10 variáveis e 40 cláusulas em cada base de crenças.

Este cenário foi escolhido após diversas tentativas por ter se mostrado bastante exigente em termos do framework, por lidar com um grande número de conjuntos, gerando uma sobrecarga considerável, sendo bom alvo para otimizações.

A medição de tempo de execução de aplicações na JVM é influenciada por diversos fatores associados à execução que nem sempre podem ser plenamente controlados, como é notado em [GBE07]. Além de variáveis comuns à esse tipo de medição em qualquer linguagem, como hardware, sistema operacional e outras aplicações concorrentes, existem ainda outras variáveis associadas à plataforma Java. Uma grande fonte de não determinismo é o compilador just-in-time (JIT), que atua durante a execução da aplicação para otimizar os pontos mais utilizados da aplicação, podendo gerar diferenças significativas de tempo entre execuções para as mesmas entradas. Outra complicação é a política de agendamento das threads, que pode gerar por si só diferenças nos tempos de execução, juntamente com a compilação JIT pode alterar até mesmo os momentos de execução da coleta de lixo. A própria estratégia de coleta de lixo pode alterar a localidade as variáveis, podendo afetar o tempo de execução. Todas estas variáveis tornam complexa a medição de tempo de execução na JVM.

Existem diversas ferramentas para efetuar a medição do perfil de execução de aplicações Java, e muitas sofrem com distorções geradas pelas complexidades do ambiente, podendo gerar resultados distintos para as mesmas situações [MDHS10], ocasionados até mesmo por diferenças algumas vezes sutis de implementação. No caso o escolhido foi o próprio analisador da IDE NetBeans, por ser livre e suprir as necessidades. Existem duas formas de medição disponíveis: instrumentação e amostragem. A medição por instrumentação atua adicionando nas instruções do programa em tempo de execução código para efetuar coleta de dados, tais como contadores de chamadas e medidores de tempo. Esta abordagem, entretanto, tende a gerar uma sobrecarga considerável, podendo gerar distorções significativas [MDHS10]. A medição por amostragem, utilizada neste trabalho, se baseia na coleta de informações sobre o estado de execução da aplicação em um grande números de momentos escolhidos de forma aleatória no tempo. Esta medição causa muito menos distorção no tempo de execução da aplicação, e ainda gera dados importantes, apesar de sabidamente ainda ser suscetível a distorções [MDHS10].

\subsubsection{Pontos críticos}

As primeiras execuções evidenciaram que os algoritmos testados passam praticamente todo o tempo criando conjuntos e consultando provadores de teoremas. Como a implementação do provador foge ao escopo deste projeto, cabe minimizar os recursos gastos manipulando conjuntos.

\subsubsection{Manipulação de conjuntos}

Primeiramente, a implementação do conjunto de sentenças foi isolada utilizando o padrão static factory, descrito em [Blo08], possibilitando alterá-la em um ponto único sem afetar os algoritmos, o que permitiu uma série de experimentos buscando soluções ótimas. 


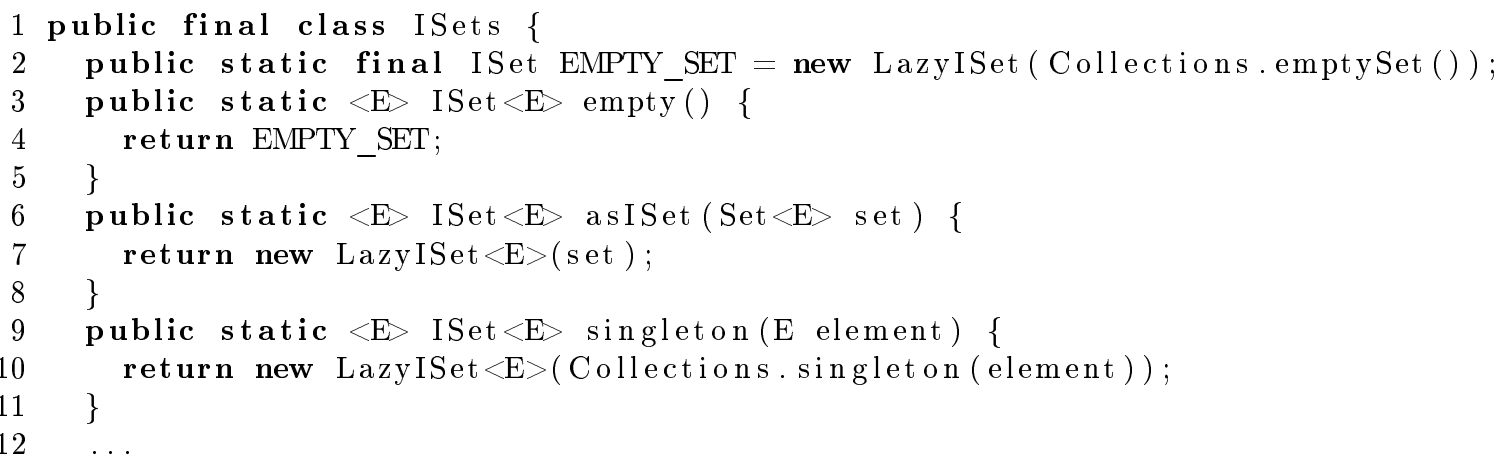

A implementação trivial de um conjunto imutável se dá com uma estratégia copy-on-write, que consiste em utilizar uma cópia protegida do conjunto, e para toda operação de alteração copiar o conjunto e retornar uma versão modificada.

Esta implementação é bastante simples e provê uma boa eficiência, mas demonstrou consumir uma quantidade enorme de memória, inviabilizando a execução mesmo de cenários de tamanho pequeno.

A alternativa para os problemas de memória enfrentados acima foi utilizar uma abordagem preguiçosa (lazy), armazenando em memória as operações que constituem os conjuntos, mas não os conjuntos em si.

Por exemplo, durante a execução da busca de conjuntos utilizando o algoritmo de Reiter é mantido um conjunto de conjuntos de corte, onde cada conjunto de corte é constituído de um outro conjunto de corte mais um elemento de um conjunto encontrado. Tratam-se, portanto, de dezenas de conjuntos derivados de um único. Suponha que seja encontrado um subconjunto de tamanho 10 a partir de um conjunto de exclusão de tamanho 5, neste caso deverão ser armazenados 10 conjuntos novos de tamanho 6. No caso do copy-on-write é necessário guardar cópias completas de todos os conjuntos. A abordagem do LazyISet é armazenar apenas as operações que geram os conjuntos, ou seja, o espaço necessário para guardar novos conjuntos é independente do tamanho do conjunto, mas dependente do tamanho da operação.

Apenas quando necessário o conjunto é efetivamente criado, utilizando as operações armazenadas. Uma vez criado o conjunto fica em memória para ser utilizado nos próximos acessos, mas caso seja necessário liberar memória para continuar a computação o conjunto resolvido poderá ser recolhido. Esse comportamento garante que apenas os conjuntos que efetivamente estão sendo utilizados no momento estão em memória.

Segue um trecho do código do LazyISet para exemplificar:

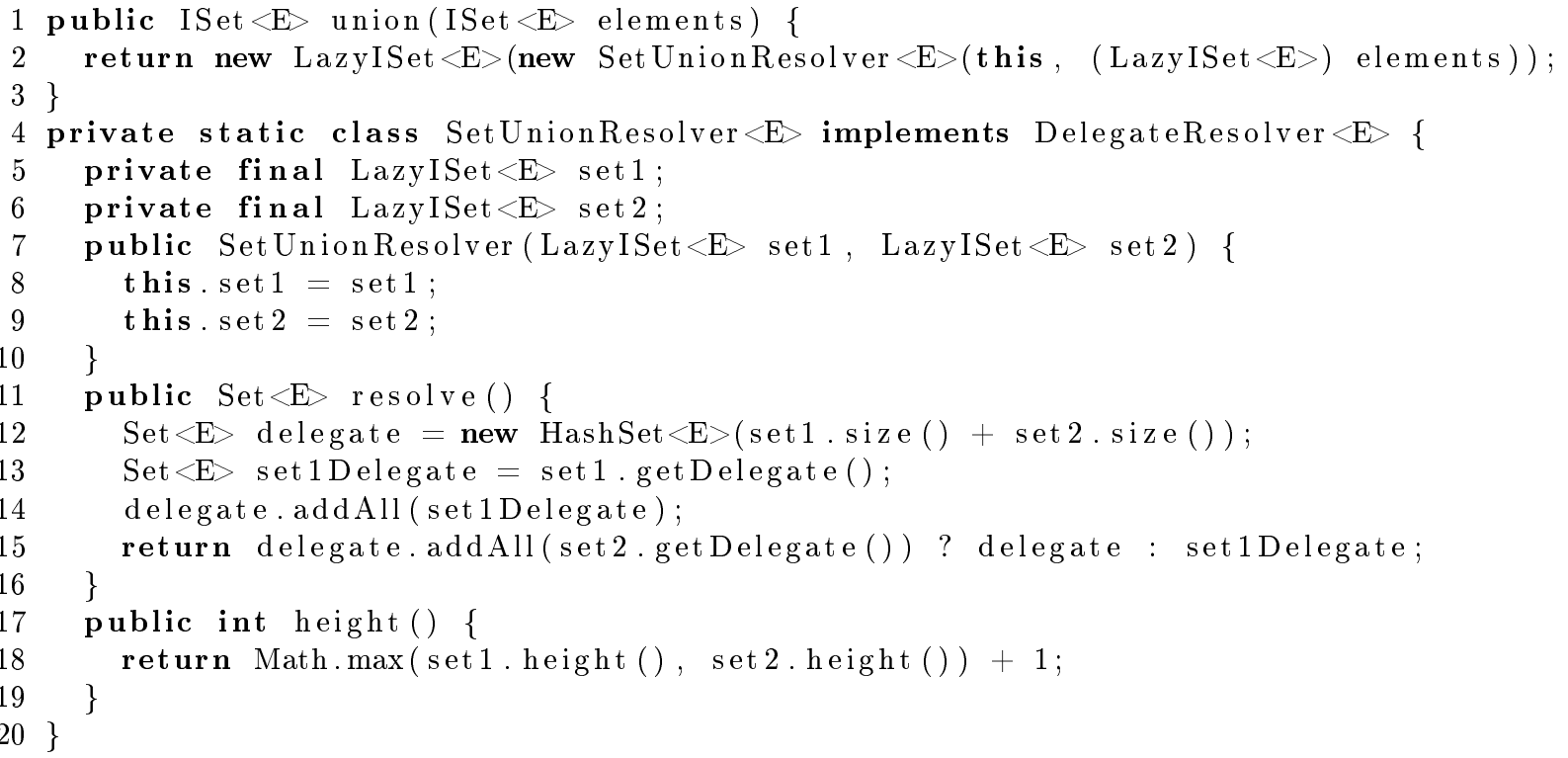


Como pode-se ver, a implementação da operação de união simplesmente retorna um novo conjunto, que é construído da união dos dois conjuntos envolvidos na operação. Os conjuntos envolvidos não são alterados de forma alguma, e a operação não implica na alocação de espaço para um novo conjunto de elementos, armazenando apenas a operação, o conjunto efetivo é calculado apenas se necessário.

Esta abordagem apresentou ganhos significativos em relação à inicial, mas mostrou-se inadequada para casos maiores. Em instâncias mais difíceis dos problemas tratados podem haver milhões de conjuntos de corte, e a cada passo todos estes conjuntos devem ser consultados. Quando o número de conjuntos é tal que o resultado da computação é descartado, isso gera uma enorme perda de tempo com recálculos. Como é comum para estes algoritmos que um grande número de conjuntos seja utilizado constantemente, uma implementação com menor consumo deve ser encontrada.

A linguagem de programação Scala $\left[\mathrm{OAC}^{+} 06\right]$ traz em sua biblioteca padrão uma gama de implementações de coleções imutáveis, adequadas ao estilo funcional de programação. A implementação de conjunto imutável utiliza hash tries, descrita em [Bag01], que atingem uma eficiência de tempo e espaço bastante superior, e levando em conta o conceito de coleções persistentes [SO96]. Benchmarks executados no framework indicaram ganhos expressivos, tanto em tempo de execução quanto em memória necessária, ao utilizar esta biblioteca, que pode ser utilizada por ser de uma linguagem que também é executada na JVM.

\subsubsection{Pontos menores}

Além do intenso trabalho no aprimoramento da implementação de conjunto, diversos outros pontos menores foram otimizados.

Grande parte das otimizações foi possível pela escolha inicial em utilizar estruturas de dados imutáveis sempre que possível. Objetos imutáveis podem efetuar otimizações agressivas facilmente, como armazenar o hash calculado para evitar recomputá-lo, o que gerou um ganho expressivo de tempo devido ao uso intenso destes métodos.

\subsection{Visão geral}

Como foi mostrado acima, o framework conta com uma estrutura que permite a criação de novos operadores com facilidade, permitindo ainda a fácil substituição de partes do programa resultante. O diagrama da figura 3.2 ilustra a composição dos operadores de contração implementados.

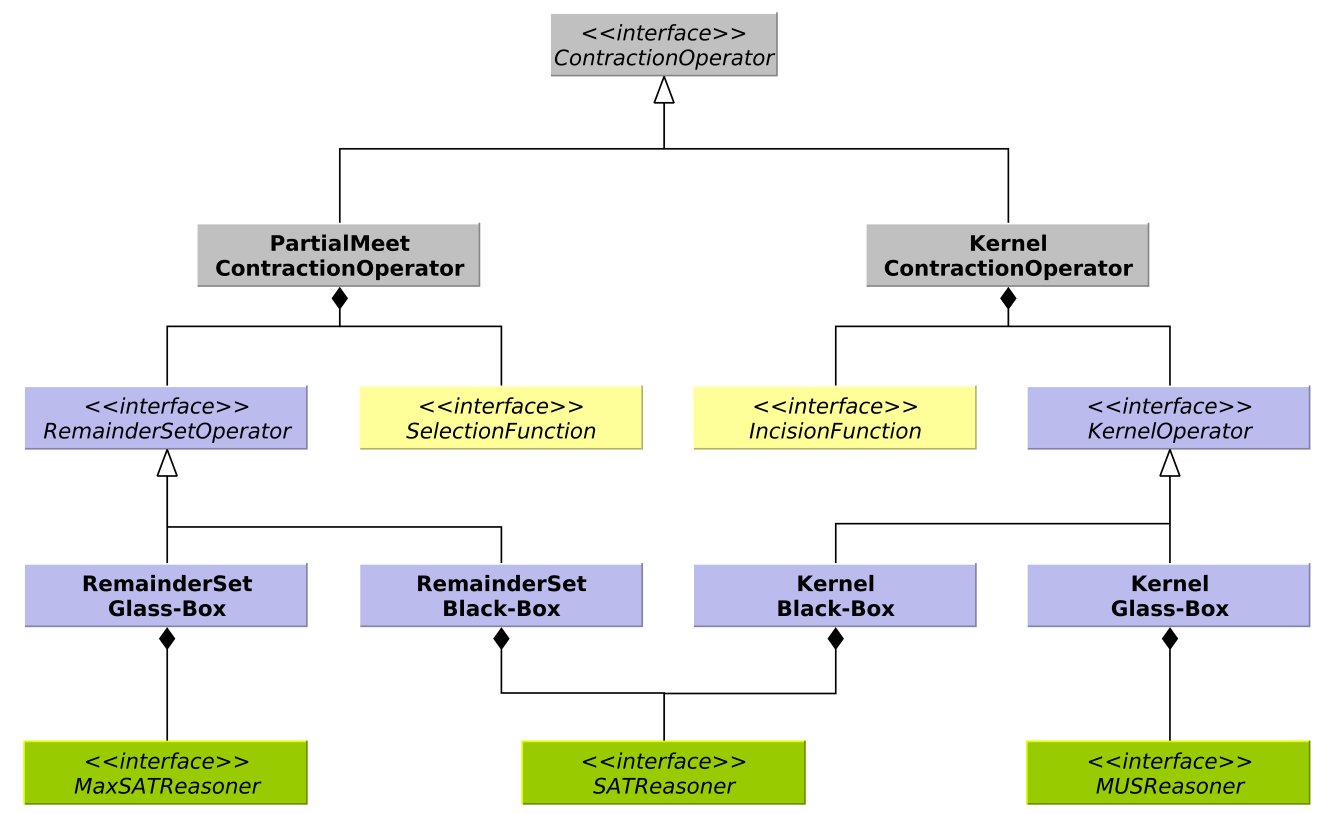

Figura 3.2: Diagrama de classes com diversas implementações de contração. 
Como pode-se observar, o próprio ContractionOperator permite múltiplas implementações. Um mesmo operador de contração pode ser montado com diferentes operadores resíduo ou kernel, e diferentes funções de seleção ou incisão. E tudo pode ocorrer com qualquer lógica ou provador de teorema que se queira utilizar. Esta separação permite que rapidamente o framework seja adaptado para trabalhar com novas lógicas, sem que nenhum algoritmo tenha que ser adaptado, apenas implementando um novo Reasoner. Novos algoritmos para cálculo do kernel ou resíduo podem ser criados e diretamente utilizados; novas funções de incisão e seleção, com heurísticas específicas, podem ser rapidamente testadas em múltiplos contextos.

O framework também inclui uma forma robusta e parametrizável para a geração de cenários, permitindo rapidamente validar a corretude e a eficiência de novos algoritmos, além de oferecer instrumentos para a exploração do comportamento dos próprios problemas.

As implementações envolvidas foram extensamente testadas para prover consumo de recursos computacionais razoável, ainda mantendo a estrutura genérica o suficiente para não comprometer, e sim facilitar, a possibilidade de outras implementações de algoritmos e lógicas. 


\section{Capítulo 4}

\section{Testes}

O framework descrito no capítulo anterior permite que uma série de experimentos sejam feitos de maneira controlada de forma a aferir os recursos computacionais utilizados por diversos algoritmos na solução de um grande número de cenários. Neste capítulo serão expostos os procedimentos e os resultados dos testes executados.

Primeiramente serão feitas algumas considerações sobre as medições realizadas durante a execução dos cenários, particularmente sobre o método de medição de tempo, que exige cuidado para obter precisão adequada.

A seguir serão explorados os relacionamentos entre as medidas executadas, analisando o comportamento dos algoritmos frente às instâncias testadas.

\subsection{Medições}

Para cada cenário e para cada algoritmo foram executadas diversas medições. Todas foram armazenadas em arquivos CSV para análise posterior e serão detalhadas abaixo.

Em primeiro lugar, temos os seguintes campos para determinar o cenário sendo executado, o operador utilizado e o algoritmo específico. São dados suficientes para, se desejado, reexecutar a medição.

- Operador (Kernel ou Resíduo)

- Algoritmo utilizado

- Semente para geração do cenário

- Número de variáveis presentes no cenário

- Número de cláusulas presentes no cenário

Em seguida o número de chamadas realizadas aos provadores de teoremas. Para os testes realizados são utilizados três tipos distintos de provadores, as contagens são apresentadas separadamente, pois as operações realizadas por estes são muito distintas.

- Número de chamadas a SAT

- Número de chamadas a UNSAT

- Número de chamadas a MaxSAT

Foram considerados os relógios de tempo de usuário e tempo de CPU, mas foi verificado que a consulta a estes relógios requer uma chamada de sistema custosa, considerando a quantidade de chamadas, ocasionando uma distorção considerável dos resultados. Devido a esta distorção, as medições de tempo são feitas utilizando apenas o relógio de parede (wall clock) mais preciso disponível 
na plataforma (System.nanoTime()), portanto todos os tempos são medidos com escala de nanosegundos, mas a precisão dependerá do sistema operacional. Foram medidos os tempos da execução do cenário e o tempo gasto nas consultas aos provadores, dando uma noção da complexidade do cenário e das consultas ao provador independentemente.

- Tempo total

- Tempo em chamadas a SAT

- Tempo em chamadas a UNSAT

- Tempo em chamadas a MaxSAT

Finalmente alguns dados sobre o resultado dos algoritmos, alguns específicos de operadores Kernel e outros de operadores por resíduo. O tamanho do resultado é uma boa indicação da adequação do algoritmo ao problema, pois em alguns casos o número de elementos da solução é significativo, tendo um impacto claro nos recursos necessários.

São medidas específicas de operadores Kernel:

- Número de elementos do Kernel

- Tamanho máximo dos $\alpha$-kernels

- Tamanho mínimo dos $\alpha$-kernels

- Tamanho médio dos $\alpha$-kernels

E medidas específicas de operadores por resíduo:

- Número de conjuntos resíduo

- Tamanho máximo dos resíduos

- Tamanho mínimo dos resíduos

- Tamanho médio dos resíduos

Com base no procedimento para a geração de cenários, e no ferramental para coleta de informações sobre execuções, é possível realizar uma bateria de testes com geração de uma vasta massa de dados brutos para análise.

\subsubsection{Medição de Tempo}

A medição do tempo é um tópico que necessita de cuidado especial, pois é de difícil aferição, principalmente devido à precisão dos relógios disponíveis e pelas diversas interferências presentes no ambiente.

Quanto aos relógios para medição de tempo, existem diversos disponíveis na plataforma Java. O de uso mais comum é o System.currentTimeMillis(), que retorna o número de milissegundos desde a meia noite do dia primeiro de janeiro de 1970, mas a precisão na escala de um milissegundo é muito grosseira para medir processos que executam em tempo muito curto, o que poderia gerar distorções. Outra alternativa é utilizar o tempo de CPU consumido pela thread (ManagementFactory.getThreadMXBean().getCurrentThreadCpuTime();), que totaliza o tempo gasto pela thread em modo usuário somado ao tempo gasto em acesso a chamadas de sistema. Este relógio provê uma precisão muito melhor, mas falha em captar a eventual utilização de múltiplas threads ou de chamadas bloqueantes. O relógio escolhido para o framework foi o System.nanoTime(), que provê o tempo de parede em nanosegundos a partir de um referencial arbitrário, permitindo uma medição precisa do tempo gasto entre duas chamadas. Na prática não há garantia de que a precisão será, 
de fato, de nanosegundos, pois há dependência do sistema operacional, mas sistemas operacionais modernos proveem precisão mais que suficiente para a medição deste tipo de algoritmo. No sistema operacional utilizado para execução dos cenários a resolução do relógio utilizado é declarada como de 1 nanosegundo.

Outra interferência comum é a execução de outros processos de maneira concorrente aos algoritmos. Caso um processo rode justamente durante a medição de um dos alvos ocorreria uma distorção no tempo. Para mitigar este tipo de interferência são eliminados serviços que possam disparar em background e nenhum outro processo é executado no sistema além do necessário durante a execução das medições.

Também foram realizadas algumas medidas para a redução de ruído durante as medições de tempo na JVM, como descritas em [GBE07]. A máquina virtual utiliza a técnica de compilação JIT (Just-in-time Compiling) para otimizar funções críticas durante a execução, tornando as primeiras execuções muito mais lentas, por ainda não estarem otimizadas. Este ruído é contornado utilizando uma etapa de aquecimento, em que um cenário é executado algumas milhares de vezes, forçando a compilação. Os dados da execução deste cenário são descartados, pois possuem tempos distorcidos pelo JIT. A coleta ocorrerá apenas em cenários posteriores.

Outra fonte de ruído é o coletor de lixo, cuja implementação selecionada é o G1, que executa em paralelo, gerando paradas muito curtas, evitando grandes influências no tempo de problemas específicos. Antes de uma série de medições em um algoritmo é forçada uma coleta de lixo, fazendo com que o custo da coleta do lixo de um algoritmo não afete o próximo. O custo da coleta acaba ficando amortizado entre as execuções, mas uma parte do tempo provavelmente não será computado. Uma medição mais precisa exigiria a execução de cada cenário diversas milhares de vezes até que ocorresse a convergência dos tempos, o que exige um grande gasto de computacional para cada execução, além de fugir ao intuito deste experimento, cujo interesse está na eficiência relativa entre as implementações.

O ambiente para a execução destes testes foi similar ao utilizado para o perfil de execução, adicionando-se parâmetros extras para disponibilização de mais memória, habilitar otimizações agressivas do JIT e para acusar sobrecarga do coletor de lixo.

- Processador: Intel ${ }^{\circledR}$ Core $^{\mathrm{TM}}$ i7 $8702.93 \mathrm{GHz}$

- Sistema operacional: Ubuntu Linux 12.04, kernel 3.2.0-29-generic-PAE

- JVM: Java HotSpot ${ }^{\text {TM }}$ Server VM 1.7.0 (build 21.0-b17)

Parâmetros: -Xmx2048m -XX:+AggressiveOpts -XX:+UseGCOverheadLimit

\subsection{Cenários Executados}

Devido ao amplo espaço de busca permitido pela lógica proposicional, foi delimitado um espaço reduzido em que as medições foram feitas.

Primeiramente, os cenários gerados se restringiram à lógica 3SAT, onde toda cláusula possui exatamente 3 literais, o que simplifica consideravelmente o espaço de busca sem prejudicar a abrangência, pois toda instância de SAT é redutível à 3SAT [Coo71].

Os testes foram realizados utilizando cenários com números determinados de variáveis e com um número crescente de cláusulas, iniciando com problemas simples. Os testes foram executados elevando o número de cláusulas até que ocorresse falha por falta de memória.

\begin{tabular}{|r|r|r|}
\hline Variáveis & Cláusulas iniciais & Cenários por número de cláusulas \\
\hline 10 & 5 & 5000 \\
\hline 15 & 7 & 1000 \\
\hline 20 & 10 & 500 \\
\hline
\end{tabular}

Tabela 4.1: Principais parâmetros dos cenários executados. 
Para cada cenário gerado, 4 implementações foram testadas:

- Kernel Black-Box

- Kernel Glass-Box

- Partial Meet Black-Box

- Partial Meet Glass-Box 


\subsection{Resultados}

Foram descritos acima procedimentos para a execução controlada de testes com diversas medições, depositadas para análise posterior. A seguir serão expostos gráficos que sumarizam os comportamentos dos algoritmos em 900 mil execuções, com uma breve análise de cada resultado encontrado. Os valores médios foram calculados desprezando 10\% dos casos extremos (para mais e para menos), visando tornar mais claro o comportamento geral.

Todos os gráficos abaixo estão em escala logarítmica para facilitar a visualização, salvo dito o contrário.

\subsubsection{Tempos médios}

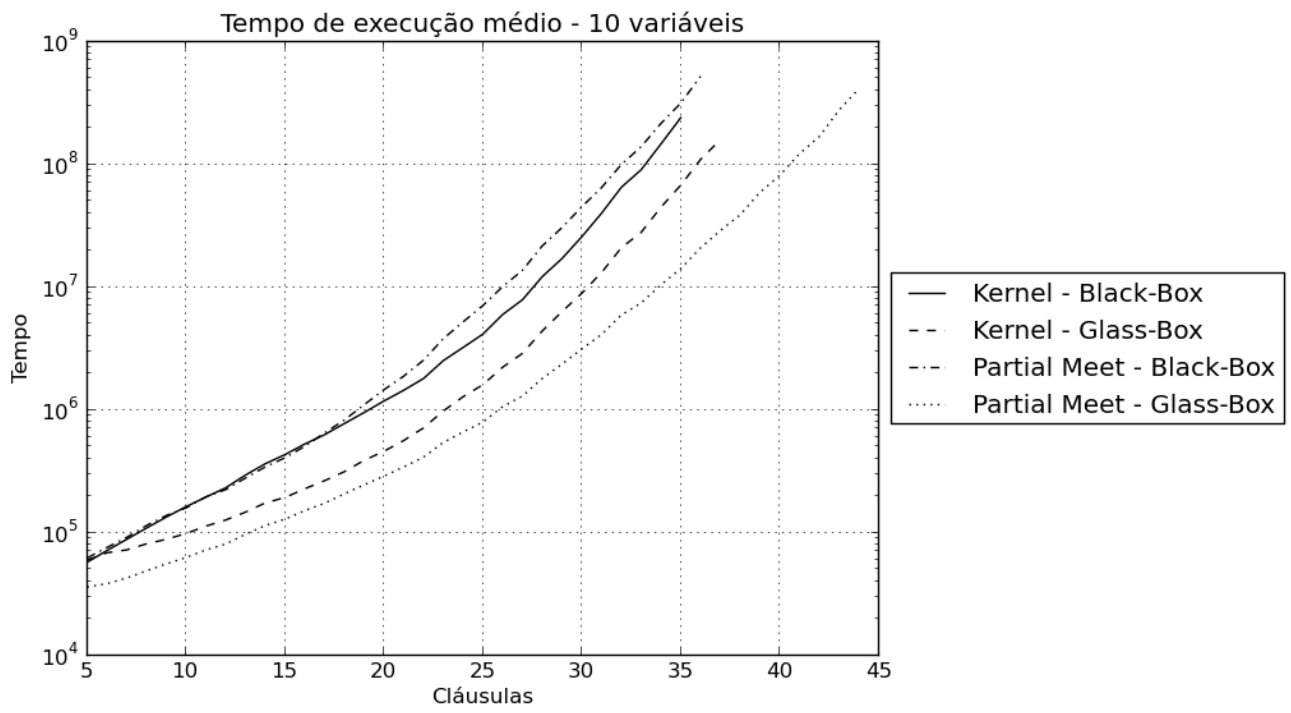

Figura 4.1: Tempo médio de execução em nanosegundos dos algoritmos por número de cláusulas em cenários com 10 variáveis

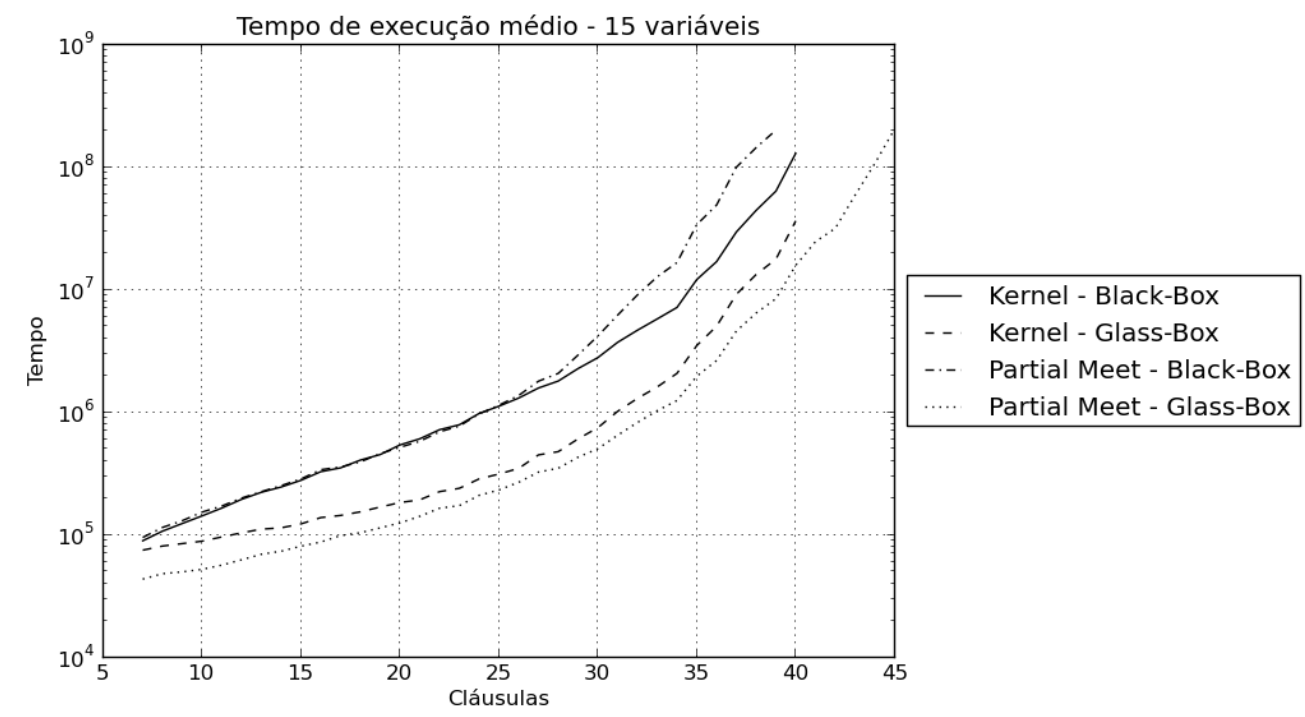

Figura 4.2: Tempo médio de execução em nanosegundos dos algoritmos por número de cláusulas em cenários com 15 variáveis

Os gráficos 4.1, 4.2 e 4.3 mostram, respectivamente, o consumo de tempo médio para a execução do operador de contração em cenários com 10, 15 e 20 variáveis. 


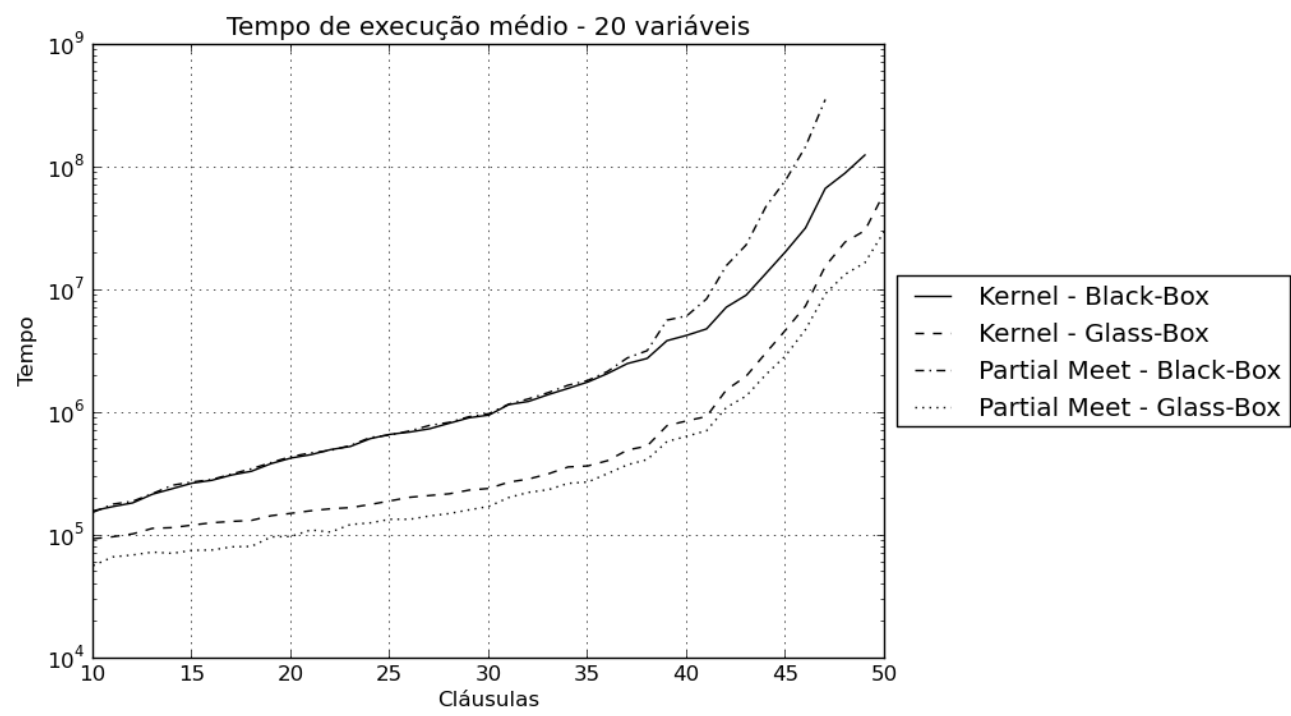

Figura 4.3: Tempo médio de execução em nanosegundos dos algoritmos por número de cláusulas em cenários com 20 variáveis

Primeiramente deve ser notado que o crescimento do tempo em função do número de cláusulas é exponencial para todos os algoritmos, evidenciado pela escala logarítmica utilizada.

Também pode-se perceber que os algoritmos Glass-Box realmente conseguem tirar proveito do provador de teoremas especializado, quase sempre se saindo muito melhor que os algoritmos BlackBox (exceto por um ponto nos cenários com 20 variáveis, em que ocorreu um empate).

Dentre os algoritmos Black-Box, a abordagem kernel teve ligeira vantagem na grande maioria dos grupos de cenários. Essa diferença foi pouco notável nos casos com menos variáveis, mas a vantagem foi crescendo juntamente com seu número.

Já entre os algoritmos Glass-Box, a implementação por kernel obteve uma taxa de crescimento significativamente maior que a taxa averiguada pela implementação por partial meet, que utiliza um provador de teoremas por MaxSAT. 


\subsubsection{Tempos mínimos}

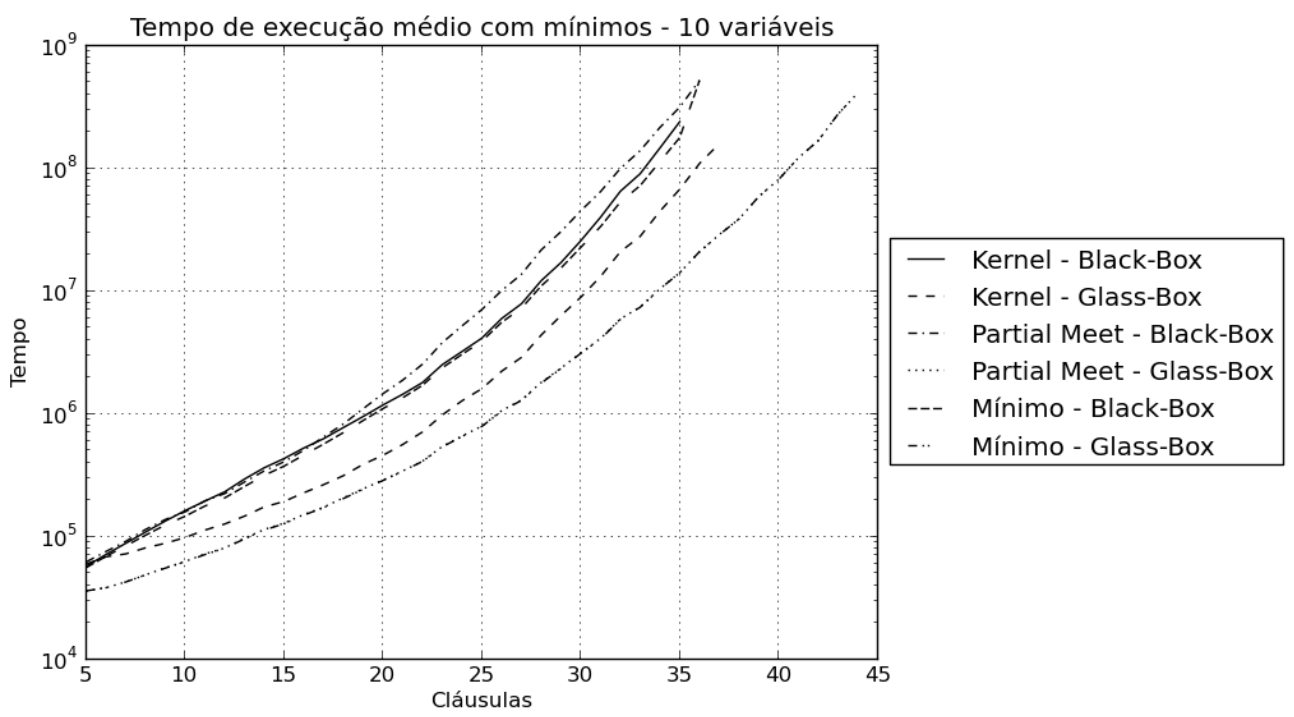

Figura 4.4: Tempo médio com mínimo dos algoritmos por número de cláusulas em cenários com 10 variáveis

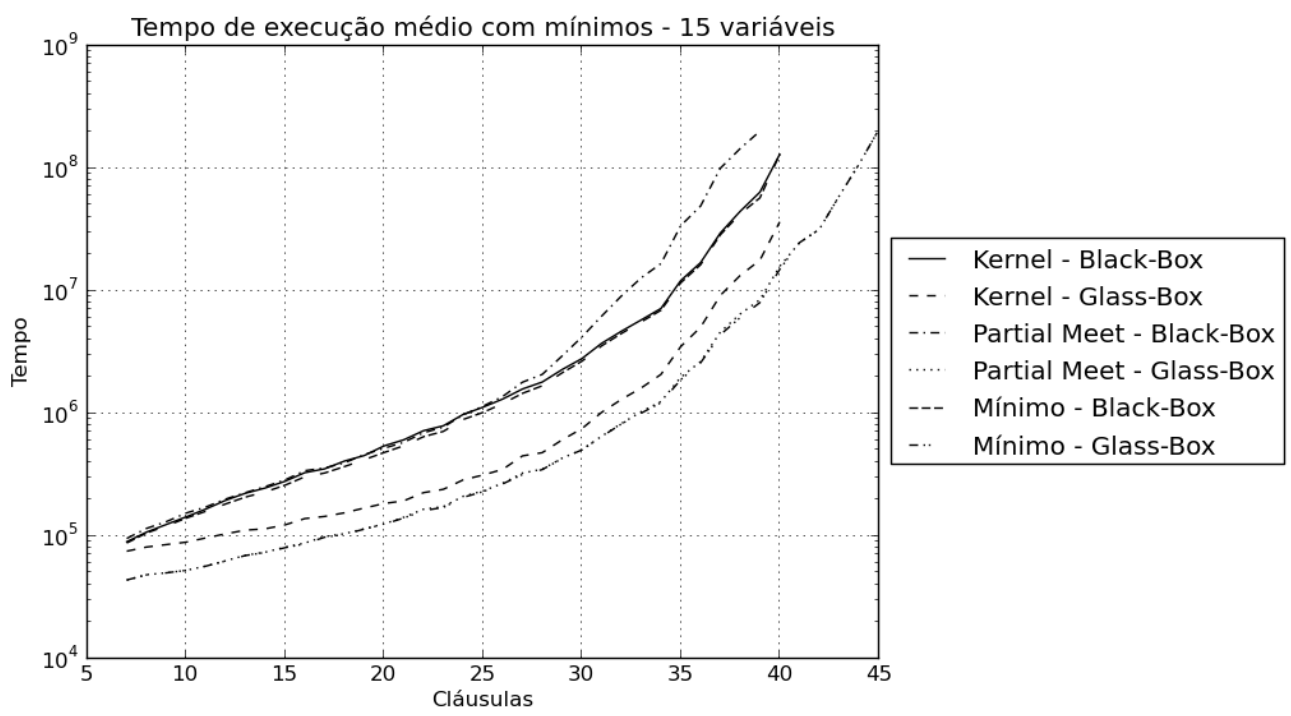

Figura 4.5: Tempo médio com mínimo dos algoritmos por número de cláusulas em cenários com 15 variáveis

Os gráficos 4.4, 4.5 e 4.6 evidenciam o máximo ganho possível com o desenvolvimento de heurísticas para escolha do melhor algoritmo para cada caso.

Apesar de tempos médios similares, no caso dos algoritmos Black-Box, ou distantes, no caso dos algoritmos Glass-Box, é de se imaginar que para algumas instâncias específicas um ou outro algoritmo se destaque. Suponha operadores de contração com heurísticas perfeitas para reconhecer se a abordagem mais rápida é kernel ou partial meet, direcionando a execução para o melhor algoritmo, realizando a decisão em tempo constante. Fazendo uso dos dados brutos podemos calcular facilmente o tempo exigido por estes algoritmos teóricos. O primeiro, Mínimo - Black-Box, seria um algoritmo que utilizaria uma heurística para determinar se irá utilizar a abordagem Black-Box por kernel ou resíduo, já Mínimo - Glass-Box opera de maneira análoga, mas delegando para implementações Glass-Box.

No caso Black-Box com 10 variáveis não houve algum ganho com a escolha, principalmente para casos com mais de 27 cláusulas. Com o crescimento do número de variáveis, o algoritmo teórico teve um desempenho muito próxima à encontrada no algoritmo por kernel. Estes dados indicam que, no 


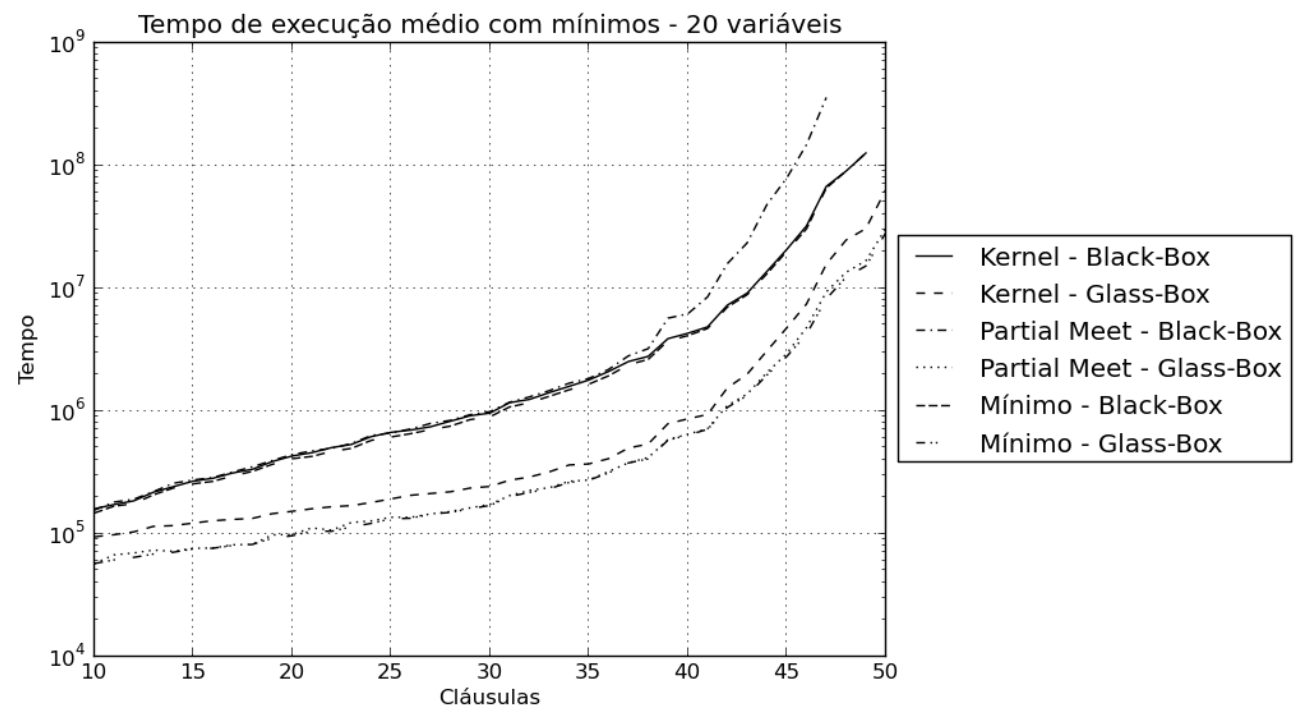

Figura 4.6: Tempo médio com mínimo dos algoritmos por número de cláusulas em cenários com 20 variáveis

espaço observado, não haveria ganho expressivo pelo desenvolvimento de tal heurística, a simples escolha do kernel irá com grande chance acertar o algoritmo mais eficiente.

Já no caso Glass-Box a situação é oposta. Em praticamente todos os casos analisados o algoritmo por partial meet possui o melhor desempenho, não havendo espaço para ganho para a heurística.

Os resultados apontam, portanto, que não há espaço para desenvolvimento de uma heurística que auxilie na escolha do algoritmo para problemas das categorias analisadas. Este método de análise pode ser utilizado para outras categorias de problemas para analisar a viabilidade do desenvolvimento de tais heurísticas, e até mesmo para medir sua eficiência. 


\subsubsection{Chamadas a provadores}

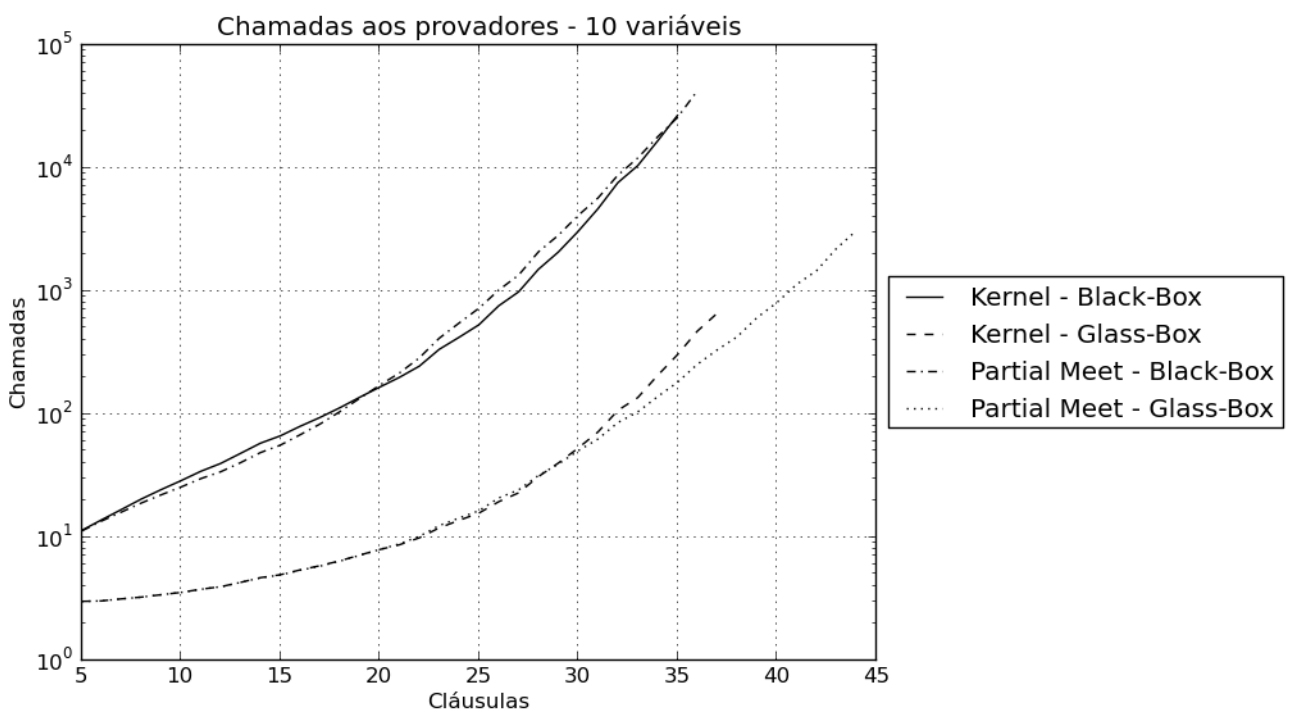

Figura 4.7: Número médio de chamadas aos provadores de teoremas por número de cláusulas em cenários com 10 variáveis

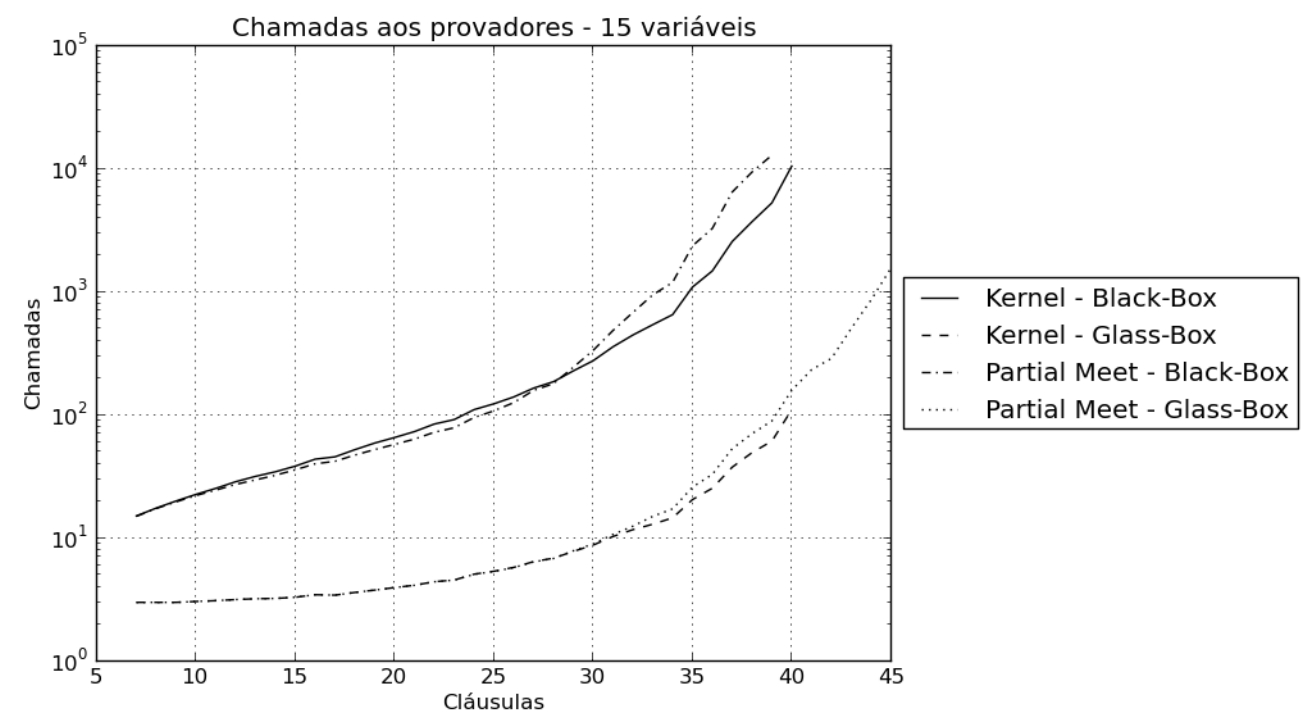

Figura 4.8: Número médio de chamadas aos provadores de teoremas por número de cláusulas em cenários com 15 variáveis

Os gráficos 4.7, 4.8 e 4.9 evidenciam o número de chamadas necessárias aos provadores de teoremas durante cada operação.

O comportamento dos algoritmos é bastante semelhante ao resultado do gráfico por tempo. Mais uma vez os algoritmos Black-Box geram números próximos, sendo que a implementação por kernel tem uma taxa crescimento um pouco maior do número de chamadas para mais cláusulas, mas em cenários com mais variáveis faz bem menos chamadas que a alternativa por partial meet.

Os algoritmos Glass-Box se saem melhor, mas o distanciamento entre as implementações por kernel e resíduo é bem mais acentuada. Apesar de todas as taxas de crescimento serem exponenciais, o número de chamadas necessárias pela busca por resíduo é drasticamente menor. Este resultado é coerente com a implementação dos algoritmos, dado que a implementação Glass-Box por resíduo efetua apenas uma chamada para encontrar ou não o resíduo em um subconjunto de elementos a cada passo do algoritmo de Reiter. 


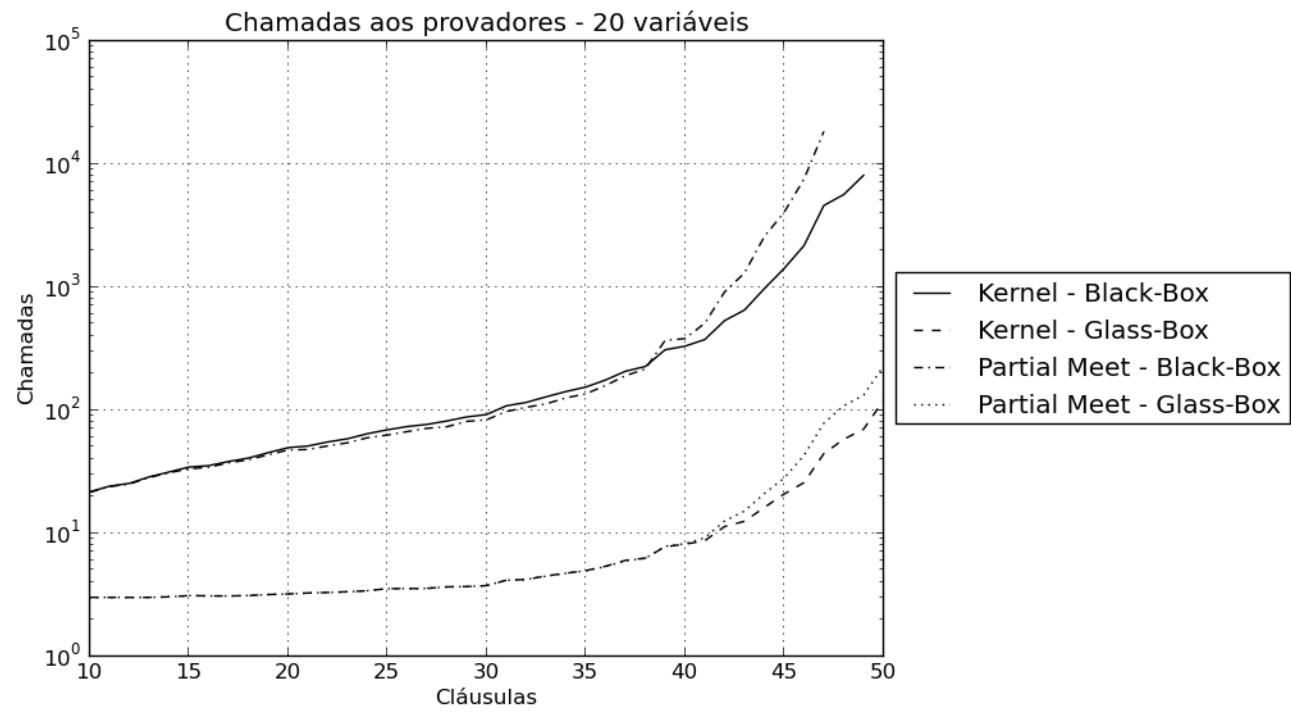

Figura 4.9: Número médio de chamadas aos provadores de teoremas por número de cláusulas em cenários com 20 variáveis

\subsubsection{Tamanho médio dos resultados intermediários}

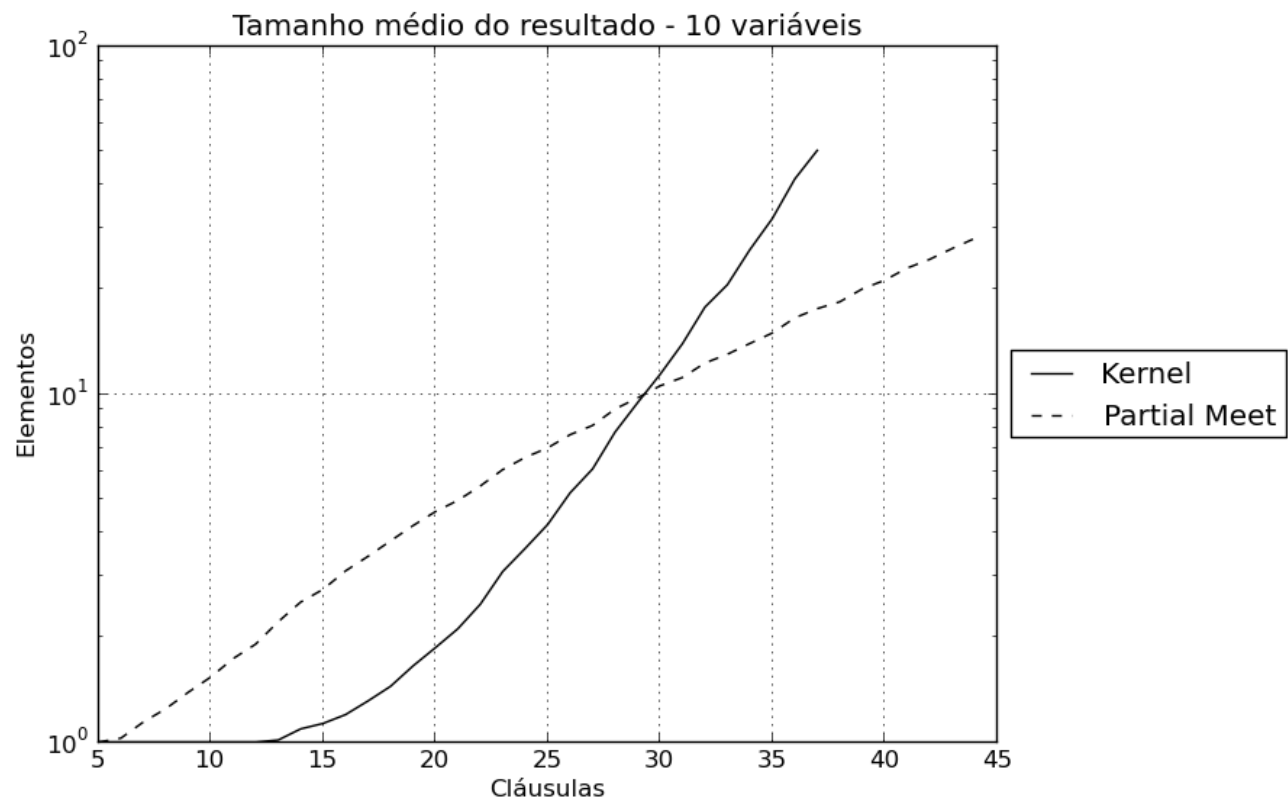

Figura 4.10: Tamanho médio do número de conjuntos do resultado intermediário por número de cláusulas em cenários com 10 variáveis

Os gráficos 4.10, 4.11 e 4.12 evidenciam o número de subconjuntos dos resultados intermediários, kernel e conjunto resíduo.

O tamanho da saída dos algoritmos, tamanho do kernel ou do conjunto resíduo, é também um indicativo da dificuldade de se obter um resultado, o que justifica a análise da saída destes algoritmos. Este número é característico de cada instância, e não é influenciado pelo algoritmo utilizado.

O gráfico acima demonstra o tamanho médio do número de elementos do kernel e do resíduo. É notável que, apesar de inicialmente ser maior, a taxa de crescimento do número de elementos do resíduo é muito menor que a taxa do número de elementos do kernel. Durante a busca de conjuntos, cada um achado gera a necessidade de outras buscas não contendo cada um dos elementos deste, 


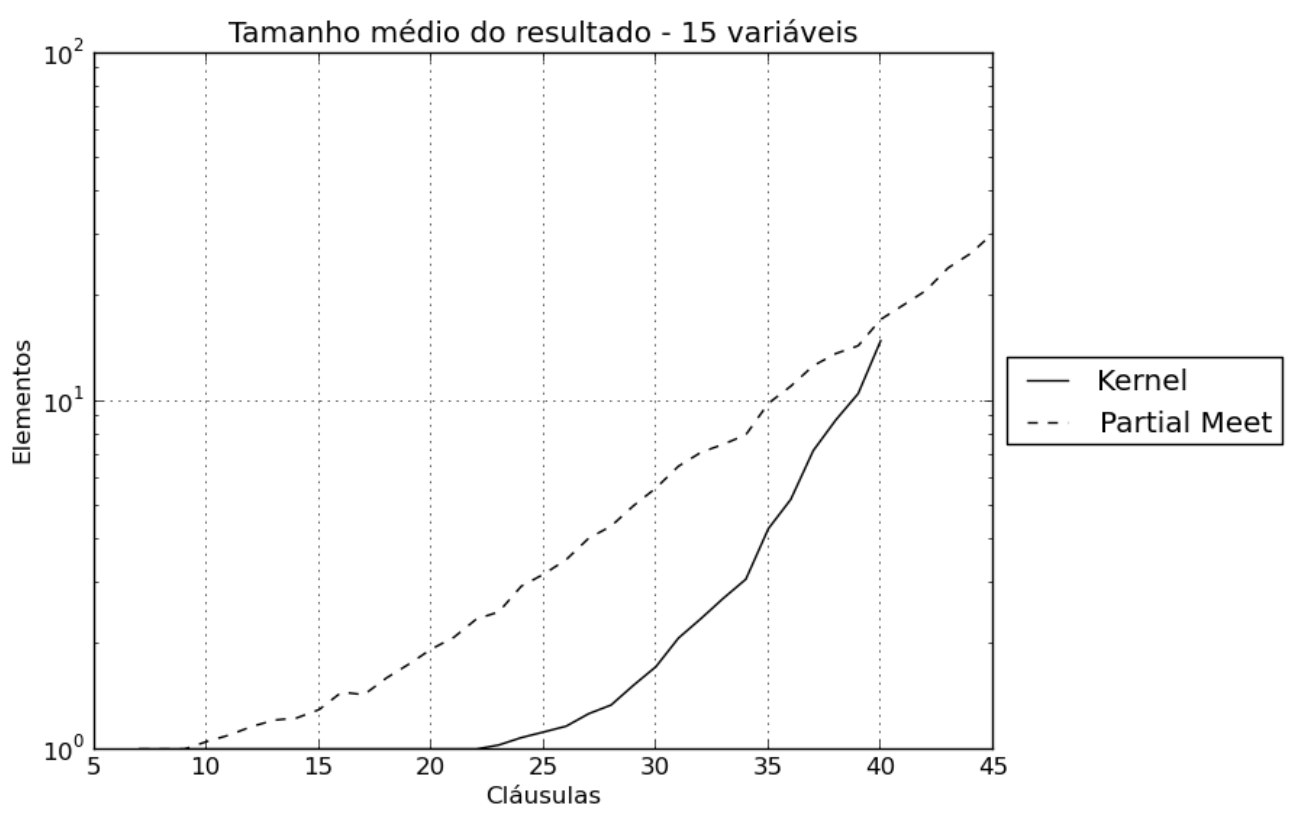

Figura 4.11: Tamanho médio do número de conjuntos do resultado intermediário por número de cláusulas em cenários com 15 variáveis

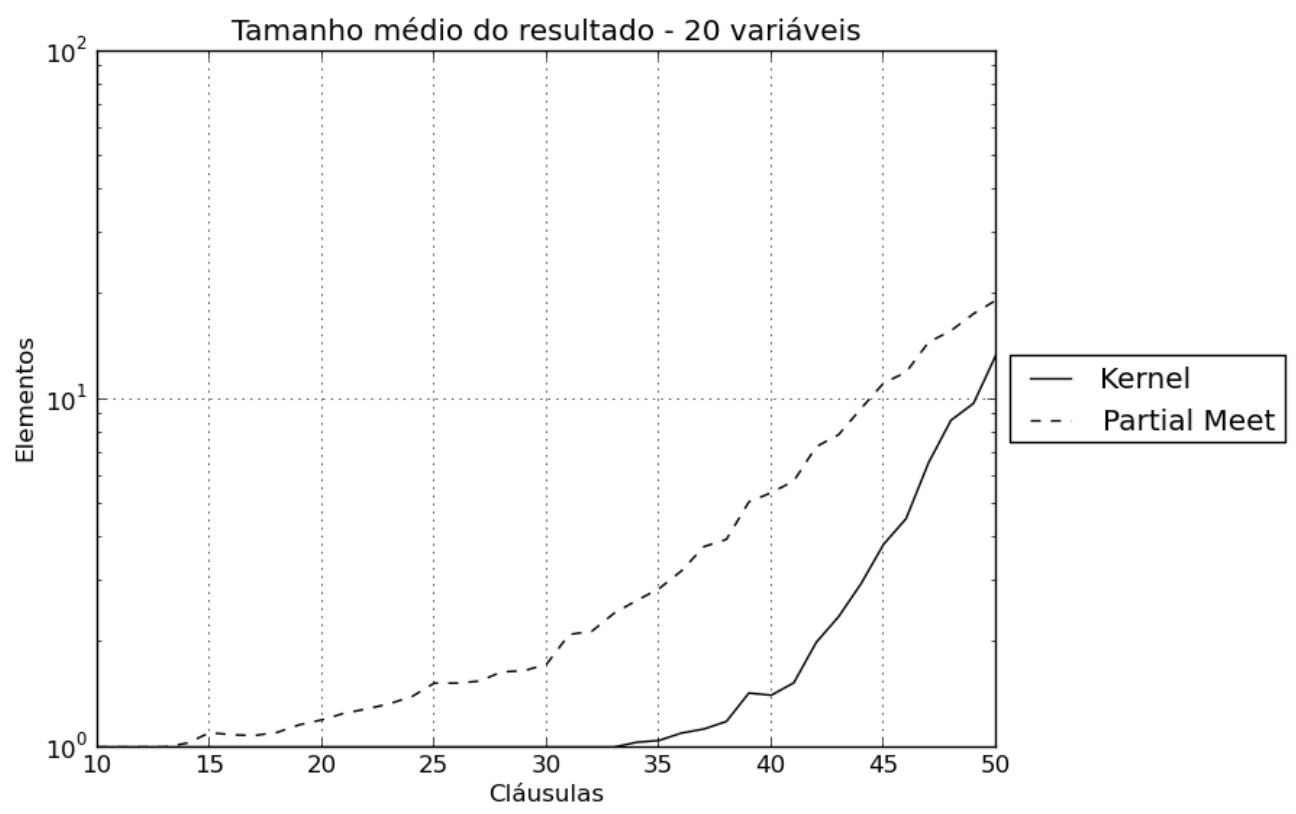

Figura 4.12: Tamanho médio do número de conjuntos do resultado intermediário por número de cláusulas em cenários com 20 variáveis

portanto cada conjunto encontrado gera necessidade de mais buscas. O crescimento no número de elementos do resultado é, portanto, um desafio para o mecanismo de busca.

No gráfico 4.10, com o caso de 10 variáveis, é observado que o tamanho médio do kernel ultrapassa o tamanho médio do partial meet. Nos casos com 15 e 20 variáveis não chega a ser observado o cruzamento, mas o crescimento indica que ele ocorreria para cenários com números de cláusulas maiores, que não foram executados devido à limitação dos recursos computacionais disponíveis. 


\subsubsection{Iterações buscando conjuntos}

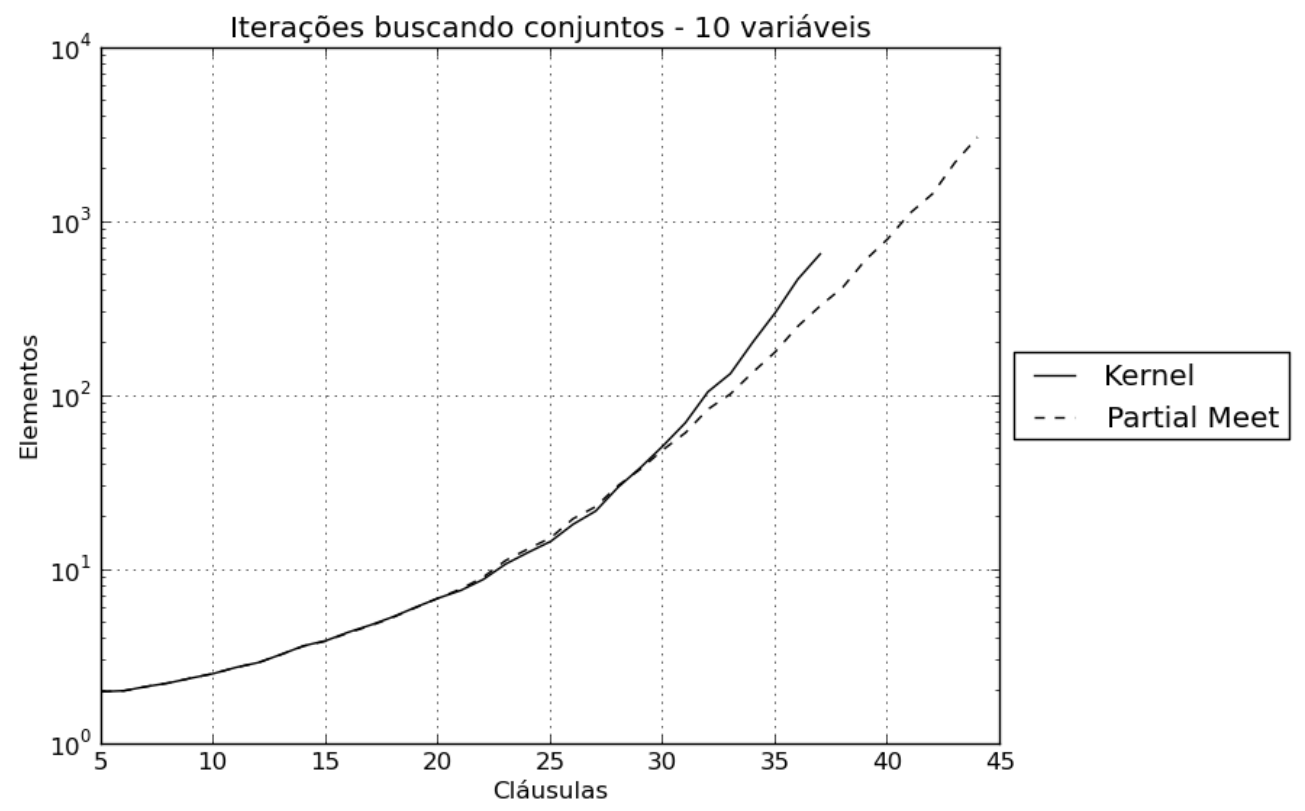

Figura 4.13: Número médio de iterações buscando subconjuntos por número de cláusulas em cenários com 10 variáveis

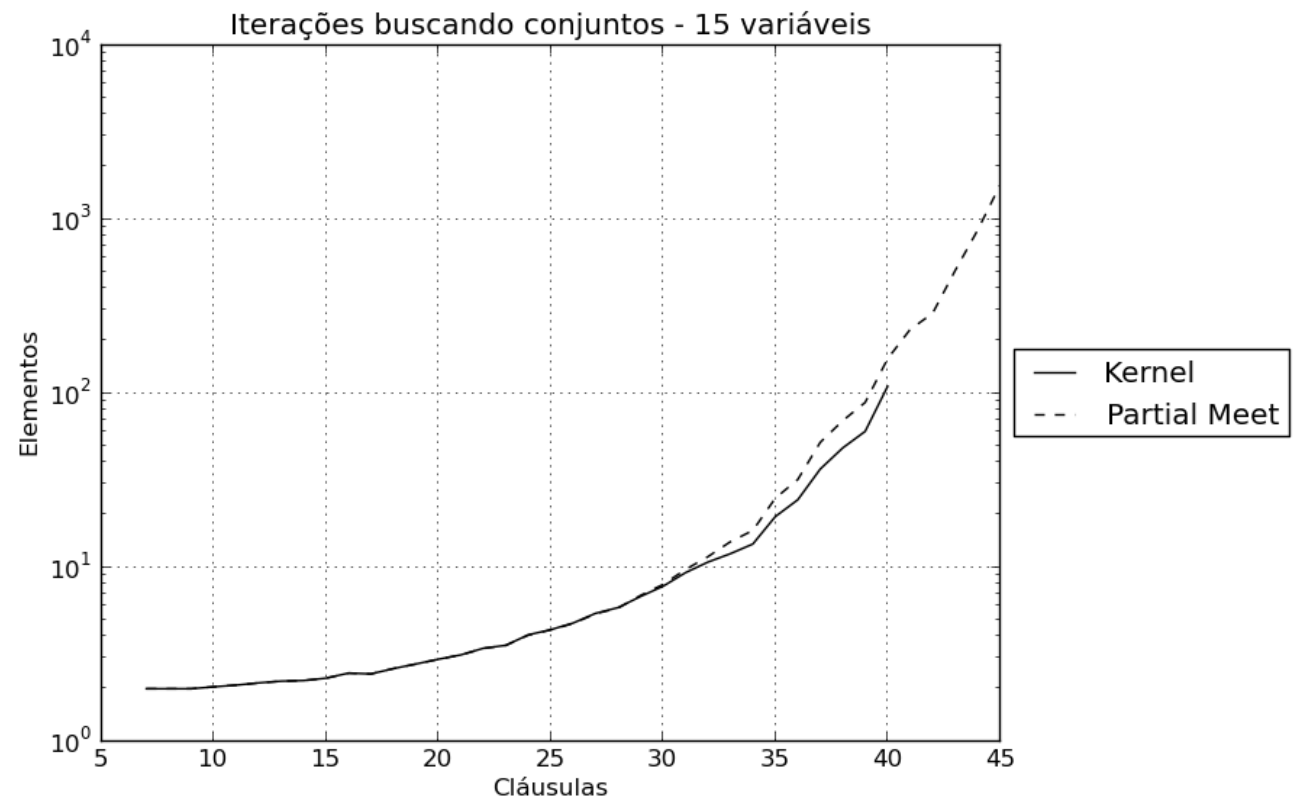

Figura 4.14: Número médio de iterações buscando subconjuntos por número de cláusulas em cenários com 15 variáveis

Os gráficos 4.13, 4.14 e 4.15 evidenciam o número de iterações necessárias buscando subconjuntos dentro do algoritmo de Reiter.

A taxa de crescimento para o caso de 10 variáveis é nitidamente maior para o caso kernel, mas para os demais números de variáveis se mantém bastante próximo.

Este resultado é contrastante com o tamanho médio do resultado, que mostrou um crescimento muito mais acentuado do número de elementos do kernel do que do conjunto resíduo. Apesar de haver muito menos subconjuntos no resíduo, são subconjuntos com mais elementos, e que requerem um maior número de conjuntos de exclusão durante a execução do algoritmo de Reiter. 


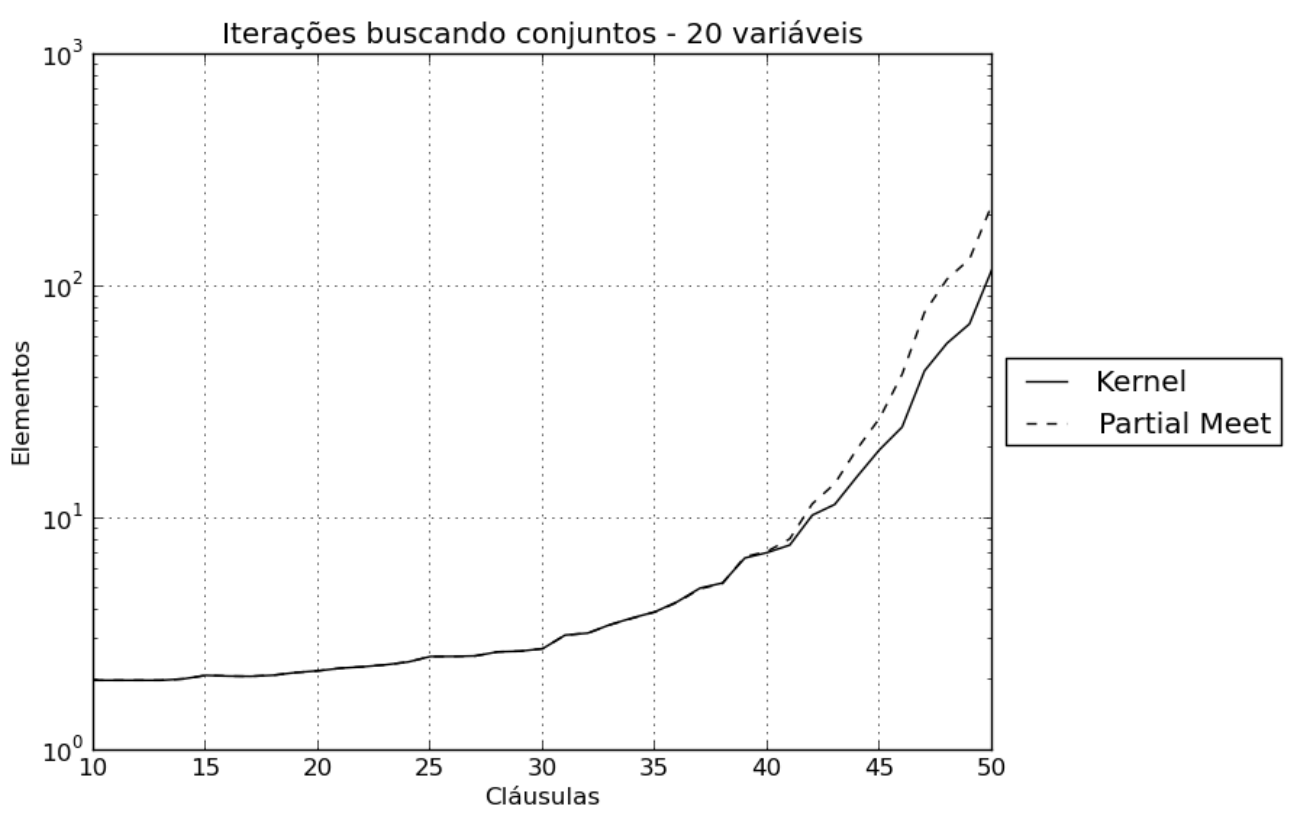

Figura 4.15: Número médio de iterações buscando subconjuntos por número de cláusulas em cenários com 20 variáveis

\subsubsection{Tempo gasto com provadores de teoremas}

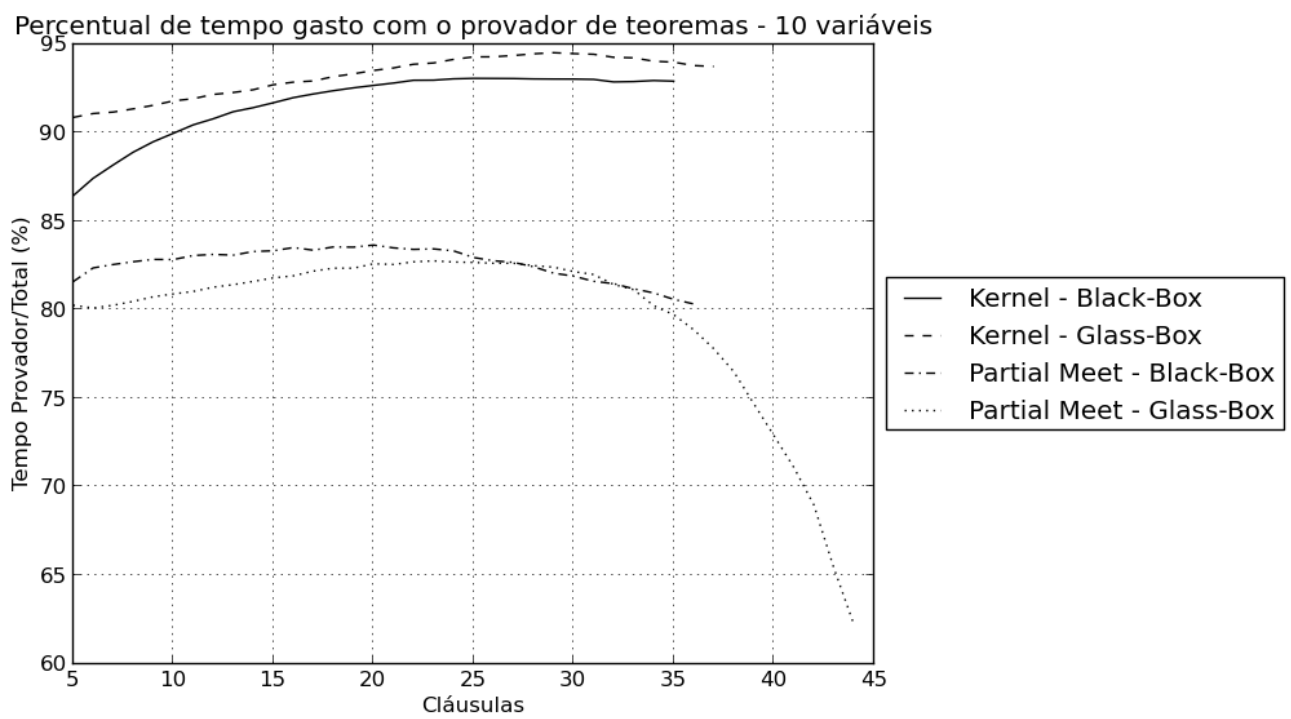

Figura 4.16: Proporção de tempo gasto com chamadas a provadores de teoremas por número de cláusulas em cenários com 10 variáveis

Os gráficos 4.16, 4.17 e 4.18 demonstram a proporção do tempo gasto com provadores de teoremas com relação ao tempo total de execução, em escala linear.

Os dados são evidência de um resultado esperado, de que o tempo da execução dos operadores é dominado pelas chamadas aos provadores, superando $80 \%$ do tempo em grande parte dos casos.

No caso da implementação por partial meet com Glass-Box ocorre uma mudança considerável com o crescimento do número de cláusulas, com uma queda expressiva da proporção do tempo utilizado pelo provador de teoremas. Foi verificado utilizando-se ferramentas de profiling que em instâncias maiores mais tempo é utilizado para verificar se os conjuntos de exclusão estão no corte. Como foi descrito anteriormente, há um crescimento do número de conjuntos de exclusão, mas em geral ocorre um crescimento do número de conjuntos de corte associados. Para cada conjunto de 


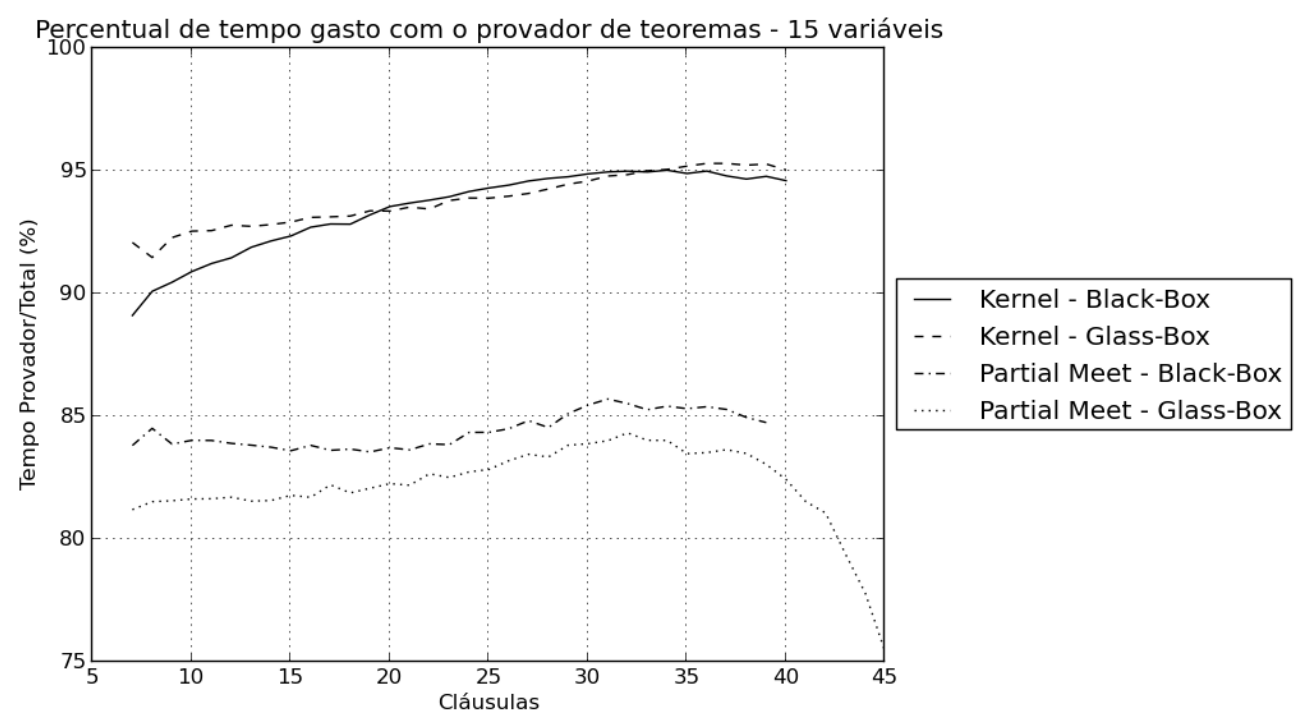

Figura 4.17: Proporção de tempo gasto com chamadas a provadores de teoremas por número de cláusulas em cenários com 15 variáveis

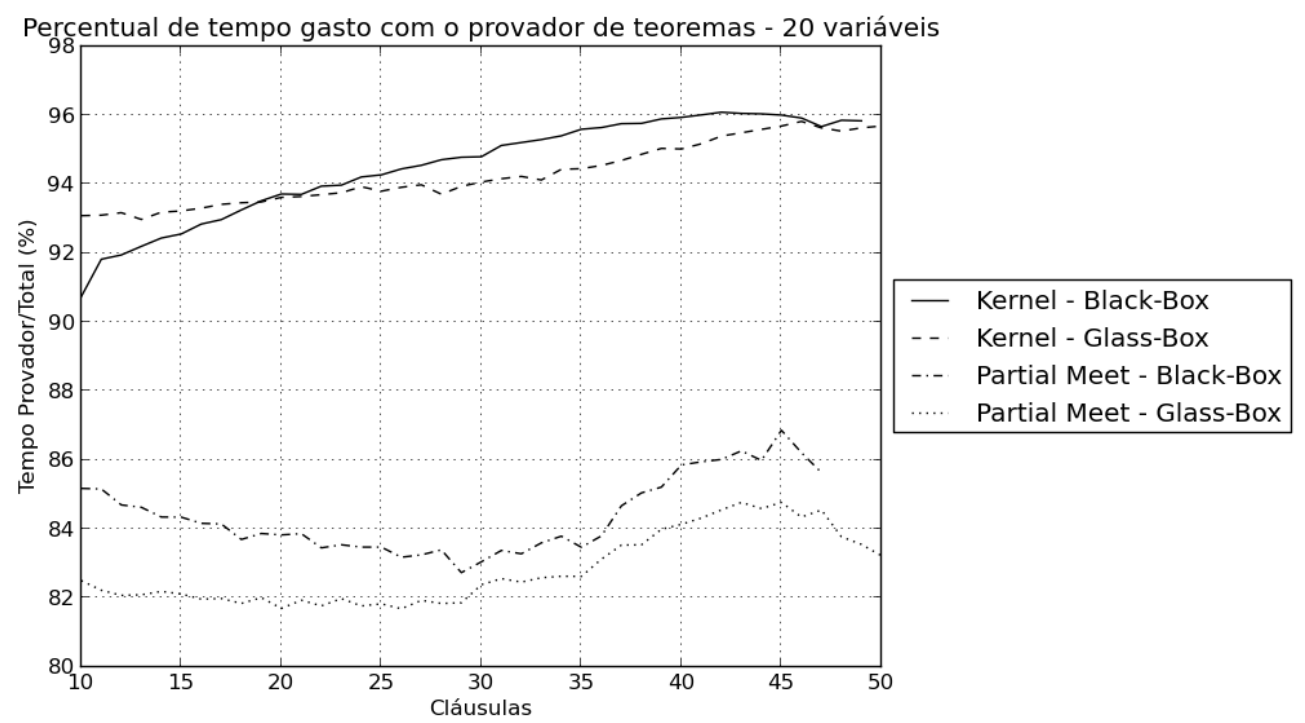

Figura 4.18: Proporção de tempo gasto com chamadas a provadores de teoremas por número de cláusulas em cenários com 20 variáveis

exclusão considerado, é necessário verificar se este já pode ser descartado, verificando se este contém todos os elementos de algum dos conjuntos de corte. Esta verificação é feita para podar o espaço de busca, mas em instâncias complexas o número de conjuntos de corte pode chegar aos milhões, tornando a verificação uma operação cara.

O fenômeno também acontece, em menor grau, para os demais algoritmos, mas de forma muito mais sutil e observado claramente apenas para os cenários de 10 variáveis. 


\section{Capítulo 5}

\section{Considerações Finais}

\subsection{Conclusão}

Nesta dissertação foi descrito um framework para testes empíricos de diferentes operadores sobre bases de crenças.

Foram apresentados os fundamentos teóricos da área de revisão de crenças, começando pelo paradigma AGM e aprofundando na modelagem do conhecimento por bases de crenças proposta por Hansson. Dentro desta modelagem foram explorados diversos operadores sobre bases, identificando duas linhas de ação comuns, kernel e partial meet. Enquanto esta chega à solução através da busca de conjunto maximais aquela utiliza conjuntos minimais, tornando as abordagens antagônicas, mas profundamente relacionadas como visto posteriormente.

Com base em uma sólida teoria, foi construído um framework computacional robusto e com grande afinidade matemática, implementando conceitos da forma mais direta possível. Esta abordagem promoveu elevado grau de reaproveitamento de código, da mesma forma que os conceitos são reutilizados entre diferentes autores, permitindo a implementação de algoritmos de forma direta e a criação de um ambiente homogêneo onde diferentes abordagens podem ser comparadas de forma justa.

Em seguida foram executadas quatro implementações distintas do operador de contração, utilizando variações black-box e glass-box dos algoritmos com abordagens kernel e partial meet. Estes quatro operadores foram executados sobre centenas de milhares de cenários gerados de forma pseudoaleatória e parametrizada, permitindo uma análise que mostrou claros comportamentos.

Os resultados indicam que, no caso proposicional com bases de crenças escolhidas uniformemente, a taxa de crescimento do número de elementos do kernel é maior que a do conjunto de resíduos. Esse comportamento faz com que a construção das operações por kernel tenha maior dificuldade com bases de crenças maiores, pois é necessário buscar e armazenar um número muito maior de conjuntos, levando por consequência a um consumo maior de memória e tempo. Apesar de existirem casos em que o algoritmo kernel desempenhou melhor que o partial meet, esses são casos raros, e mesmo uma heurística perfeita geraria um ganho não expressivo. Segue, portanto, que para o caso proposicional arbitrário a abordagem glass-box por partial meet é superior à kernel em termos de desempenho, executando em tempo consideravelmente menor.

Além da análise dos algoritmos acima no caso proposicional, também é contribuição deste trabalho o próprio framework, pois diversos aspectos da implementação foram direcionados para permitir a sua utilização em projetos futuros. Uma linguagem popular foi escolhida e o código mantido claro, para facilitar seu uso e evolução por novos colaboradores. A afinidade matemática levou a algoritmos claros e independentes de lógicas e provadores de teoremas, permitindo o uso da implementação em uma gama maior de trabalhos. O grande número de testes unitários permite que o framework possa continuar sendo desenvolvido sem colocar em risco a estabilidade e corretude do que já foi feito. Por fim, a própria estrutura para geração e execução de cenários e medição de recursos é reaproveitável, permitindo a exploração de outros subconjuntos da própria lógica proposicional, outros algoritmos e mesmo outras lógicas. 
Todo o código fonte do framework criado durante este trabalho está disponível em http://code. google.com/p/bcontractor/, e contém todas as implementações descritas.

\subsection{Trabalhos Futuros}

O framework foi criado tendo a extensibilidade em mente, ou seja, permitir que trabalhos futuros possam se aproveitar da estrutura já desenvolvida.

Um ponto claro a ser explorado é a utilização do framework para diferentes lógicas. Mais especificamente, com foco em fragmentos específicos da lógica proposicional clássica, tais como os descritos em [CPPW12] e em diferentes lógicas de descrição, tais como descrito em [Kal06, RW09].

A estrutura desenvolvida também é solo fértil para a implementação de novos operadores sobre bases de crenças, além de heurísticas para os operadores descritos nesta dissertação. 


\section{Referências Bibliográficas}

[AGM82] Carlos E. Alchourrón, Peter Gärdenfors e David Makinson. On the logic of theory change: Contraction functions and their associated revision functions. Theoria, 48:1437, 1982. 6,7

[AGM85] Carlos E. Alchourrón, Peter Gärdenfors e David Makinson. On the logic of theory change: Partial meet contraction and revision functions. The Journal of Symbolic Logic, 50(2):510-530, 1985. 1, 5, 7, 8, 9, 15

[AM85] CarlosE. Alchourrón e David Makinson. On the logic of theory change: Safe contraction. Studia Logica, 44:405-422, 1985. 7, 11

[Bag01] Phil Bagwell. Ideal hash trees. Relatório técnico, École Polytechnique Fédérale de Lausanne, 2001. 31

[Blo08] Joshua Bloch. Effective Java (2nd Edition) (The Java Series). Prentice Hall PTR, Upper Saddle River, NJ, USA, 2 edição, 2008. 29

[Coo71] Stephen A. Cook. The complexity of theorem-proving procedures. Em Proceedings of the third annual ACM symposium on Theory of computing, STOC '71, páginas 151-158, New York, NY, USA, 1971. ACM. 35

[CPPW12] Nadia Creignou, Odile Papini, Reinhard Pichler e Stefan Woltran. Belief revision within fragments of propositional logic. Em Principles of Knowledge Representation and Reasoning (KR2012). AAAI Press, 2012. 48

[CW91] Timothy S. C. Chou e Marianne Winslett. The implementation of a model-based belief revision system. SIGART Bull., 2(3):28-34, Junho 1991. 2

[FFI06] Marcelo A. Falappa, Eduardo L. Fermé e Gabriele K. Isberner. On the logic of theory change: Relations between incision and selection functions. Em Proceeding of the 2006 conference on ECAI 2006, páginas 402-406, Amsterdam, The Netherlands, The Netherlands, 2006. IOS Press. 14, 15

[FPA04] Giorgos Flouris, Dimitris Plexousakis e Grigoris Antoniou. Generalizing the AGM postulates: preliminary results and applications. Em Proceedings of NMR, páginas 171179, 2004. 19

[Gär88] Peter Gärdenfors. Knowledge in flux: Modeling the dynamics of epistemic states. Cambridge University Press, Cambridge, Massachusetts, United States of America (USA), 1988. 6,8

[GBE07] Andy Georges, Dries Buytaert e Lieven Eeckhout. Statistically rigorous java performance evaluation. Em In Proceedings of the ACM SIGPLAN Conference on ObjectOriented Programming, Systems, Languages, and Applications (OOPSLA, páginas 5776. ACM, 2007. 29, 35 
[GM88] Peter Gärdenfors e David Makinson. Revision of knowledge systems using epistemic entrenchment. Em Moshe Vardi, editor, Proceedings of TARK, páginas 83-95. Morgan Kaufmann, 1988. 7

[Gro88] Adam Grove. Two modellings for theory change. Journal of Philosophical Logic, 17:157170, 1988. 7

[GSW89] Russell Greiner, Barbara A. Smith e Ralph W. Wilkerson. A Correction to the Algorithm in Reiter's Theory of Diagnosis. Artificial Intelligence, 41:79-88, 1989. 23

[Han91] Sven Ove Hansson. Belief Base Dynamics. Tese de Doutorado, Uppsala University, 1991. $1,8,9,10$

[Han92] Sven Ove Hansson. A dyadic representation of belief. Em Peter Gärdenfors, editor, Belief Revision, volume 29 of Cambridge Tracts in Theoretical Computer Science, páginas 89-121. Cambridge University Press, 1992. 12

[Han93] Sven Ove Hansson. Reversing the Levi identity. Journal of Philosophical Logic, 22:637$669,1993.8,9,10$

[Han94] Sven Ove Hansson. Kernel contraction. J. of Symbolic Logic, 59(3):845-859, 1994. 11, $12,14,16,17,22$

[Han97] S.O. Hansson. Special Issue on Non-prioritized Belief Revision. Theoria (Göteborg). THEORIA, Filosofiska institutionen, 1997. 10, 13

[Han99] Sven Ove Hansson. A Textbook of Belief Dynamics : Theory Change and Database Updating (Applied Logic Series). Springer, Março 1999. 15, 17

[HW02] Sven Ove Hansson e Renata Wassermann. Local change. Studia Logica, 70(1):49-76, 2002. 19

[Kal06] Aditya Kalyanpur. Debugging and Repair of OWL Ontologies. Tese de Doutorado, University of Maryland at College Park, 2006. 23, 48

[Lib99] Paolo Liberatore. BReLS: a system for revising, updating, and merging knowledge bases. Em Proceedings of NRAC, 1999. 2

[LRW12] Renato U. Lundberg, Márcio M. Ribeiro e Renata Wassermann. A framework for empirical evaluation of belief change operators. Em Leliane N. Barros, Marcelo Finger, Aurora T. Pozo, Gustavo A. Giménez-Lugo e Marcos Castilho, editors, Advances in Artificial Intelligence - SBIA 2012, Lecture Notes in Computer Science, páginas 12-21. Springer Berlin Heidelberg, 2012. 2

[LS08] Mark H. Liffiton e Karem A. Sakallah. Algorithms for computing minimal unsatisfiable subsets of constraints. J. Autom. Reason., 40:1-33, January 2008. 23

[MDHS10] Todd Mytkowicz, Amer Diwan, Matthias Hauswirth e Peter F. Sweeney. Evaluating the accuracy of java profilers. SIGPLAN Not., 45(6):187-197, Junho 2010. 29

[Neb96] Bernhard Nebel. How hard is it to revise a belief base? Relatório técnico, AlbertLudwigs University at Freiburg, 1996. 16

$\left[\mathrm{OAC}^{+} 06\right]$ Martin Odersky, Philippe Altherr, Vincent Cremet, Iulian Dragos, Gilles Dubochet, Burak Emir, Sean McDirmid, Stéphane Micheloud, Nikolay Mihaylov, Michel Schinz, Lex Spoon, Erik Stenman e Matthias Zenger. An Overview of the Scala Programming Language (2. Edition). Relatório técnico, École Polytechnique Fédérale de Lausanne, 2006. 31 
[Rei87] Raymond Reiter. A theory of diagnosis from first principles. Artif. Intell., 32:57-95, April 1987. 23

[Rib10] Márcio Moretto Ribeiro. Revisão de crenças em lógicas de descrição e outras lógicas não clássicas. Tese de Doutorado, Universidade de São Paulo, 2010. 23, 25

[RW09] Marcio M Ribeiro e Renata Wassermann. Base Revision for Ontology Debugging. Journal of Logic and Computation, 19(5):721-743, 2009. 48

[SO96] Chris Okasaki September e Chris Okasaki. Purely Functional Data Structures. Tese de Doutorado, 1996. 31

[Was00] Renata Wassermann. Resource-Bounded Belief Revision. Tese de Doutorado, University of Amsterdam, 2000. 10, 12, 13

[WS00] Mary-Anne Williams e Aidan Sims. Saten: An object-oriented web-based revision and extraction engine. Em Proceedings of NMR 2000, 2000. 2 